\title{
MANUAL ON CHARACTERISTICS OF LANDSAT COMPUTER-COMPATIBLE TAPES PRODUCED BY THE EROS DATA CENTER DIGITAL IMAGE PROCESSING SYSTEM
}

REVISED, DECEMBER 1978

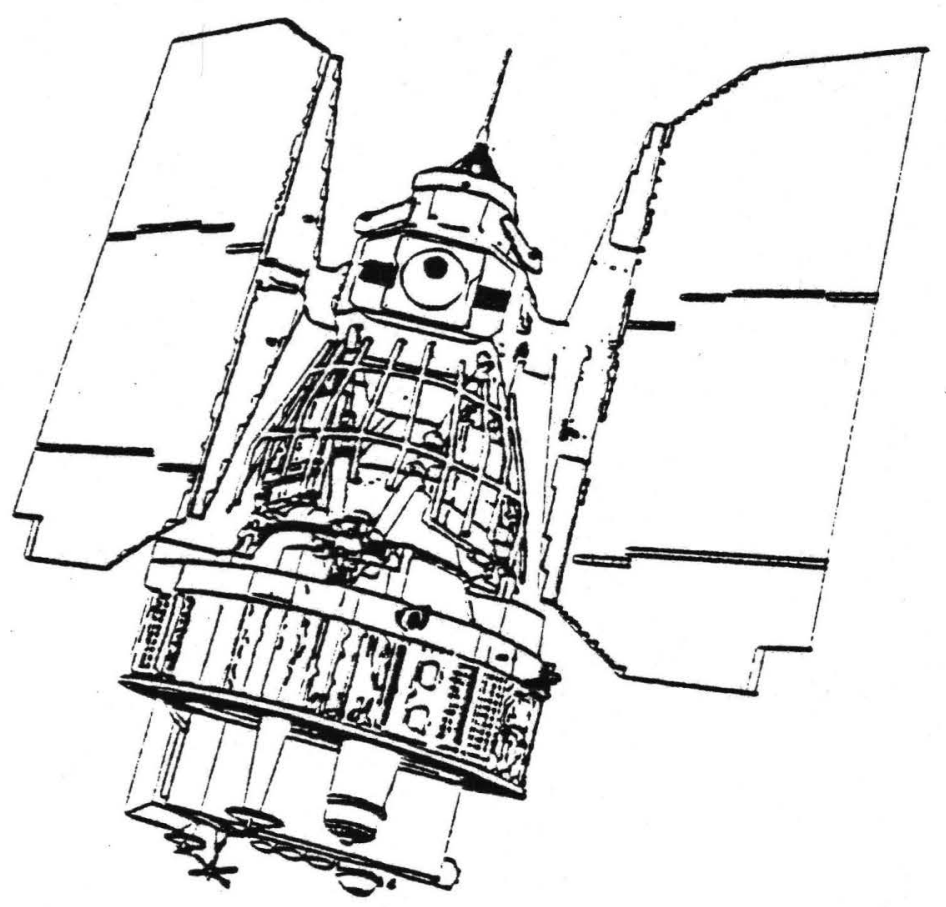

VERSION 0.0

COMPILED BY PATRICK F. HOLKENBRINK

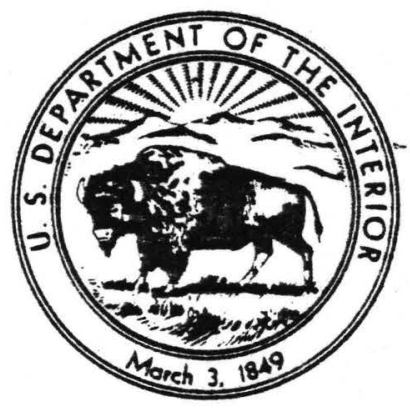

UNITED STATES GEOLOGICAL SURVEY 1978 
Direct inquiries to:

User Services Section

U.S. Geological Survey

EROS Data Center

Sioux Falls, South Dakota 57198 
Original pages are indicated by a zero, and other pages are identified by the change number in effect for those pages. Insert latest change pages; destroy superseded pages. Dates of issue for original pages and change pages are as follows:

\section{Original: 15 December 1978}

The total number of pages in this document is 78 , consisting of the following:

Page No. Change No.

Title......... . 0

ii . . . . . . . . 0

A........... 0

iii thru vi...... 0

1 thru 70 ...... 0 
CHANGE RECORD

(Receipt of changes may be indicated in the spaces below if desired)

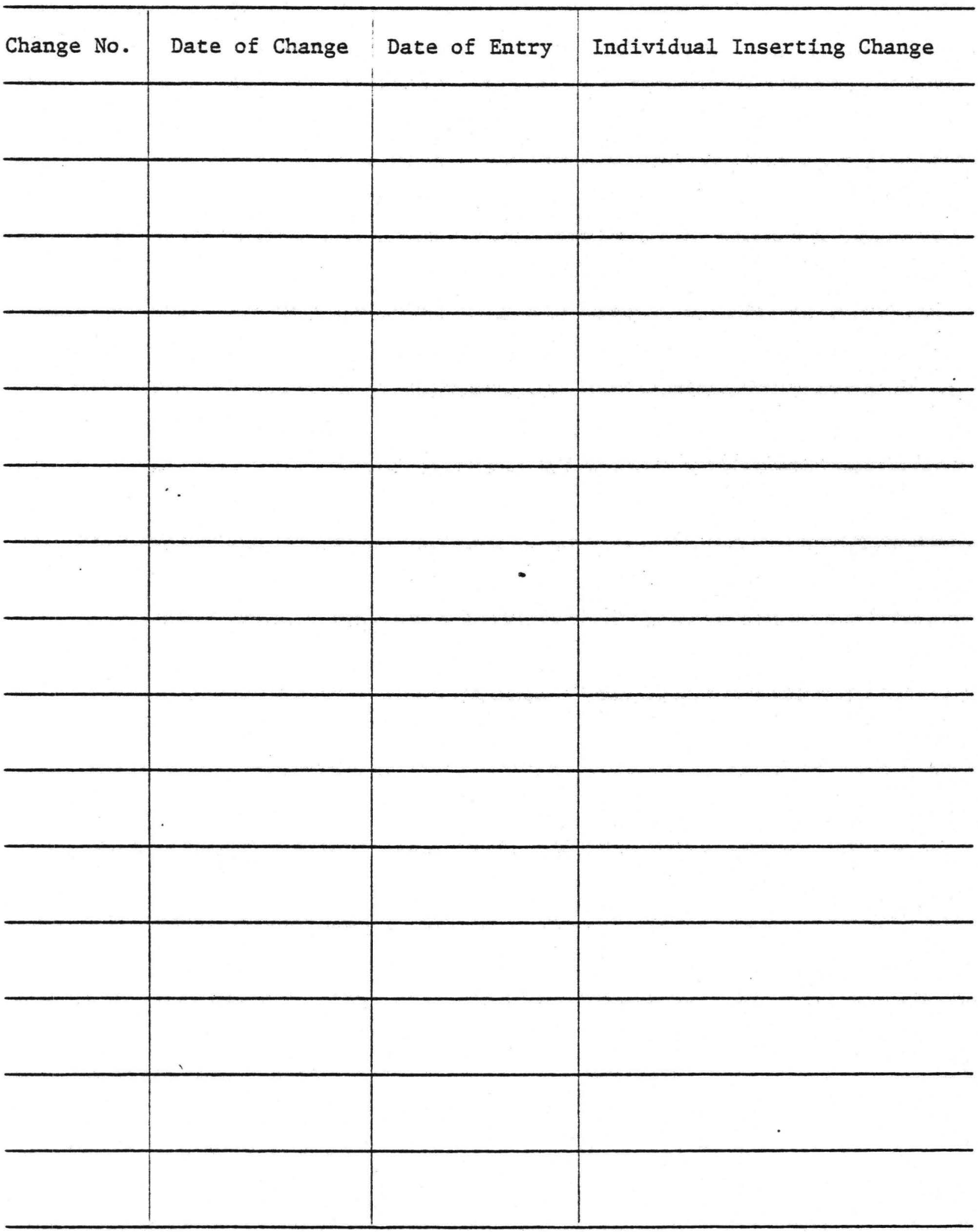




\section{CONTENTS}

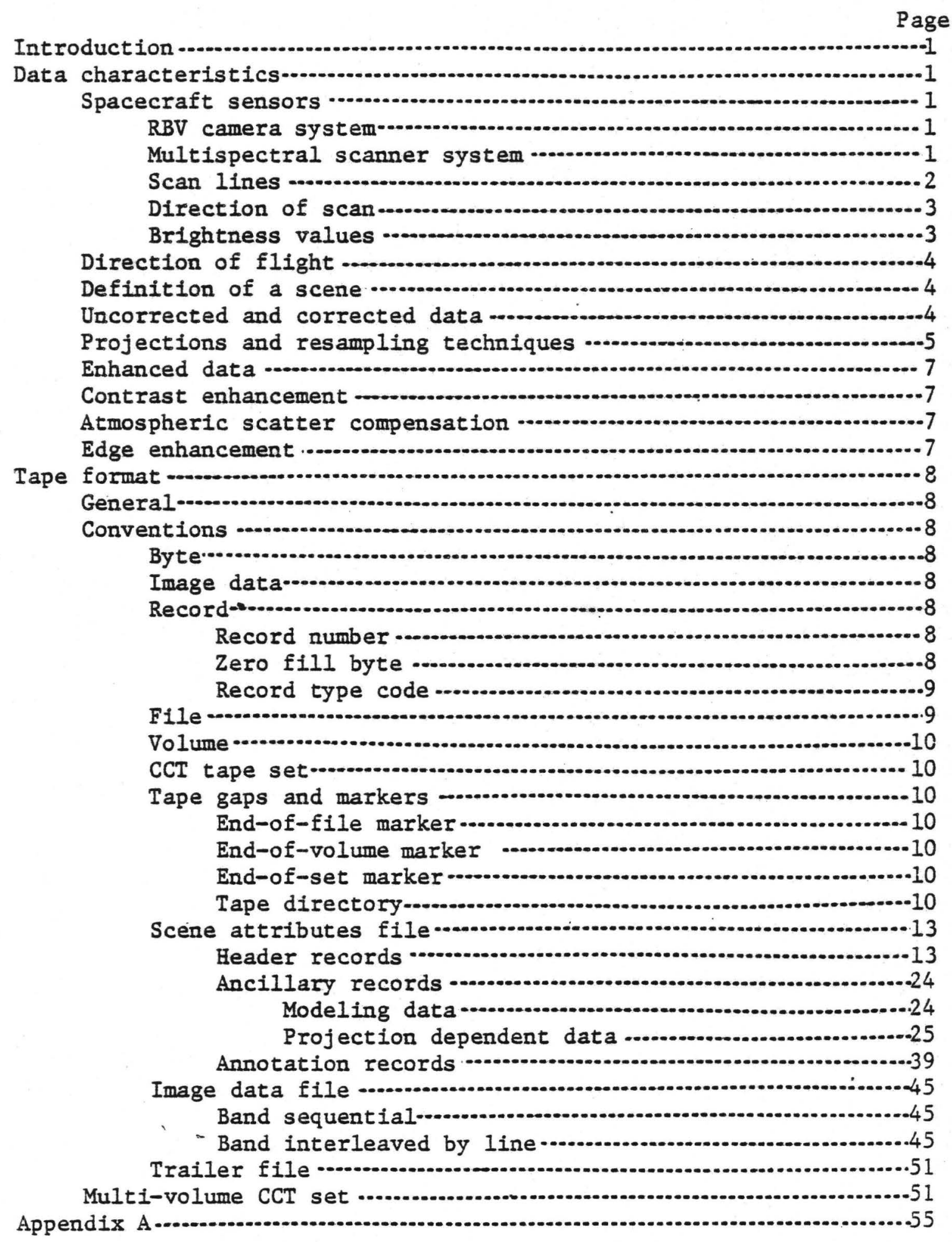




\section{CONTENTS}

$\begin{array}{lll}\text { Page } & \text { Pag }\end{array}$

Appendix B

Systematic geometric corrections .......................................56

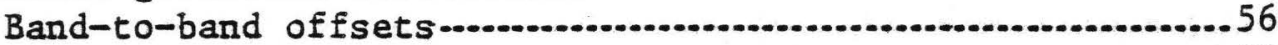

Line length correction-............................................. 56

Earth rotation

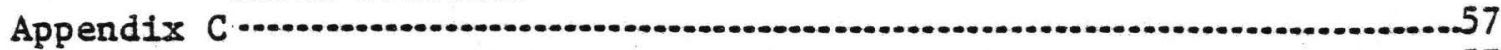

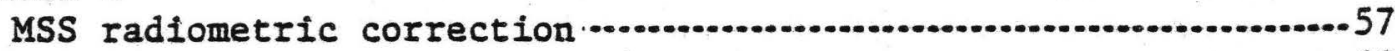

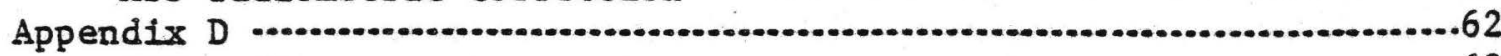

RBV radiometric correction .............................................. 62

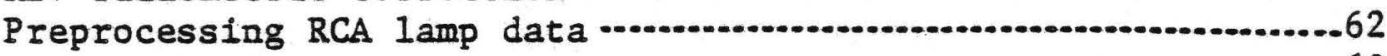

Zoning the image ................................................................... 63

Calibration lamp image processing ........................................... 65

Radiometric correction of data ............................................. 65

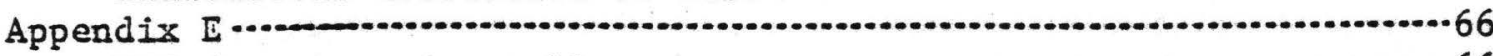

MSS decompressing tables .......................................................66 66

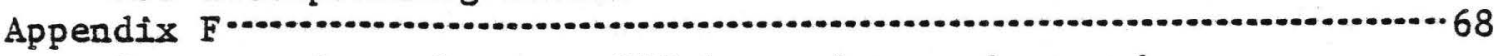

Correspondence between CCT image data and ground

area covered ..................................................................... 68

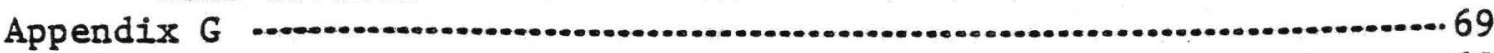

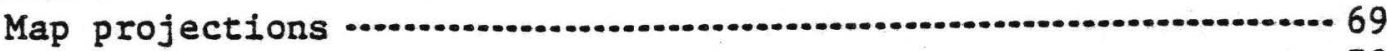

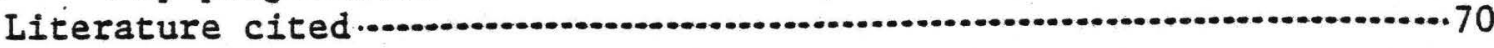




\section{ILLUSTRATIONS}

Figure 1. Format of a fully processed Landsat-3 RBV scene, showing the locations of subscenes A, B, C,

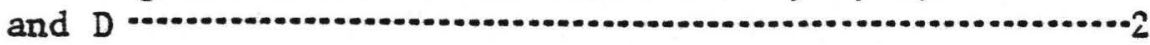

2. Square data array of fully processed RBV imagery.........-2

3. Rectangular data array of fully processed MSS

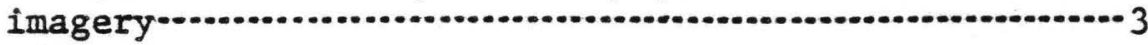

4. Band 8 partially processed data replication.............. .3

5. Ground-scan pattern for three MSS detectors ................. 3

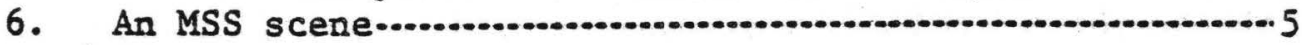

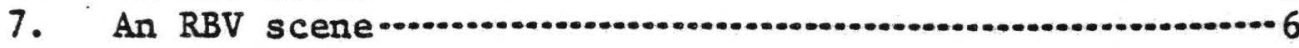

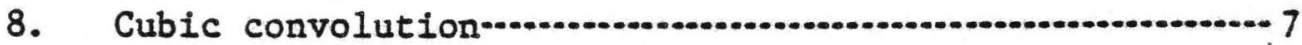

9. Data format of EDIPS CCT's ................................... 9

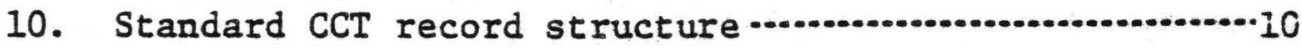

11. Standard placement of CCT annotation information

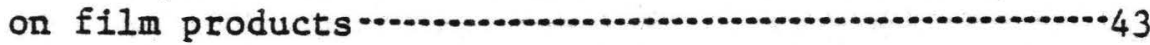

12. An example of the placement of two tick-mark coordinates and their corresponding annotation with respect to fully processed image data .............44 44

13. Examples of tick-mark annotation for UTM and PS ...... 45

14. Scan-line count for MSS ........................................ 48

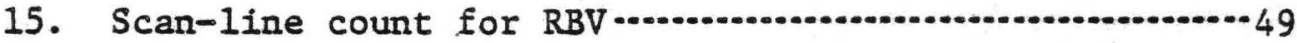

16. Examples of interleaving of MSS image data of $\mathrm{N}$ bands of $\mathrm{n}$ lines each .........................................5 50

17. Illustrations of transition between volumes of a

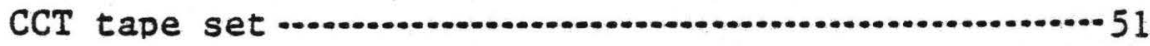

C-1. MSS radiometric-calibration algorithm .....................58

D-1. Preprocessing of RCA lamp data ...............................63

D-2. Zoning the image .................................................63

D-3. Calibration-lamp image processing ..........................64

D-4. Radiometric-correction-coefficient application..........65

F-1. Comparison of the constant mirror velocity and the variable mirror velocity................................68 68

F-2. Overlay of pixels, corresponding to a variable mirror velocity.....................................................69

F-3. Comparison of distance covered on the ground for a constant mirror velocity and a variable mirror velocity 


\section{TABLES}

Table 1. Tape directory: record byte assignments........................1I

2. Header record: record-byte assignments........................-13

2-a. Active-detector-status bytes..................................... 24

3. Modeling data records: record-byte assignments .............25

4. MSS projection-dependent-data records: record-byte

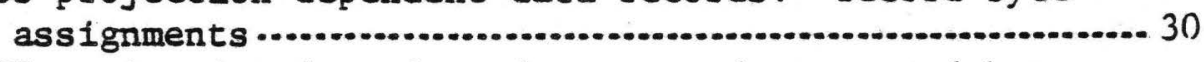

5. RBV projection-dependent-data records: record-byte assignments........................................................... 34

6. Annotation record: record-byte assignments .................. 39

7. MSS uncorrected image-data record ................................ 46

8. MSS fully corrected image-data record ........................ 47

9. RBV uncorrected image-data record .............................. 48

10. RBV corrected image-data record ................................ 49

11. Trailer record: record-byte assignments...................... 52

12. Break points of multi-volume CCT sets ......................... 53

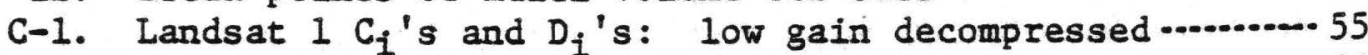

C-2. Landsat $1 C_{i}^{\prime}$ 's and $D_{i}^{\prime}$ 's: high gain decompressed $\ldots . . . . .60$

C-3. Landsat $2 C_{i}^{\prime}$ 's and $D_{i}^{\prime}$ s: low gain decompressed...........6C

C-4. Landsat $2 C_{i}^{\prime}$ 's and $D_{i}^{\prime} s$ : high gain decompressed.........-61

C-5. Landsat $3 C_{i}^{\prime}$ 's and $D_{i}^{\prime}$ s: Low gain decompressed ...........61

C-6. Landsat $3 C_{i}^{\prime}$ 's and $D_{i}^{\prime} s$ : high gain decompressed..........62 62

E-1. Landsat 1 decompression values ................................... 66

E-2. Landsat 2 decompression values .................................. 67

E-3. Landsat 3 decompression values .................................. 68 


\title{
MANUAL ON CHARACTERISTICS OF LANDSAT COMPUTER-COMPATIBLE TAPES PRODUCED BY THE EROS DATA CENTER DIGITAL IMAGE PROCESSING SYSTEM
}

\author{
COMPILED BY PATRICK F. HOLKENBRINK ${ }^{1}$
}

\section{INTRODUCTION}

Landsat data are received by National Aeronautics and Space Administration (NASA) tracking stations and converted into digital form on high-density tapes (HDTs) by the Image Processing Facility (IPF) at the Goddard Space Flight Center (GSFC), Green belt, Maryland. The HDTs are shipped to the EROS Data Center (EDC) where they are converted into customer products by the EROS Data Center digital image processing system (EDIPS). This document describes in detail one of these products: the computer-compatible tape (CCT) produced from Landsat $-1,-2$, and -3 multispectral scanner (MSS) data and Landsat-3 only return-beam vidicon (RBV) data. Landsat-1 and -2 RBV data will not be processed by IPF/EDIPS to CCT format.

\section{DATA CHARACTERISTICS}

\section{SPACECRAFT SENSORS}

The image data received and processed by IPF and EDIPS are scanned, or imaged, by the sensors onboard the Landsat spacecraft. Each spacecraft carries two sensor systems: a return-beam vidicon (RBV) camera system and a multispectral scanner (MSS) system. A more detailed description of these sensors is given in Section P of the Landsat Data Users Handbook, Revised.

\footnotetext{
${ }^{1}$ Technicolor Graphic Services, Inc. Prepared for the United States Geological Survey under contract no. 14-08-0001-16439.
}

RBV CAMERA SYSTEM

On Landsat-3, the RBV system consists of two independent cameras. The ground-area image is stored on the photosensitive surface of the camera tube, which after shuttering, is scanned to produce a video signal output. The shuttered panchromatic cameras produce two side-by-side images rather than three images of the same area as produced by the three independent narrow-band cameras on Landsat-1 and -2. Each camera covers an area $99 \times 99 \mathrm{~km}$ with an instantaneous field of view of about 19 meters. Each RBV image is referred to as a subscene; the four subscenes that comprise a Landsat scene are labeled A, $B, C$, and D (fig. 1). The four RBV images approximately coincide with one MSS frame. Figure 2 shows a fully processed RBV subscene with 81 reseau marks (nine rows of nine) on the tube surface.

\section{MULTISPECTRAL SCANNER SYSTEM}

The multispectral scanner (MSS) is a line-scanning device that uses an oscillating mirror to continuously scan perpendicular to the spacecraft's orbital path. The MSS's on Landsat-1 and -2 have six detectors in each of four spectral bands, operating in the spectral interval from 0.5 to 1.1 micrometers. These detectors provide outputs that are sampled, digitized, and transmitted to Earth as a continuous strip of image data for each mirror sweep. At GSFC, all data received are reprocessed, framed as individual scenes, and encoded on 
HDTs. Figure 3 shows a fully processed MSS scene.

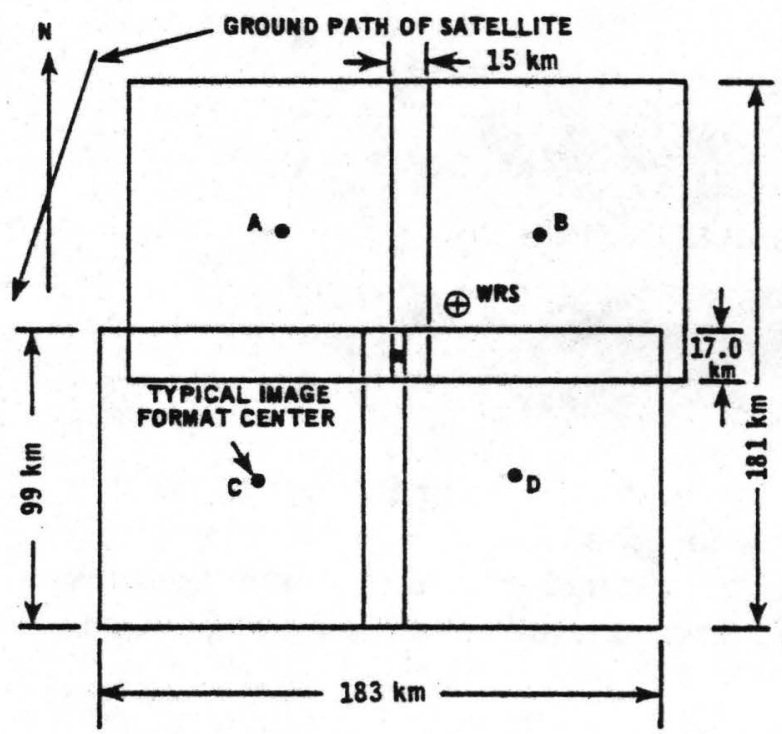

$\oplus$ World Reference System nominal scene center. The actual location of scene with respect to the nominal scene center varies with spacecraft attitude.

- Scene center; mutual intersection of the four subecenes.

Figure 1.-Format of a fully processed Landsat-3 RBV scene, showing the locations of subscenes $A, B, C$, and D.

On Landsat-3, a fifth spectral band operates, using only two detectors, in the thermal-infrared region of 10.4 to 12.6 micrometers. Thus, spatial resolution of this band is less than the other four. Because of the reduced sampling rate of the thermal band, as compared with the other four bands, its pixels must be replicated in the unprocessed image array for three across and for three scan lines by the GSFC data processing facility. Figure 4 shows the relationship that allows all bands to have the same number of pixels. This expanded image array is resampled and corrected to produce the standard thermal image. Thus, the replication pattern is not discernable in a fully processed scene.

\section{SCAN LINES}

Each image is made up of parallel scan lines that contain a large number of picture elements (pixels). For the $\mathrm{MSS}_{2}$, the actual number of these pixels depends on mirror motion and other factors. The greatest deviation for Landsat-1 and -2 is \pm seven pixels. The relationship between these pixels and the corresponding ground area is discussed in Appendix F. The distance covered by a scan line varies with the altitude. Experience has shown that the variations have resulted in scan line changes of approximately $\pm 4 \mathrm{~km}$ in the worst case. For RBV, the number of pixels in each scan line is electronically fixed.

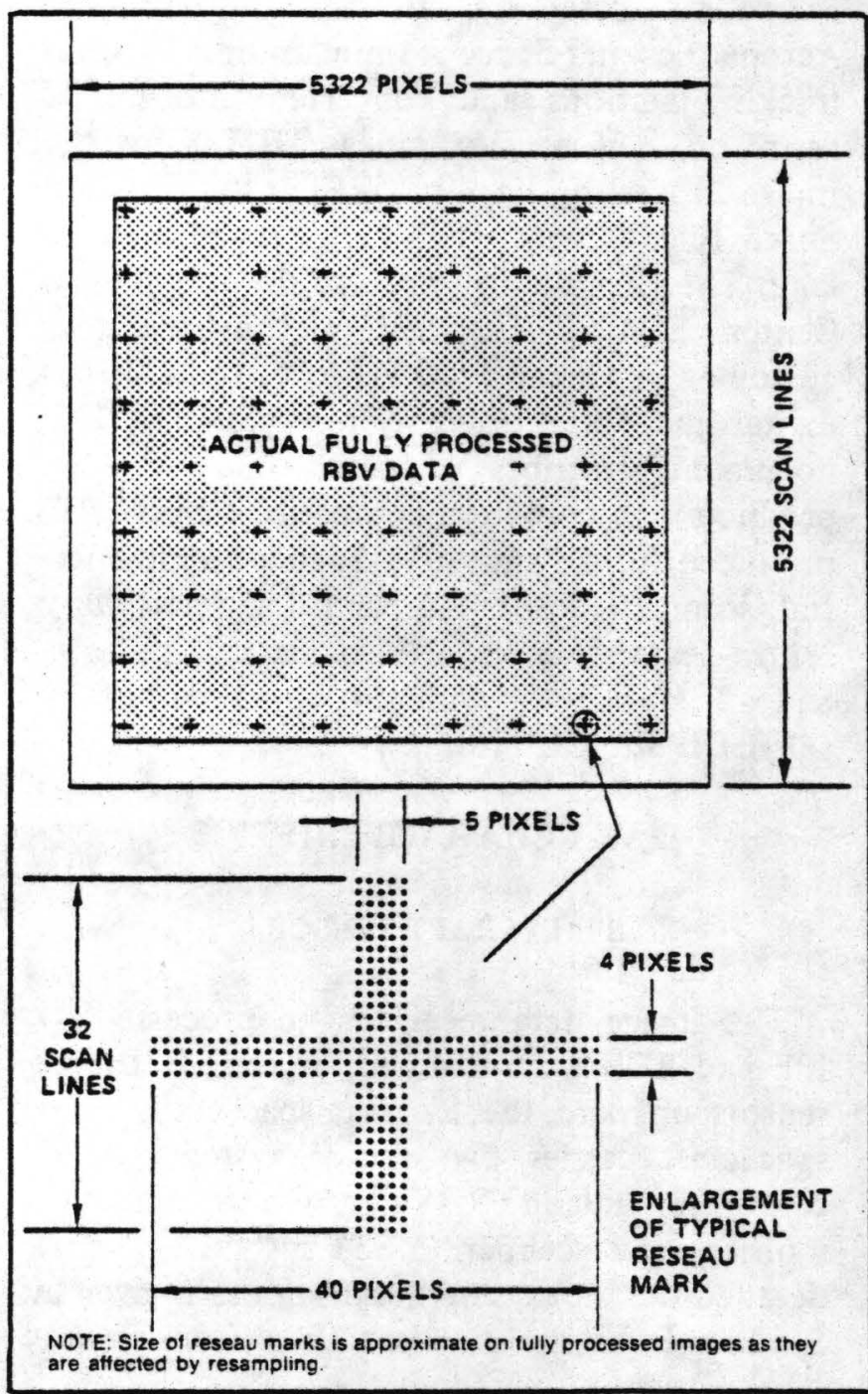

Figure 2.-Square data array of fully processed RBV imagery. 


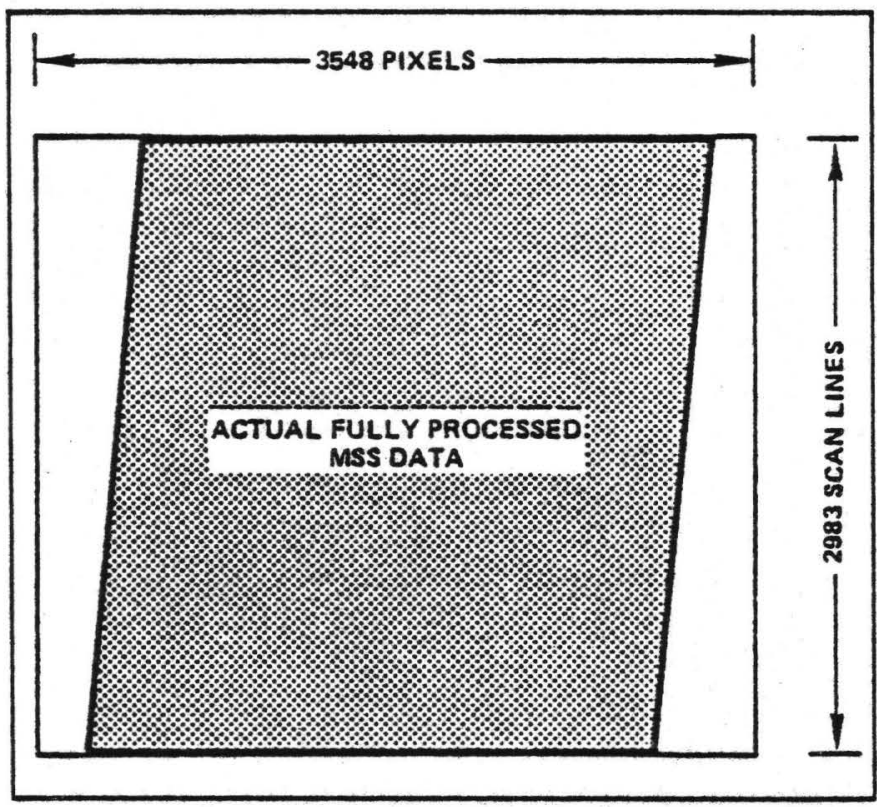

Figure 3.-Rectangular data array of fully processed MSS imagery.

\section{DIRECTION OF SCAN}

The scan mirror, or electron beam, operates in a scan-and-retrace cycle. The active scan is normal and right-to-left with respect to the satellite direction. The full cycle normally produces a $185 \mathrm{~km}$ sweep for MSS and a $99 \mathrm{~km}$ sweep for each RBV subscene. Figure 5 shows the composite scan pattern of the MSS.

\section{BRIGHTNESS VALUES}

Each pixel is encoded in a byte. Each byte is composed of eight binary digits (bits), which are arranged to represent differing brightness values as binary numbers. As there are eight binary bits (each of which may be on or off), 256 values may be represented in each byte. However, not all of these values are possible. The satellite has two modes of transmission: linear and compressed. Bytes 3592 through 3596 of the header record identifies the transmission mode for each band.

Linear-transmission mode allows each pixel

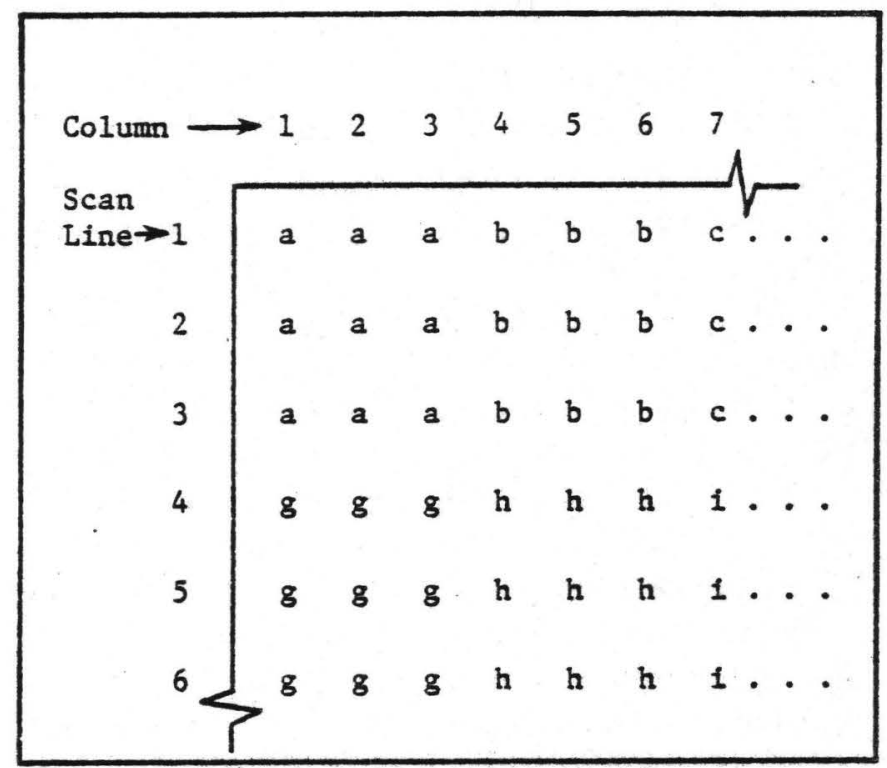

Figure 4.-Band 8 partially processed data replication.

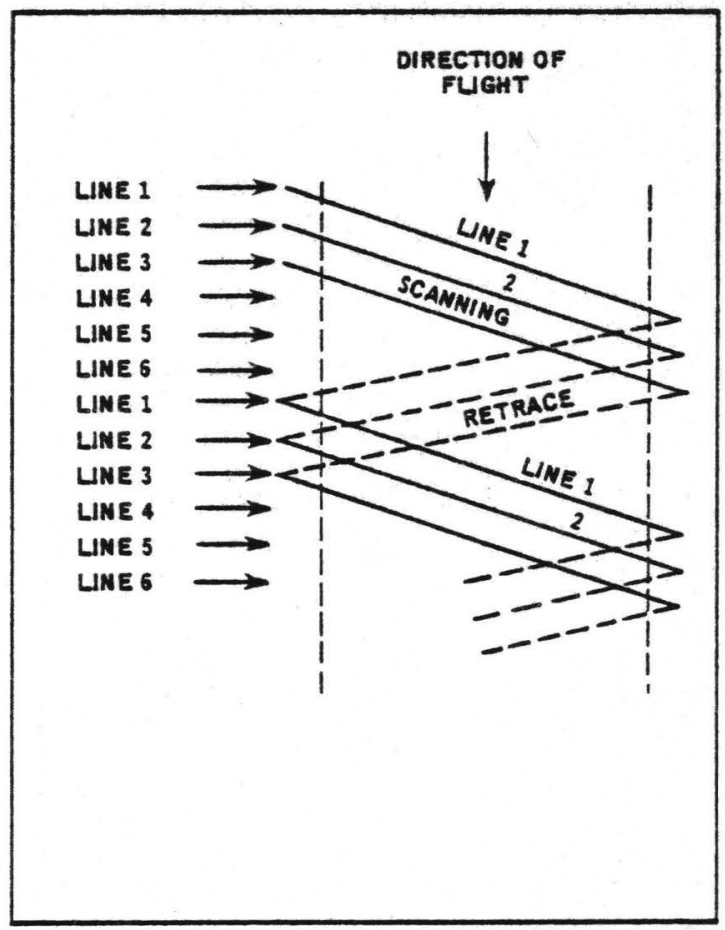

Figure 5.-Ground-scan pattern for three MSS detectors. 
to have a brightness-value range of 0 to 63 . RBV and MSS band 7 and band 8 data are transmitted in linear mode.

Compressed-transmission mode allows each pixel to have a brightness-value range of 0 to 127. MSS bands 4 through 6 are transmitted in compressed mode. These data are compressed to improve the signal-to-noise ratios. By compressing the high brightnessvalue signals, the quantization noise more nearly matches photomultiplier noise.

All data are received as six bit binary numbers (dynamic range of 0 to 63). However, processing at GSFC decompresses all data received in compressed transmission mode (see Appendix E). This processing expands the range of data to a dynamic range of 0 to 127 for decompressed data while linear data remains at a brightness range of 0 to 63 .

All image data bytes on a CCT have seven bits of information:

$$
\begin{array}{|l|l|l|l|l|l|l|l|}
\hline 0 & \mathrm{x} & \mathrm{x} & \mathrm{x} & \mathrm{x} & \mathrm{x} & \mathrm{x} & \mathrm{x} \\
\hline
\end{array}
$$

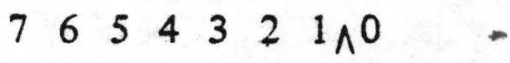

In either mode, valid data are in bits 0 to 6 of each image byte. If the transmission mode is linear, there is an implied binary point between bits 0 and 1 as shown by the $\Lambda$ in the drawing. This allows the user the option of using the additional radiance fraction which becomes available at GSFC during the processing of the data. The user can decide whether the digital byte is interpreted as holding maximum value of 127 or 63.5 If the mode is compressed, the pixel brightness level has a range of 0 to 127 and occupies bits 0 to 6 with no binary point implied. If the user simply interprets each pixel byte as an integer, all bands automatically register to the same brightness scale.

\section{DIRECTION OF FLIGHT}

The spacecraft is in a near-polar orbit, which allows two periods of imaging. When the spacecraft travels north to south, it is in descending mode. Conversely, the ascending mode is a south to north direction. The transition points near the poles are not fixed terrestrial locations, but describe circles at approximately $82^{\circ}$ N. and S. latitudes.

The spacecraft's orbital progress produces the along-track scan pattern, when combined with the scan-and-retrace cycle, provides complete coverage of the full image area.

\section{DEFINITION OF A SCENE}

An MSS scene is an imaged ground area normally $185 \mathrm{~km}$ (cross-track) by $170 \mathrm{~km}$ (spacecraft direction) imaged by one, four, or five spectral bands. On Landsat-3, an RBV scene is detected by two panchromatic cameras with no spectral separation. Each RBV scene, normally $183 \mathrm{~km}$ by $181 \mathrm{~km}$, is a composition of four RBV subscenes, with each subscene $99 \mathrm{~km}$ by $99 \mathrm{~km}$.

\section{UNCORRECTED AND CORRECTED DATA}

CCT data can be requested as four separate products:

CCT-AM: partially processed MSS data (without geometric corrections applied).

CCT-PM : fully processed MSS data (with geometric corrections applied and resampled to a map projection).

CCT-AR : partially processed RBV data (without geometric corrections applied).

CCT-PR : fully processed RBV data (with geometric corrections applied and resampled to a map projection).

All four CCT products have been radiometrically corrected as discussed in Appendixes $\mathrm{C}$ and D.

A partially processed image is defined as one for which the correction data are provided as ancillary information, but which are not applied to the video data. An uncorrected scene has the systematic corrections and resampling transformations to two projections in the ancillary records on the CCT-AM for MSS and the 
CCT-AR for RBV.

A fully processed CCT scene has systematic and geometric corrections applied and the data resampled to a specified projection. Such a scene is recorded on a CCT-PM (for MSS data) or CCT-PR (for RBV data).

Some of the systematic corrections include:

$$
\begin{aligned}
& \text { band-to-band offsets } \\
& \text { line lengths } \\
& \text { earth rotation (skew) } \\
& \text { detector-to-detector sampling delay }
\end{aligned}
$$

A discussion of each of these major corrections is given in Appendix B. The other systematic corrections (pitch, yaw, altitude, use of ground control points, and so forth) are discussed in the Landsat Data Users Handbook. The exact method available to users to perform the geometric transformation contained in the ancillary information is given in Appendix A.

The differences between fully processed and partially processed image arrays are shown in figures 6 and 7. In addition, it should be noted that the actual image data are spatially corrected in the fully processed CCT. The dotted line on the right side of the partially corrected MSS array (fig. 6) indicates a vary- ing line length. The correction transformation is applied in the corrected array and provided in the ancillary data for an uncorrected array.

\section{PROJECTIONS AND RESAMPLING TECHNIQUES}

In the process of geometrically correcting an image array, four different images can result because of the combinations of the two projections and two resampling techniques available.

Landsat data can be geometrically corrected to three map projections. The standard projection is Space Oblique Mercator (SOM). As an option, the data can be corrected to either Polar Stereographic (PS) or Universal Transverse Mercator (UTM). If the scene nadir is between $65^{\circ} \mathrm{N}$. latitude and $65^{\circ} \mathrm{S}$. latitude then the scene can be corrected to UTM. If the spacecraft nadir is outside of these bounds, then the alternative projection is PS. Appendix $G$ provides information about these projections.

A CCT-AM or CCT-AR has the annotation records and transformation coordinates for both the standard SOM projection and the
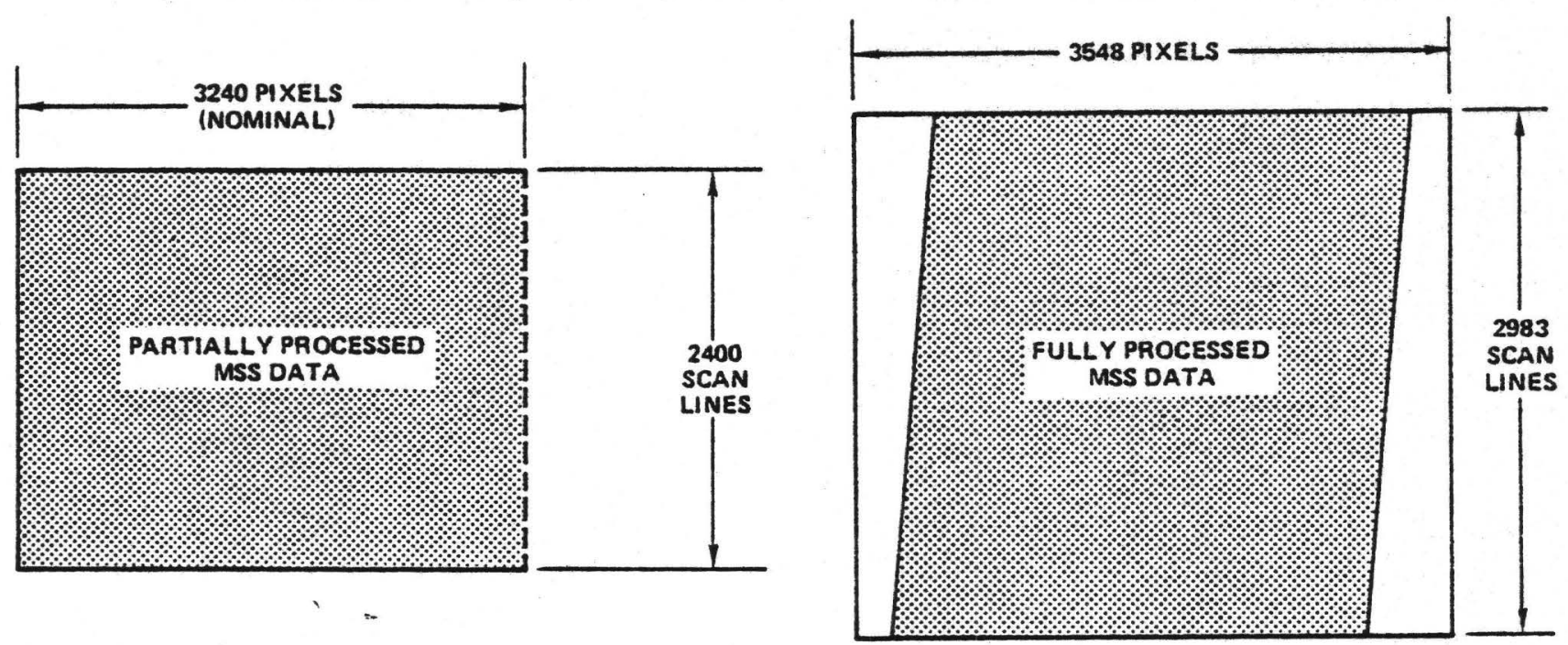


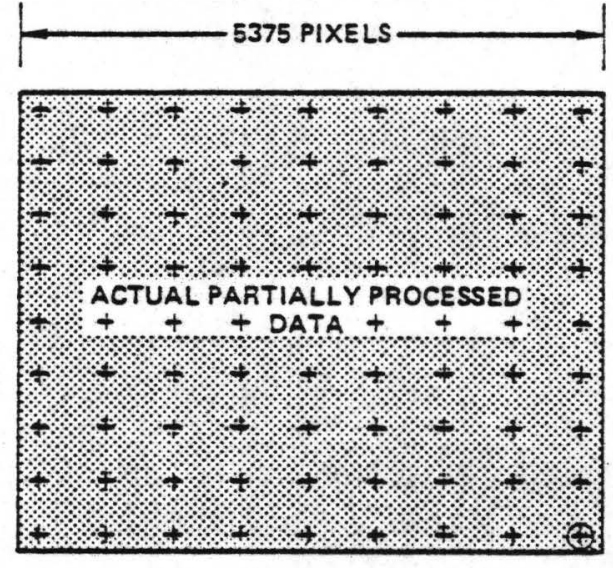

GEOMETRICALLY UNCORRECTED INPUT SPACE

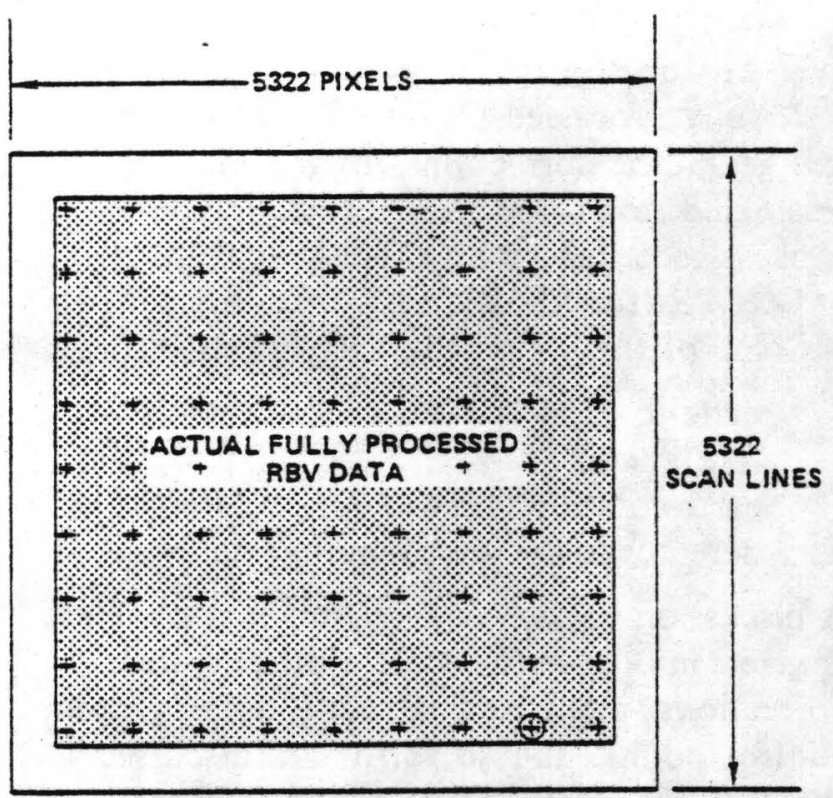

GEOMETRICALLY CORRECTED OUTPUT SPACE

Figure 7.-An RBV scene.

optional UTM or PS projection. A CCT-PM or CCT-PR has the image data and annotation record for the SOM projection or the UTM or PS projection if requested.

When correcting image data points, either nearest-neighbor or cubic-convolution resampling techniques can be used to interpolate the brightness levels of the calculated points.

The nearest-neighbor technique adjusts the new pixel having the closest relative location to the new computed pixel location. For example, given:

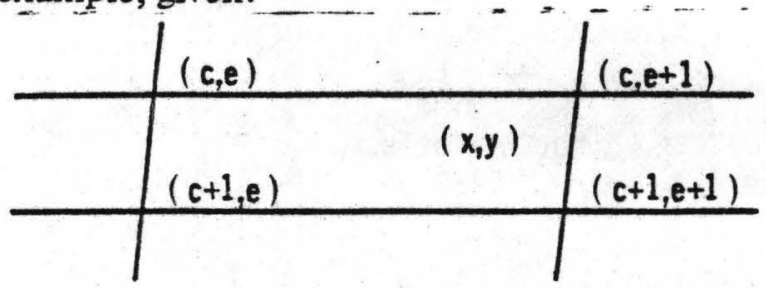

each pixel location is defined as $(x, y)$.

$\mathrm{X}$ is line value (vertical position) defined as c.d where $c$ is integer portion, $d$ is fractional portion.

$\mathrm{y}$ is column value (horizontal position) defined as e.f where e is integer portion, $\mathrm{f}$ is fractional portion.

$$
\begin{aligned}
& I(x, y)=I\left(c_{0} d, e_{0} t\right)=I(a, b) \\
& \text { where } a= \begin{cases}c & \text { if } d<.5 \\
c .1 & \text { if } d \geq .5\end{cases} \\
& b= \begin{cases}e & \text { if } f<.5 \\
e & 1 \text { if } f \geq .5\end{cases}
\end{aligned}
$$

Cubic convolution is the standard resampling technique performed during the correction process. Sixteen input image-pixel-intensity values are used to compute the intensity value of each output pixel (fig. 8). The algorithm uses four input points in the following:

$$
\begin{aligned}
& \left.\begin{array}{rl}
I_{k} & =d\left\{d \left[d\left(1_{k 4}-1_{k 3}+I_{k 2}-1_{k 1}\right)\right.\right. \\
& \left.+\left(-1_{k 4}+I_{k 3}-21_{k 2}+21_{k 1}\right)\right] \\
& \left.+\left(I_{k 3}-1_{k 1}\right)\right\} \\
& +I_{k 2}
\end{array}\right\}
\end{aligned}
$$

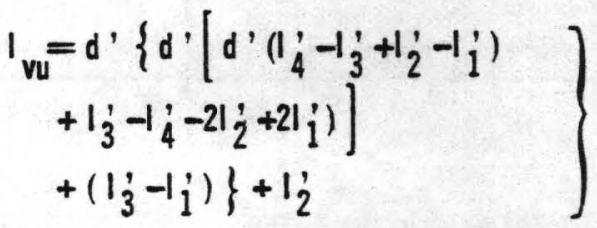

Formula (1) is evaluated for each row of four points. The four input image brightness values 
$\mathrm{I}_{\mathrm{k} 1}, \mathrm{I}_{\mathrm{k} 2}, \mathrm{I}_{\mathrm{k} 3}, \mathrm{I}_{\mathrm{k} 4}$ and horizontal distance $\mathrm{d}$ are used to obtain an intermediate interpolated brightness value $I_{k}$. Then these four intermediate interpolated values $\mathrm{I}_{1}, \mathrm{I}_{2}, \mathrm{I}_{3}, \mathrm{I}_{4}$ and the vertical distance $d$ are used in formula (2) to obtain the final brightness value $\mathrm{I}_{\mathrm{vu}}$.

\section{ENHANCED DATA}

EDIPS can provide certain enhancements to each image. A user may order a CCT product and specify any one of the following enhancements. The header record of each band indicates which options were performed. Enhancements can only be provided with fully processed CCT's.

\section{CONTRAST ENHANCEMENT}

Landsat data usually occupy a small subset of the total brightness range. To provide

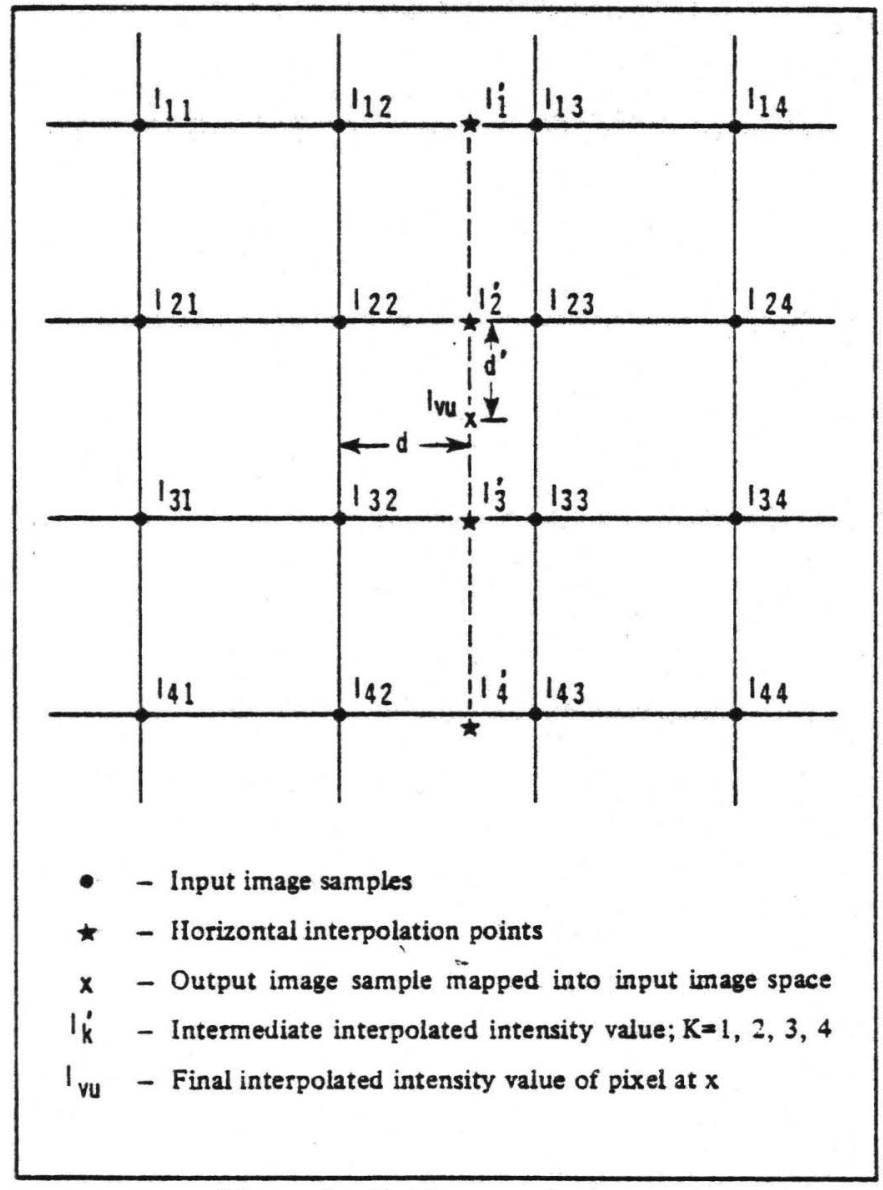

Figure 8.-Cubic convolution. optimal contrast and color variation when color compositing, a linear contrast stretch may be performed on the image data.

The contrast-enhancement algorithm is either an automatic or parametric linear stretch of minimum-maximum brightness levels defined by:

$$
\text { OUTPUT }=\left[\frac{\text { INPUT-MINIMUM }}{\text { maximum-minimum }}\right] \cdot 127
$$

where output values less than the lower threshold are set to zero and any values above the upper threshold are set to 127 . The minimum and maximum values may be obtained by an algorithm either automatically based on brightness-value distribution or specified by the user at the time of the order. These values may be specified in either gray-level values or percents. If contrast enhancement is performed, the maximum and minimum values used for each band or subscene will be given in their respective trailer records.

\section{ATMOSPHERIC SCATTER COMPENSATION}

The algorithm for atmospheric scatter compensation performs a simple bias on each pixel value:

$$
\text { OUTPUT }=\text { INPUT }- \text { BIAS }
$$

The bias may be specified at the time of the order to remove the effects of atmospheric contaminants. If the compensation is performed on the image data, the actual bias value used is given in the trailer record of each band.

\section{EDGE ENHANCEMENT}

Edge enhancement is a technique to "sharpen" the Landsat image by enhancing the highfrequency image components. This is done by exaggerating the difference between the pixel and the N x M neighborhood (kernel) immediately surrounding it. The kernel size (N, M) is specified at the time of order with $\mathrm{N}, \mathrm{M}$ as 1 , $3,5,7$, or 9 . The kernel does not have to be 
square or the same for each band or subscene; but $\mathrm{N}$ and $\mathrm{M}$ must be odd valued integers. The local average is computed as follows:

$$
\begin{array}{ll}
\mathrm{SV}(\mathrm{I}+1, \mathrm{~J}) & :=\mathrm{SV}(\mathrm{I}, \mathrm{J})-\mathrm{T}(\mathrm{I}+1, \mathrm{~J})+\mathrm{B}(\mathrm{I}+1, \mathrm{~J}) \\
\mathrm{SH}(\mathrm{I}, \mathrm{J}+1) & :=\mathrm{SH}(\mathrm{I}, \mathrm{J})+\mathrm{SV}(\mathrm{I}, \mathrm{J}+\mathrm{N})-\mathrm{SV}(\mathrm{I}, \mathrm{J}) \\
\mathrm{X} 1(\mathrm{I}, \mathrm{J}) & :=\mathrm{SH}(\mathrm{I}, \mathrm{J}) /\left(\mathrm{N}^{*} \mathrm{M}\right), \mathrm{I}, \mathrm{J}=1,2,3 \ldots
\end{array}
$$

$\mathrm{SV}(\mathrm{I}, \mathrm{J})$ is the sum of the pixel values inside the kernel box along the vertical axis.

$\mathrm{SH}(\mathrm{I}, \mathrm{J})$ is the sum of the SV(I, J) values inside the kernel box along the horizontal axis.

$T(I, J)$ is the scan line uncovered by advancing the filter to line $I$.

$B(I, J) \quad$ is the scan line covered by advancing the filter to line I.

After computing the local average $\mathrm{X} 1(\mathrm{I}, \mathrm{J})$, the output (enhanced) pixel value $\mathrm{Y}(\mathrm{I}, \mathrm{J})$ is given by:

$$
\mathrm{Y}(\mathrm{I}, \mathrm{J}) \quad:=\mathrm{X}(\mathrm{I}, \mathrm{J})+\mathrm{X}(\mathrm{I}, \mathrm{J})-\mathrm{X} 1(\mathrm{I}, \mathrm{J})
$$

If edge enhancement is performed on the video data, the kernel size employed is giverr in the trailer record of each band.

\section{TAPE FORMAT}

\section{GENERAL}

The CCT's produced by EDIPS are classified by two major data distinctions: sensor type (MSS or RBV), and whether or not geometric corrections have been applied to the image data. Four types of CCT's result:

CCT-AM: partially processed MSS data (with geometric corrections applied).

CCT-PM: fully processed MSS data (with geometric corrections applied and resampled to a map projection).

CCT-AR: partially processed RBV data (without geometric correcitons applied).

CCT-PR: fully processed RBV data (with geometric corrections applied and resampled to a map projection).

These CCT's can be produced in either a band interleaved by line (BIL) or a band sequential (BSQ) format and in either 800 bpi or 1600 bpi densities. RBV data is produced on a per subscene basis which is equivalent to BSQ with only one band. While each of these CCT's may require varying numbers of records and tape reels, a general data format that applies to all CCT's is shown in figure 9.

\section{CONVENTIONS}

\section{BYTE}

A byte is eight bits in length and may contain character or numeric data. The most significant bit occurs first and is the left-most bit of the byte.

\section{IMAGE DATA}

Image data will be right-justified in a byte with the most significant bit zero filled. A binary value of zero is low radiance for RBV and bands 4 through 7, and "cold" for MSS band 8 data. Each image datum is a pixel.

\section{RECORD}

A record is a collection of data items and is treated as a logical unit. Tape directory data, header data, ancillary data, annotation data, image data, and trailer data occupy separate sets of records. Records are structured to contain six bytes of identification codes, data, and a variable number of zero fill bytes (fig. 10). The first six bytes are: record number, zero fill byte, and record type code.

\section{RECORD NUMBER}

This is a sequential count of the record number within a file. Records are numbered sequentially, starting with one. The number is coded in binary, with the left-most bit being the most significant.

\section{ZERO FILL BYTE}

This byte is binary-zero filled and used for data alignment. 


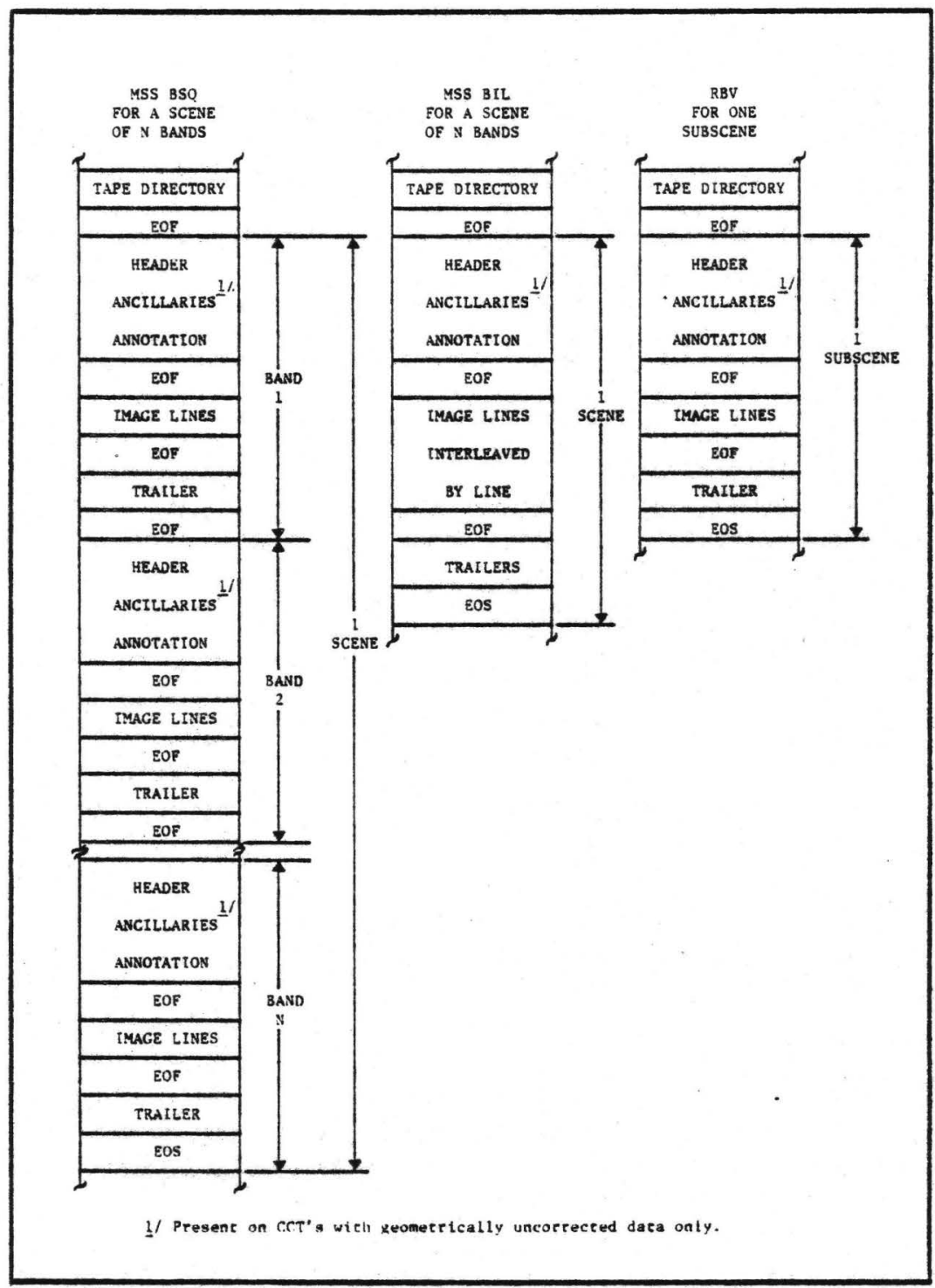

Figure 9.-Data format of EDIPS CCT's.

RECORD TYPE CODE

Each record contains one of six types of information, uniquely identified by the record type code. The record type codes are binary numbers with the following octal values:

$\begin{array}{lll}\text { Tape directory } & & 0118 \\ \text { Header } & & 0228 \\ \text { Ancillary } & & 0448 \\ \text { Annotation } & - & 3338 \\ \text { Image } & & 3558 \\ \text { Trailer } & & 3668\end{array}$

A file is a collection of related records treated as a unit. The amount of data con- tained in a file depends on sensor type (MSS or RBV), the interleaving of image data, and whether or not the data are geometrically corrected. A CCT contains four types of files:

Tape-directory data

Scene-attributes data

Image data

Trailer data

Each file can contain one or more records as defined below. The total number of files on the CCT depends on the format: BSQ or BIL (fig. 9). The length of records within each file is fixed and blocked one (1). The tape directory file has a fixed length on all CCT tapes 
and gives the lengths of records in all subsequent files.

Only an image-data file may be split between reels of CCT's. It should be noted that one RBV image data file contains one RBV subscene of imagery. One MSS image file contains either one image (band) in BSQ or one scene in BIL (fig. 9).

\section{VOLUME}

A volume is one physical unit of a storage medium on which data can be recorded and subsequently read. In this document, a volume always refers to a reel of magnetic tape.

\section{CCT TAPE SET}

A CCT tape set may consist of one or more volumes and contain data for one MSS scene or one RBV subscene.

\section{TAPE GAPS AND MARKERS}

Tape gaps, load point, end-of-tape (EOT) marks, and other tape characteristics are standard for the industry as defined by the
American National Standards Institute (ANSI, 1973a and b).

\section{END-OF-FILE MARKER}

The end-of-file marker (EOF) is a specifically coded block which separates files. The EOF is the tape mark described in the referenced ANSI documents.

END-OF-VOLUME MARKER

The end-ofvolume (EOV) indicator consists of two consecutive EOF's and marks the end of recorded data on the tape.

END-OF-SET MARKER

The end-of-set marker (EOS) consists of three consecutive EOF's and occurs on the last volume of a multivolume set.

\section{TAPE DIRECTORY}

The tape directory appears once at the beginning of each volume and identifies the contents, documentation level, and format of the CCT set. It consists of one record 360 bytes long as shown in table 1 .

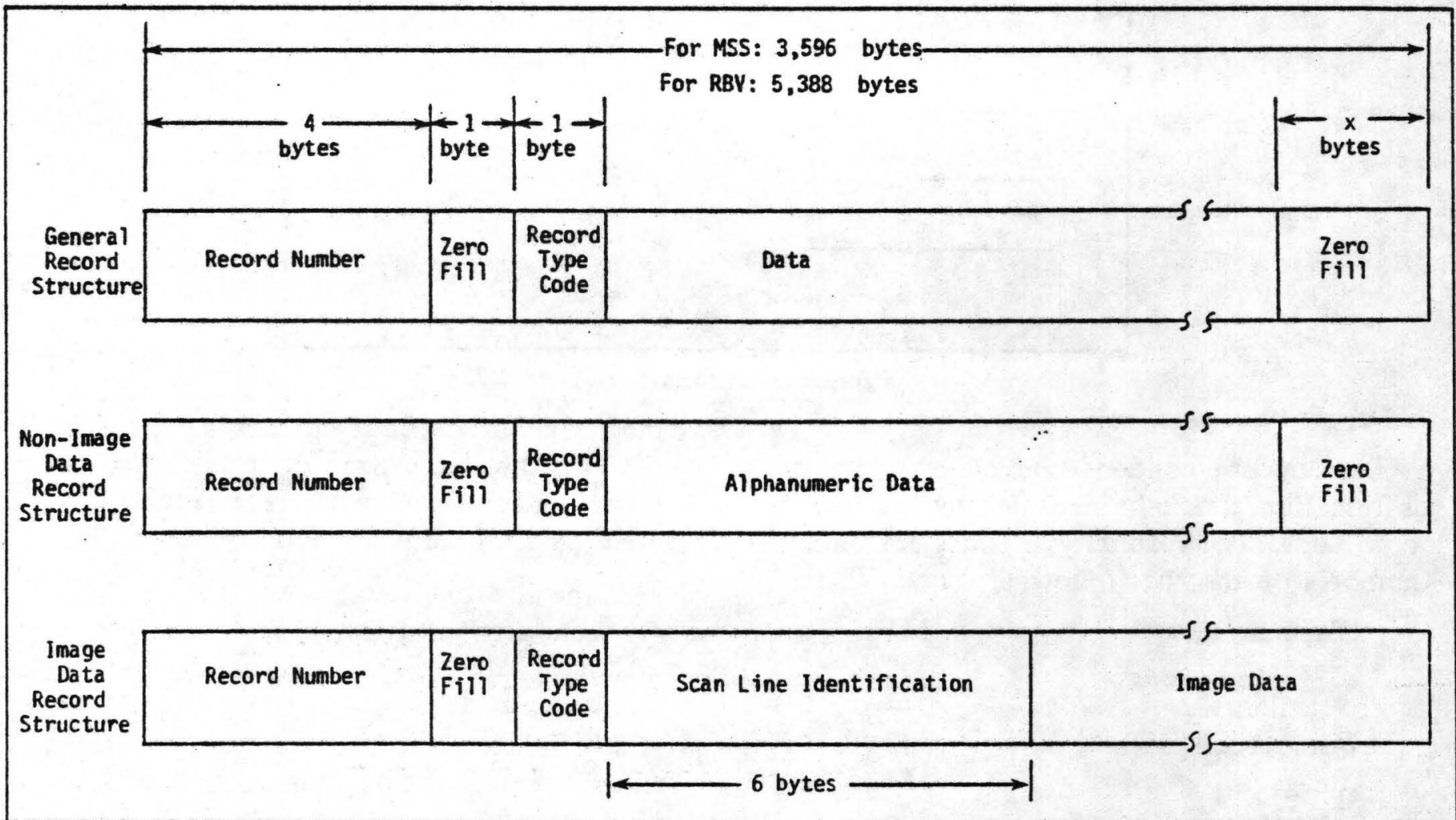

Figure 10.-Standard CCT record structure. 
TABLE 1.--Tape directory: Record-byte assignments

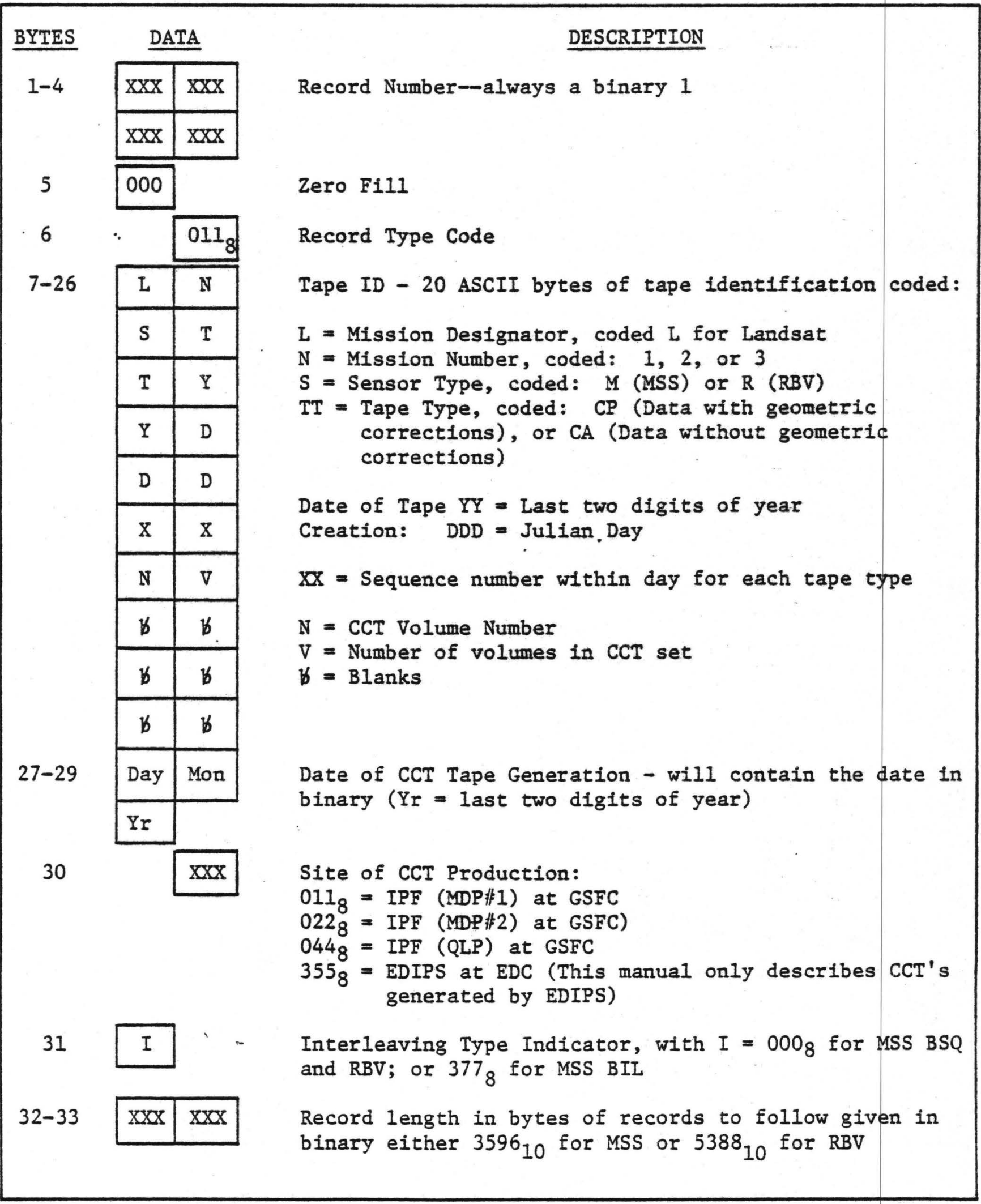


TABLE 1.--(cont'd)

\begin{tabular}{|c|c|c|}
\hline BYTES & \multicolumn{2}{|c|}{ DATA } \\
\hline 34 & & 且 \\
\hline $35-52$ & A & D \\
\hline & D & D \\
\hline & D & H \\
\hline & H & M \\
\hline & $M$ & S \\
\hline & B & M \\
\hline & $P$ & $P$ \\
\hline & $P$ & R \\
\hline & R & R \\
\hline
\end{tabular}

\begin{tabular}{|l|l|l|}
\hline $53-358$ & 000 & 000 \\
\hline $359-360$ & SSS & LLI \\
\hline
\end{tabular}

Source HDT - one ASCII byte where:

If $\mathrm{H}=\mathrm{C}$, the source HDT contains geometrically corrected data

If $\mathrm{H}=U$, the source HDT contains geometrically uncorrected data

If $\mathrm{H}=\not$, field is $\mathrm{N} / \mathrm{A}$

Scene Identification - an 18 byte ASCII field giving Scene ID and WRS Designator of the data on the tape (or tape set) defined as follows -

Scene ID - unique scene identifier of the form: ADDDDHIMMSB where

$A=$ Landsat mission $=1,2$, or 3

DDDD = Day number, relative to launch, at time of observation

$\mathrm{HH}$ - Hour at time of observation

MM = Minute at time of observation

$S$ - Tens of seconds at time of observation

$B=$ Blank

WRS Designator - unique terrestrial scene of the form: MPPPRRR where

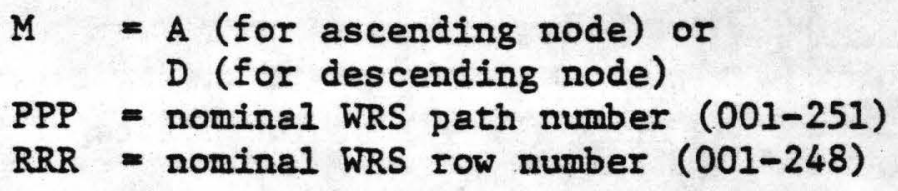

\section{Zero Fill}

Version level on the CCI set.

SSS--Binary version number of the software. (Changes each release of module which generates $\mathrm{CCT}^{\prime} \mathrm{s}_{\text {.) }}$

LIL--Binary version number of the document which describes the CCT format. V.R (Changes each version of the CCT document. Revision changes have no impact.) 


\section{SCENE ATTRIBUTES FILE}

The scene attributes file can contain up to three types of records: header, ancillary, and annotation. The total number of records in the file depends on the sensor and whether or not the data are geometrically corrected. The attributes file contains records of descriptive information concerning the image within the image file. A CCT in BSQ format contains one attributes file that contains the header, ancillary (if present) and annotation reconds for the bands on the CCT set. The header record is the first record of each attributes file, followed by all the ancillary (if present), and then the annotation records. For both BIL and BSQ formats, the relative order as given below is important.

HEADER RECORDS

A header record is present for each band on a BSQ CCT set and only once in a BIL CCT set. It identifies the contents of the data that follow and describes the format in which the data are recorded. Header data are further subdivided into six groups:

a) Scene identification

b) Spacecraft description

c) Time of exposure and WRS information

d) Data set characteristics
1) Header data
2) Annotation
3) Ancillary data
4) Image data
5) Trailer data
e) Special purpose fields
f) EDIPS processing information for MSS
for RBV

Table 2 shows the layout of header records, and table $2 a$ the active detector-status bytes.

TABLE 2.--Header record: Record-byte assignments

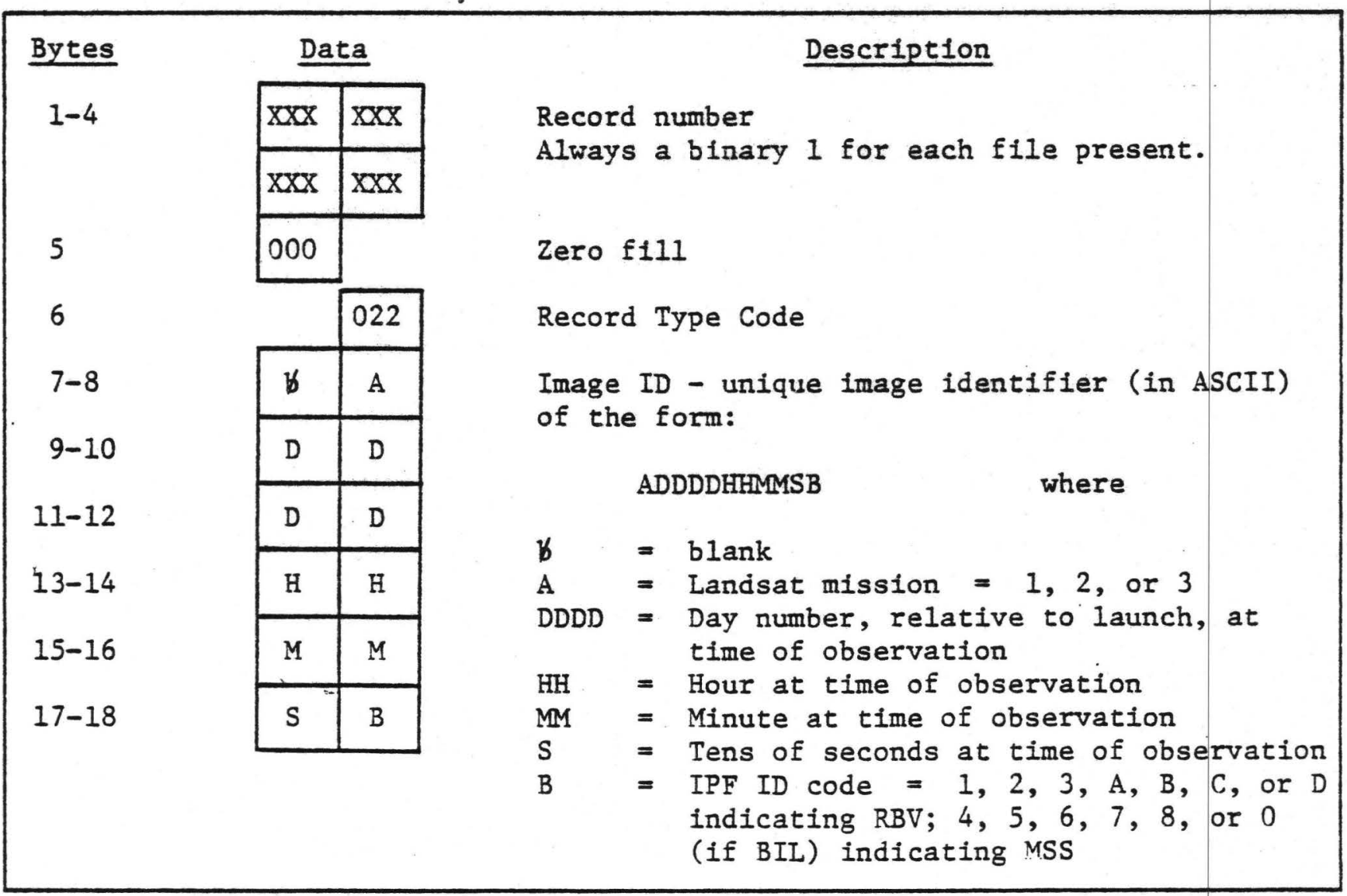


TABIE 2.--(cont'd)

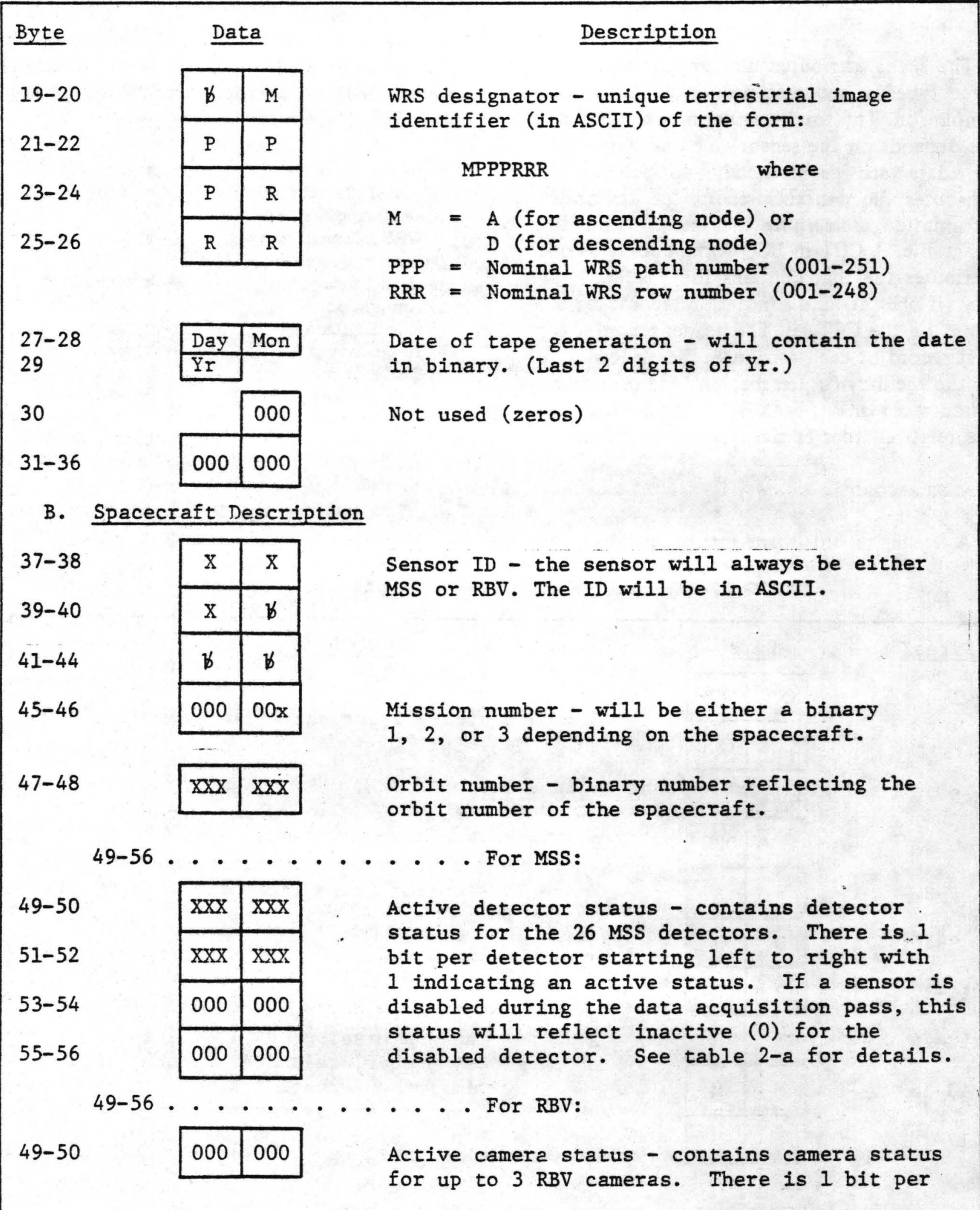


TABLE 2.--(cont'd)

\begin{tabular}{|c|c|c|c|}
\hline Bytes & \multicolumn{2}{|c|}{ Data } & Description \\
\hline $51-52$ & 000 & $00 x$ & \multirow{2}{*}{$\begin{array}{l}\text { camera as shown below. A bit set to } 1 \text { indicates } \\
\text { an activated camera. (If a camera is disabled } \\
\text { during the data acquisition pass, this status } \\
\text { will be shown as a } 0 \text { for the disabled camera.) }\end{array}$} \\
\hline \multirow[t]{2}{*}{$53-56$} & 000 & 000 & \\
\hline & & \multirow[b]{2}{*}{ - } & 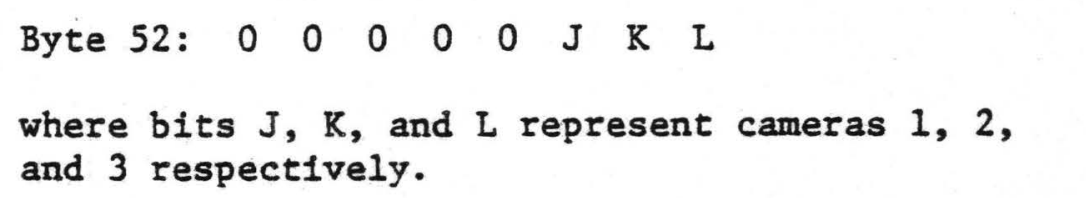 \\
\hline 57 & $x \times x$ & & \multirow{2}{*}{$\begin{array}{l}\text { Active detector/camera count - a binary value } \\
\text { representing the number of active detectors/ } \\
\text { cameras based on the active detector/camera } \\
\text { status } \\
\text { Nominal number (in binary) of pixels/scan } \\
\text { line in original geometrically uncorrected image }\end{array}$} \\
\hline $58-59$ & $\mathrm{xxx}$ & $x x x$ & \\
\hline $60-62$ & 000 & 000 & Not used (zeros) \\
\hline \multicolumn{4}{|c|}{ C. Time of Exposure/WRS Designator } \\
\hline $63-72$ & 000 & 000 & \multirow{2}{*}{$\begin{array}{l}\text { Not used (zeros) } \\
\text { WRS designator in fully processed image (in } \\
\text { binary): scan line number of WRS }\end{array}$} \\
\hline $73-74$ & \multicolumn{2}{|c|}{$x \times x \times x x$} & \\
\hline \multirow[t]{2}{*}{$75-76$} & \multicolumn{2}{|c|}{$x \times x \times x x$} & \multirow{2}{*}{$\begin{array}{l}\text { Pixel number of WRS } \\
\text { Center picture exposure time (in ASCII): }\end{array}$} \\
\hline & & & \\
\hline $77-78$ & Yr & $Y_{r}$ & Last 2 digits of year $(00-99)$ \\
\hline $79-80$ & D & $\mathrm{D}$ & \multirow{2}{*}{$\begin{array}{l}\text { Julian day of year ( } 3 \text { digits: 001-366) } \\
\text { Hour ( } 2 \text { digits: 00-99) }\end{array}$} \\
\hline $81-82$ & D & $\mathrm{Hr}$ & \\
\hline $83-84$ & $\mathrm{Hr}$ & Min & \multirow{2}{*}{$\begin{array}{l}\text { Minutes (2 digits: } 00-59 \text { ) } \\
\text { Seconds (2 digits: } 00-59 \text { ) }\end{array}$} \\
\hline $85-86$ & Min & $\mathrm{Sec}$ & \\
\hline $87-88$ & Sec & ms & \multirow[t]{3}{*}{ Milliseconds ( 3 digits: 000-999) } \\
\hline $89-90$ & ms & $\mathrm{ms}$ & \\
\hline $91-92$ & $b$ & $b$ & \\
\hline
\end{tabular}


TABLE 2.--(cont'd)

Bytes Data Description

D. Data Identification and Characteristics

$93-94$

\begin{tabular}{|l|l|}
\hline $\mathrm{XXX}$ & $\mathrm{XXX}$ \\
\hline
\end{tabular}

Header record length - either $3596_{10}$ for MSS or $5^{388_{10}}$ for RBV

$95-96$

\begin{tabular}{|l|l|}
\hline $\mathrm{xxx}$ & $\mathrm{xxx}$ \\
\hline $\mathrm{xxx}$ & $\mathrm{xxx}$ \\
\hline
\end{tabular}

Number of header records - nominally 1

$97-98$

Annotation Data Characteristics

$99-100$

$\mathrm{XXX} \quad \mathrm{XXX}$

Annotation record length - either 359610

for MSS or $5388_{10}$ for RBV

$101-102$

\begin{tabular}{|l|l|}
\hline$x x x$ & $x x x$ \\
\hline
\end{tabular}

Number of annotation records - 1 if data are geometrically corrected, 2 if uncorrected

\section{Ancillary Data Characteristics}

103-104

\begin{tabular}{|l|l|}
\hline$x x x$ & $x x x$ \\
\hline
\end{tabular}

$105-106$

\begin{tabular}{|l|l|}
\hline$X X X$ & $X X X$ \\
\hline
\end{tabular}

107

108

109

110

$\mathrm{xxx}$

XXX

$\mathrm{xxX}$

$\operatorname{XXX}$
Ancillary record length - either $3^{3596} 10$ for MSS or $5388_{10}$ for $\mathrm{RBV}$

Number of ancillary records - 0 if data are geometrically corrected, 2610 if MSS uncorrected, $30_{10}$ if $\mathrm{RBV}$ uncorrected

Geometric corrections applied - either $000_{8}$ (no) or 3778 (yes)

Geometric correction data present - either $000_{8}$ (no) or $377_{8}$ (yes)

Radiometric correction applied - either 0008 (no) or 3778 (yes)

Radiometric correction data present - either $000_{8}$ (no) or $377_{8}$ (yes)

Image Data Characteristics

$111-112$

113-114

$115-116$

\begin{tabular}{|l|l|}
\hline$x x x$ & $x x x$ \\
\hline
\end{tabular}

\begin{tabular}{|c|c|}
\hline 000 & 000 \\
\hline $\mathrm{xxx}$ & $\mathrm{xxx}$ \\
\hline
\end{tabular}

Image record length - either $3596_{10}$ for MSS or 538810 for $\mathrm{RBV}$

Not used (zeros)

Number of calibration/quality data words per scan line 
TABLE 2.--(cont'd)

\begin{tabular}{|c|c|c|c|c|}
\hline Bytes & & Data & & Description \\
\hline 117 & $\mathrm{XXX}$ & & & $\begin{array}{l}\text { Image data format }=0008 \text { for unframed } \\
\text { rectangular image, } 3778 \text { for framed rectangular } \\
\text { image, } 3668 \text { for framed square image }\end{array}$ \\
\hline $118-119$ & 000 & 000 & & Not used (zeros) \\
\hline 120 & & $\mathrm{XXX}$ & & $\begin{array}{l}\text { Interleaving type indicator - elther } 0008 \text { for } \\
\text { BSQ or } 3778 \text { for BIL }\end{array}$ \\
\hline 121 & $\mathrm{xxx}$ & & & $\begin{array}{l}\text { BIL line interleaving count }-510 \text { if Landsat-3, } \\
{ }^{4} 10 \text { if Landsat- } 1 \text { or }-2,0 \text { for N/A }\end{array}$ \\
\hline 122 & & 008 & & $\begin{array}{l}\text { Number of bits per pixel - for this application } \\
\text { it will be constant } 810\end{array}$ \\
\hline 123 & $\mathrm{xxx}$ & & & $\begin{array}{l}\text { Resampling applied: } \\
3008=\text { None, } \\
0118=\text { Cubic convolution, or } \\
0228=\text { Nearest neighbor }\end{array}$ \\
\hline 124 & $\mathrm{xxx}$ & & & 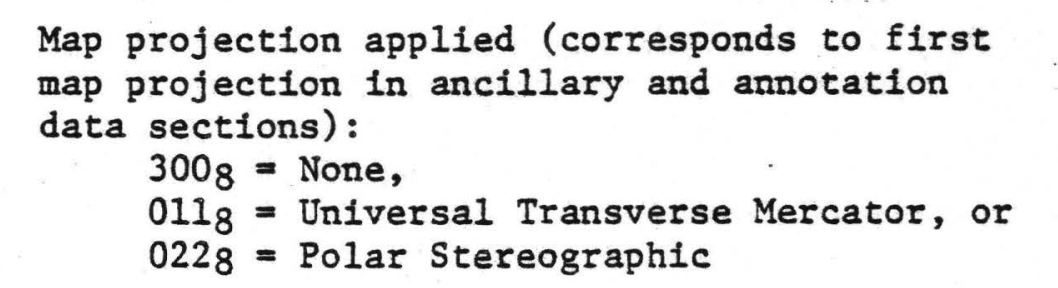 \\
\hline $125-126$ & - $\cdot$ & - • & - $\cdot$ & . . . . For MSS \\
\hline $125-126$ & $\mathrm{xxx}$ & $\operatorname{xxx}$ & & $\begin{array}{l}\text { WRS offset from fully processed image } \\
\text { center - right (positive) left (negative). } \\
\text { pixel displacement of the World Reference } \\
\text { System designation with respect to the picture } \\
\text { center pixel (scan line } 1492 \text {, pixel 1774). } \\
\text { (Most significant bit indicates the sign; "0" = } \\
\text { positive with WRS to right of picture center } \\
\text { and "l" = negative with WRS left of picture } \\
\text { center.) For image data without geometric } \\
\text { corrections, zeros }\end{array}$ \\
\hline $125-126$ & •`. & - & - $\cdot$ & . . . . For RBV \\
\hline $125-126$ & 000 & 000 & & Not used (zeros) \\
\hline $127-128$ & 000 & 000 & & Not used (zeros) \\
\hline
\end{tabular}


TABLE 2.--(cont'd)

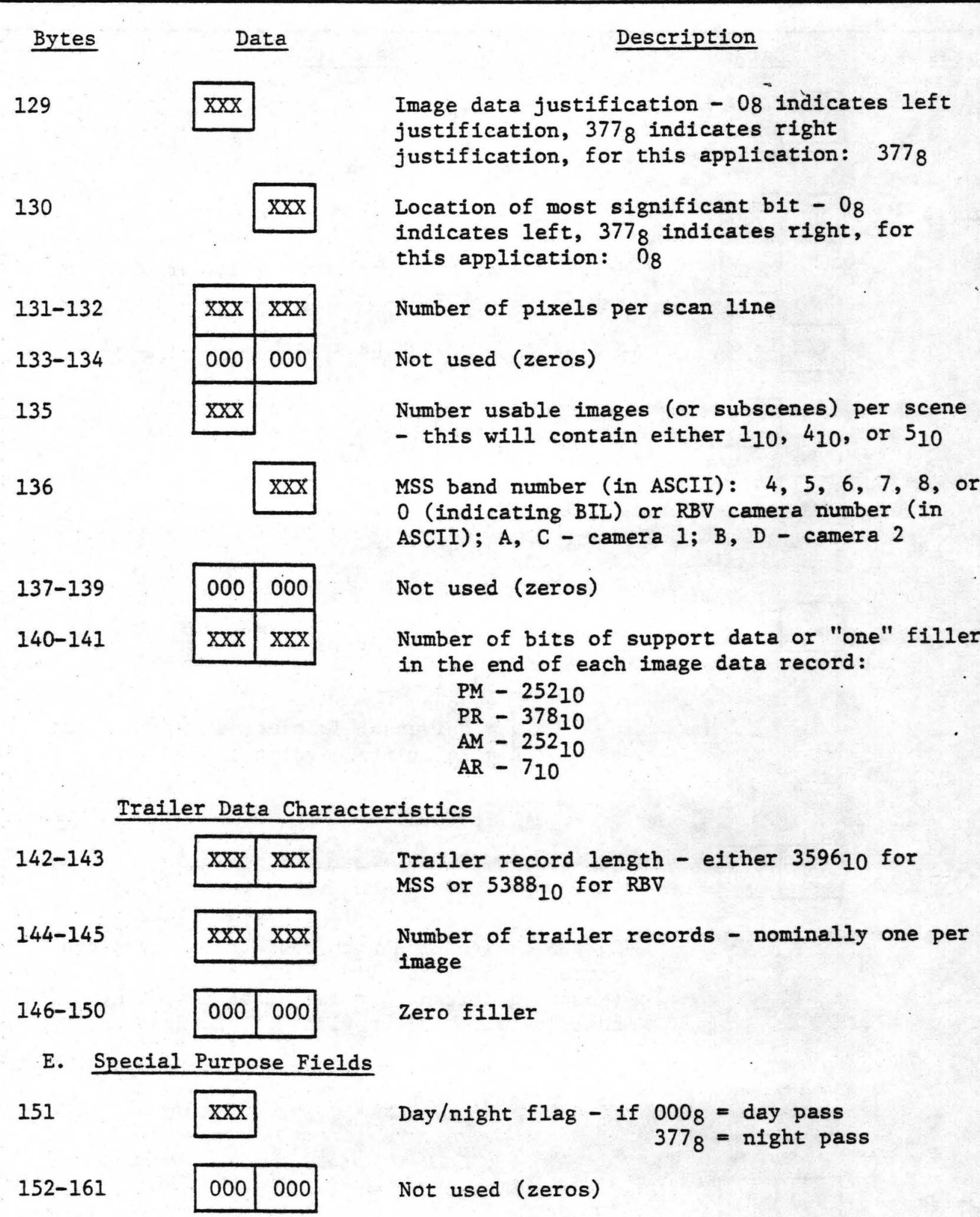


TABLE 2.--(cont'd)

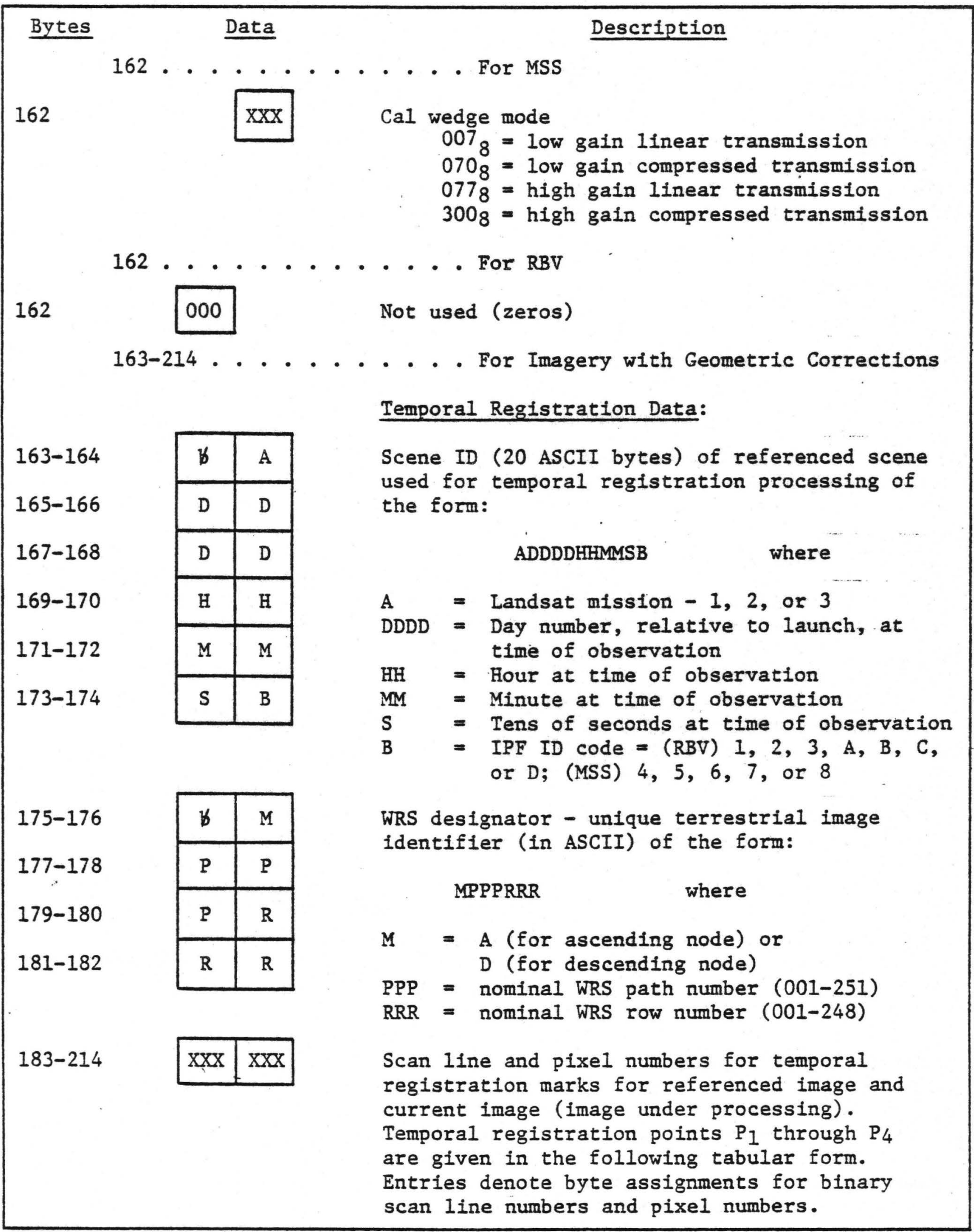


TABLE 2.--(cont'd)

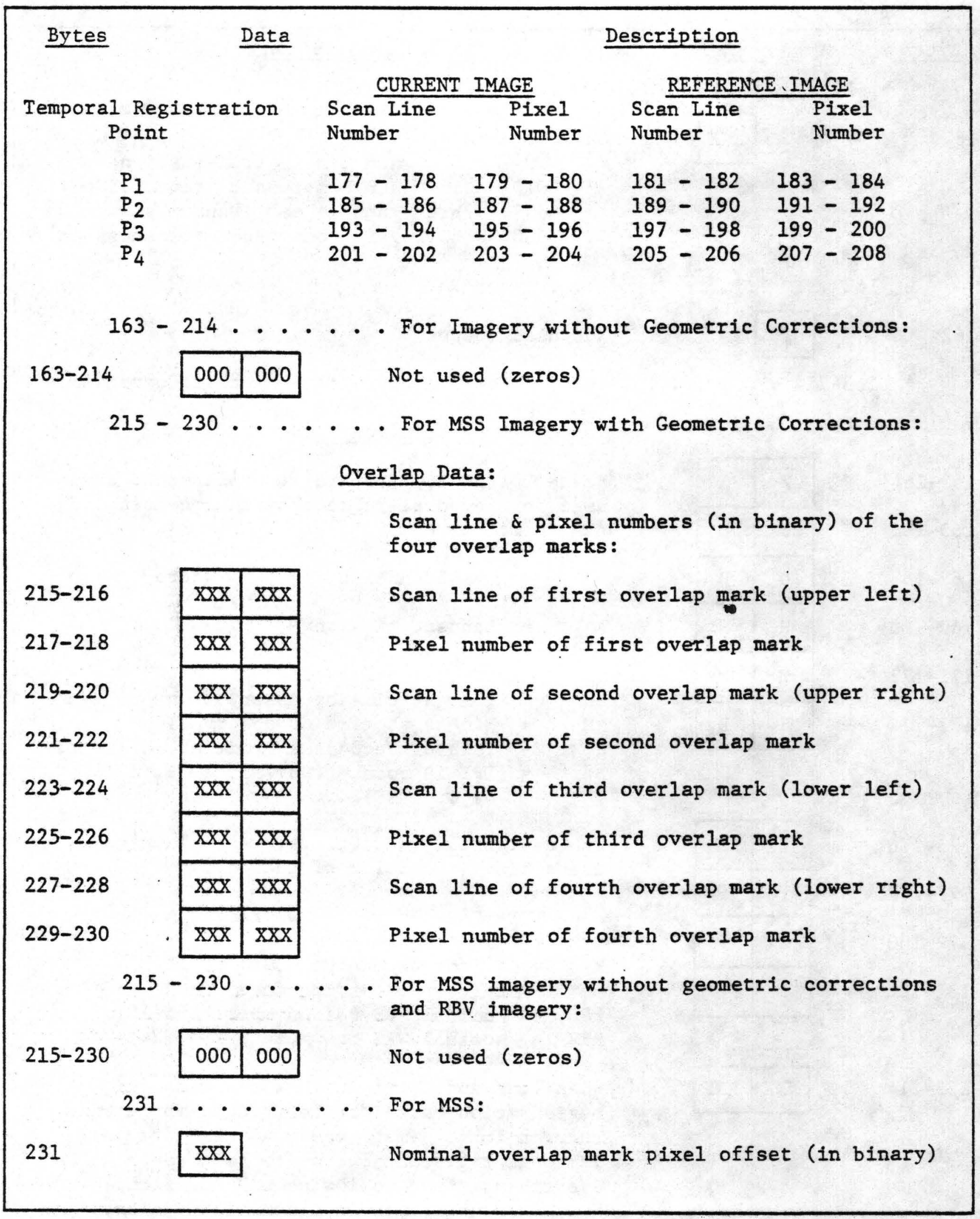




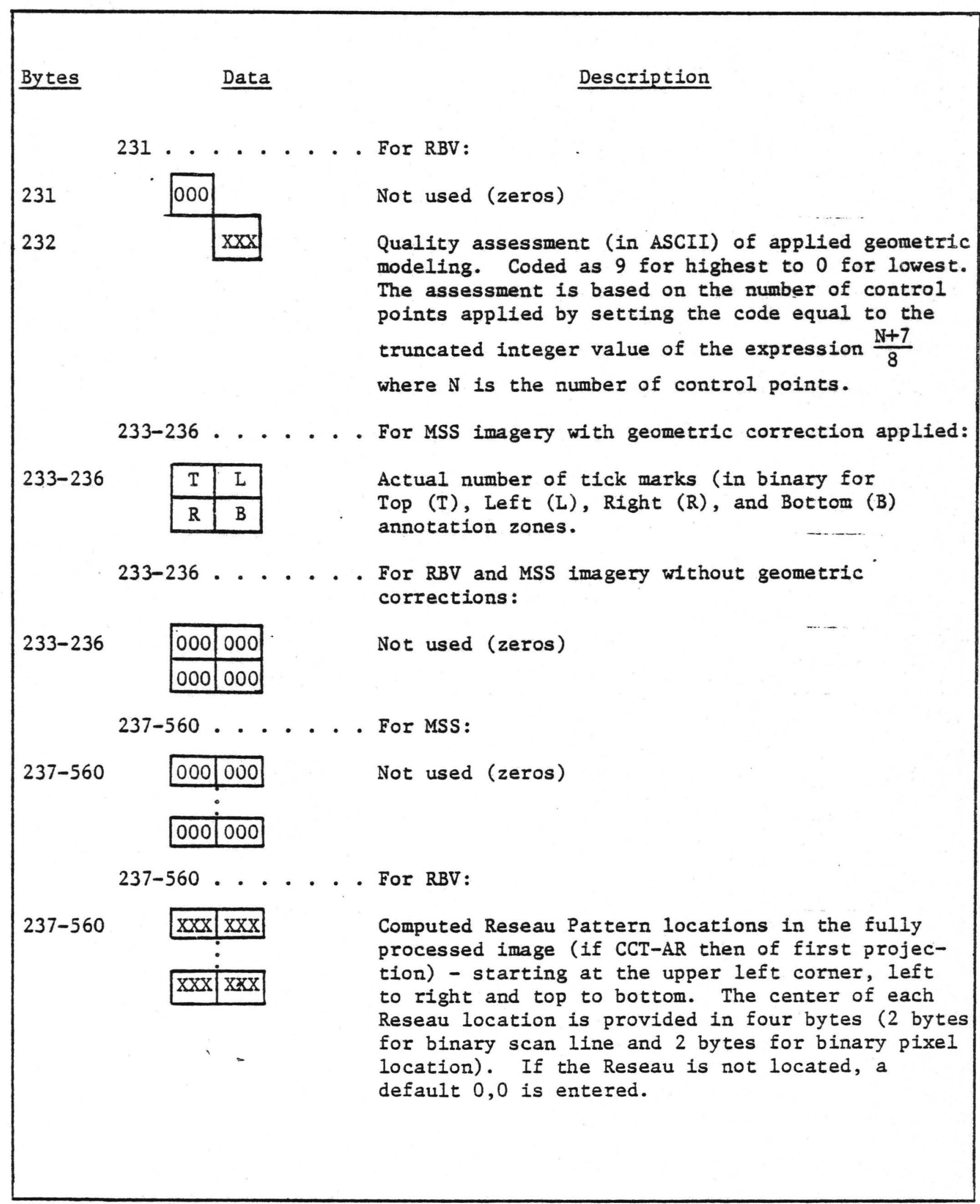


Table 2.--(cont'd)

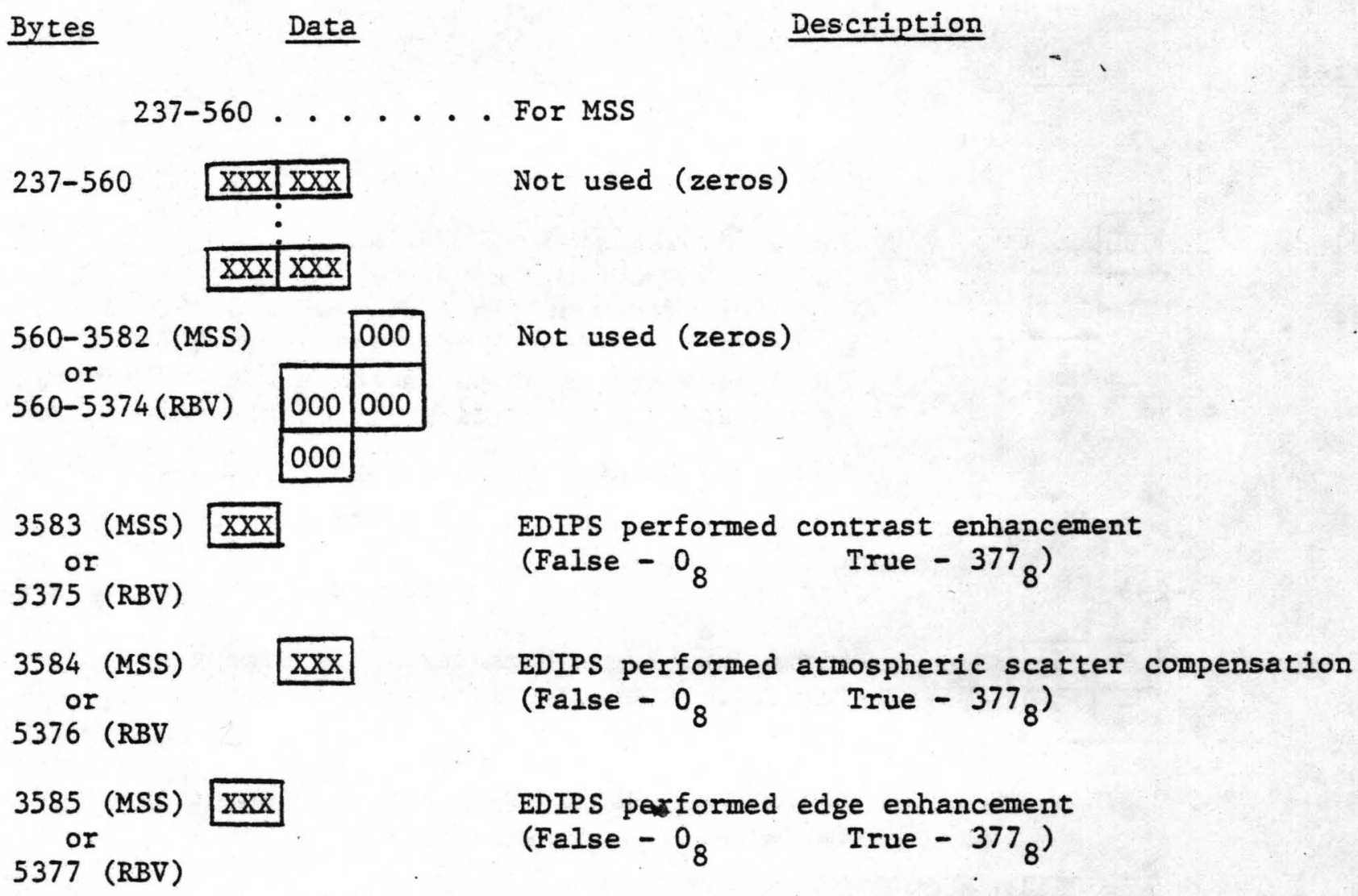

Indication of data present by band - actual data is indicated as present by a 1 in the proper bit position. Positions for placement of the 1 for bands 4 through 8 is as follows:

\section{8}

When data for a given band is not present, it's position will contain a zero rather than a 1 . 
Table 2.--(cont'd)

Bytes

Data

3587

\begin{tabular}{|l|l|}
\hline$G(4)$ & $G(5)$ \\
\hline$G(6)$ & $G(7)$ \\
\hline$G(8)$ & \\
\hline
\end{tabular}

3592-3596

\begin{tabular}{|l|l|}
\cline { 2 - 2 } \multicolumn{1}{c|}{} & $T(4)$ \\
\hline$T(5)$ & $T(6)$ \\
\hline$T(7)$ & $T(8)$ \\
\hline
\end{tabular}

\section{Description}

A five-byte field, with one byte for each of MSS bands $4,5,6,7$, and 8 to indicate sensor gain options, ASCII coded:

$$
\begin{aligned}
& G=\text { "H", high gain } \\
& G=\text { "L", low gain }
\end{aligned}
$$

A five-byte field with one byte for each of MSS bands $4,5,6,7$, and 8 to indicate the type of MSS transmission, ASCII coded:

$$
\begin{aligned}
& T=\text { " } I ", \text { linear mode } \\
& T=" 2 ", \text { compressed mode }
\end{aligned}
$$


TABLE 2-a.--Active-detector-status bytes

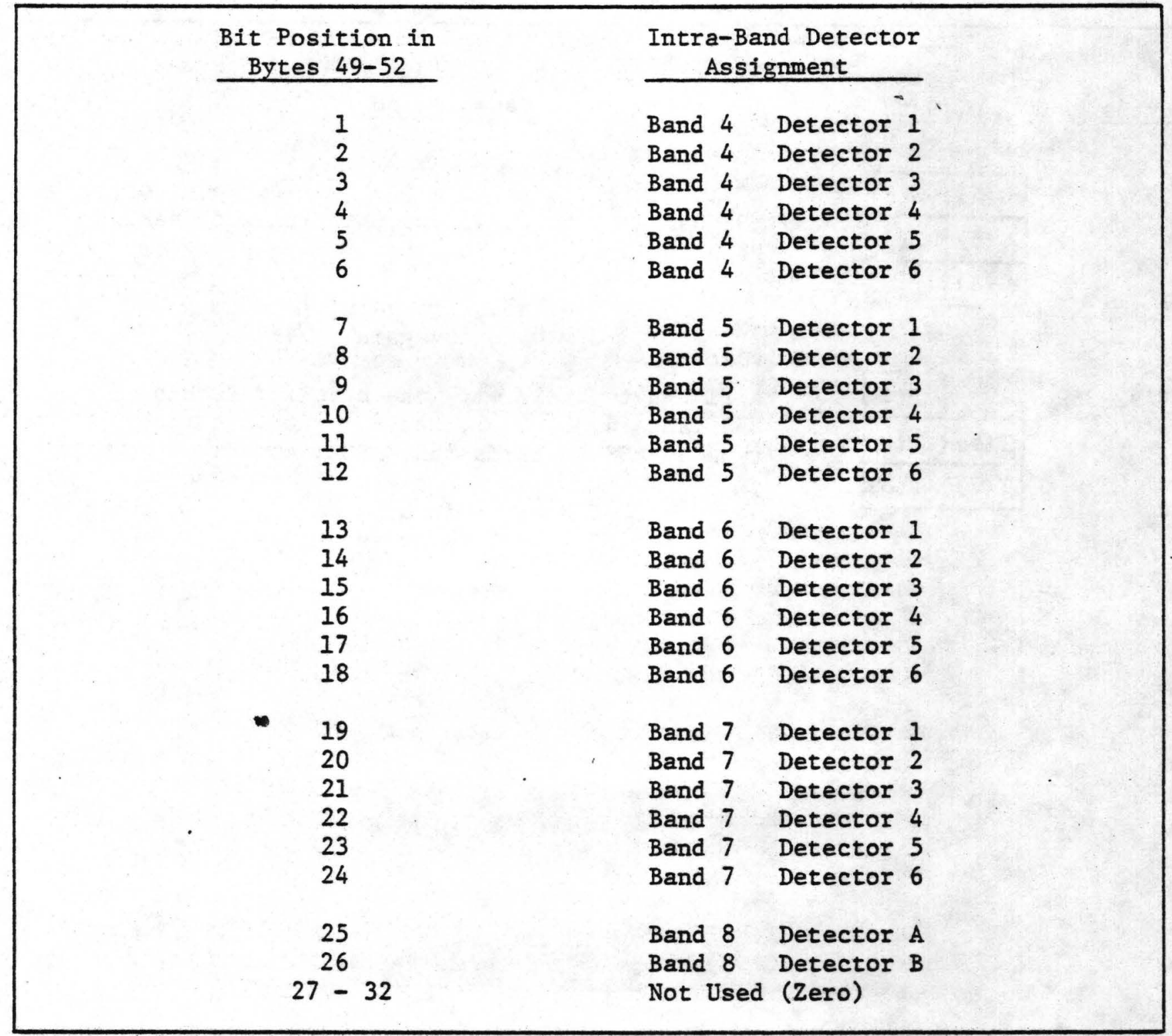

\section{ANCILLARY RECORDS}

The ancillary records occur only on CCT's that are geometrically uncorrected (CCT-AM or CCT-AR). The number of records depends on the sensor. The ancillary records contain various kinds of correction data that the user can apply to the image data to produce a geometrically correct image. For each band or subscene, the ancillary information for two projections is provided (SOM and either PS or UTM).

The contents of the ancillary records can be divided into two areas: geometric-modeling data and projection-dependent data. The first two records of ancillary data contain the modeling data.

MODELING DATA. The modeling information of the ancillary data shown in table 3 provides characteristics of the corrected image array and satellite. The numerical data is in one of three formats: fixed point binary or floating point binary, or single precision floating point binary. 


\begin{tabular}{l|l} 
SIGN & INTEGER \\
\hline \multicolumn{1}{c|}{ Bit 0 } & Bits 1 through 31 \\
$+=0$ &
\end{tabular}

Fixed Point Binary (FB)

where bit 0 is the most significant bit

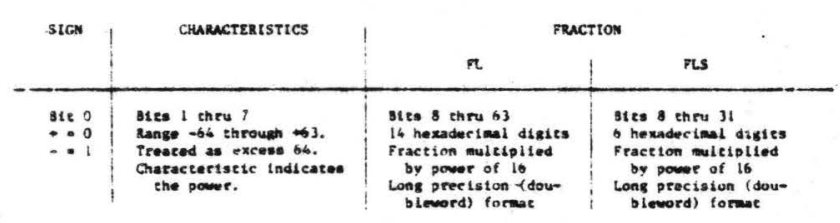

PROJECTION DEPENDENT DATA. The remaining ancillary records are the projection dependent data. Header byte 124 indicates which additional projection besides SOM is included: PS or UTM. For MSS data, 8 records each provide projection correction to two of the three projections. For RBV data, the modeling data are followed by 14 records for each of the two projections. All horizontal-row (HRS) and vertical-row (VRS) coordinates are given in four byte signed values as:

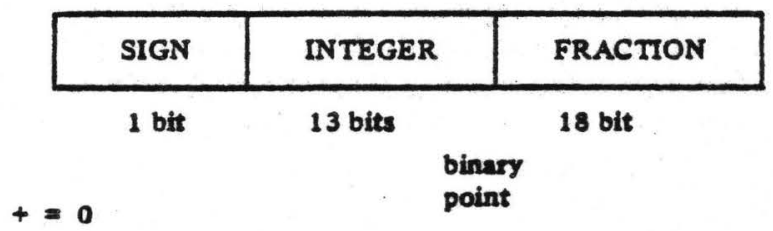

$-21$

Tables 4 and 5 show the layouts of the projection dependent data for MSS and RBV, respectively. In summary, the ancillary records on a CCT-AM are 2 modeling, 8 UTM or PS, 8 SOM, and 8 records of zero fill. A CCT-AR contains 2 modeling, 14 UTM or PS, and 14 SOM records. The correct application of the ancillary projection data is discussed in Appendix A.

TABLE 3.--Modeling data records: Record-byte assignments

\begin{tabular}{|c|c|c|}
\hline Record 1 & ENCODED $1 /$ & DESCRIPTION \\
\hline $1-4$ & FP & Record Number \\
\hline 5 & $000_{8}$ & Zero Fill \\
\hline 6 & $044_{8}$ & Record Type Code \\
\hline $7-10$ & FP & Nominal number of pixels per input line \\
\hline $11-14$ & FP & $\begin{array}{l}\text { Number of input lines in the partially processed } \\
\text { image }\end{array}$ \\
\hline $15-22$ & FL & $\begin{array}{l}\text { Nominal scale of input inter-pixel distance in } \\
\text { meters per pixel }\end{array}$ \\
\hline $23-30$ & FL & $\begin{array}{l}\text { Nominal scale of input inter-line distance in } \\
\text { meters per pixel }\end{array}$ \\
\hline I/ See & der model: & data. \\
\hline
\end{tabular}


Record 1

$31-34$

$35-38$

$39-44$

47-54

55-62

$63-70$

71-102

$103-110$

$111-118$

$119-126$

$127-134$

$135-142$

$143-150$

$151-158$

159-262
ENCODED

FP

FP

FL

FL

FL

FL

FL

FL

FL

FL

FL

FL

FL

FI

FP

\section{DESCRIPTION}

Number of pixels per output line of fully processed image

Number of lines per output image of fully processed image

Scale of fully processed output inter-pixel distance in meters per pixel

Scale of fully processed output inter-line distance in meters per pixel

Nominal spacecraft altitude in meters

Nominal input image width in meters

MSS mirror model coefficients ( 4 values)

( 8 bytes each). Zero fill if RBV

MSS maximum mirror angle in radians. Zero fill if $\mathrm{RBV}$

Scan skew constant. Zero fill if $\mathrm{RBV}$

Time between successive MSS mirror sweeps in seconds. Zero fill if $\mathrm{RBV}$

Time for the active portion of an MSS mirror sweep in seconds. Zero fill if RBV

Major semi-axis of Earth ellipsoid (sensor and scene independent)

Minor semi-axis of Earth ellipsoid (sensor and scene independent)

Earth curvature constant (dependent on spacecraft's nominal altitude). Zero fill if $\mathrm{RBV}$

MSS sampling delay constants (26 values, each detector) measured in input image along-scan pixels ( 4 bytes each). Zero fill if RBV 


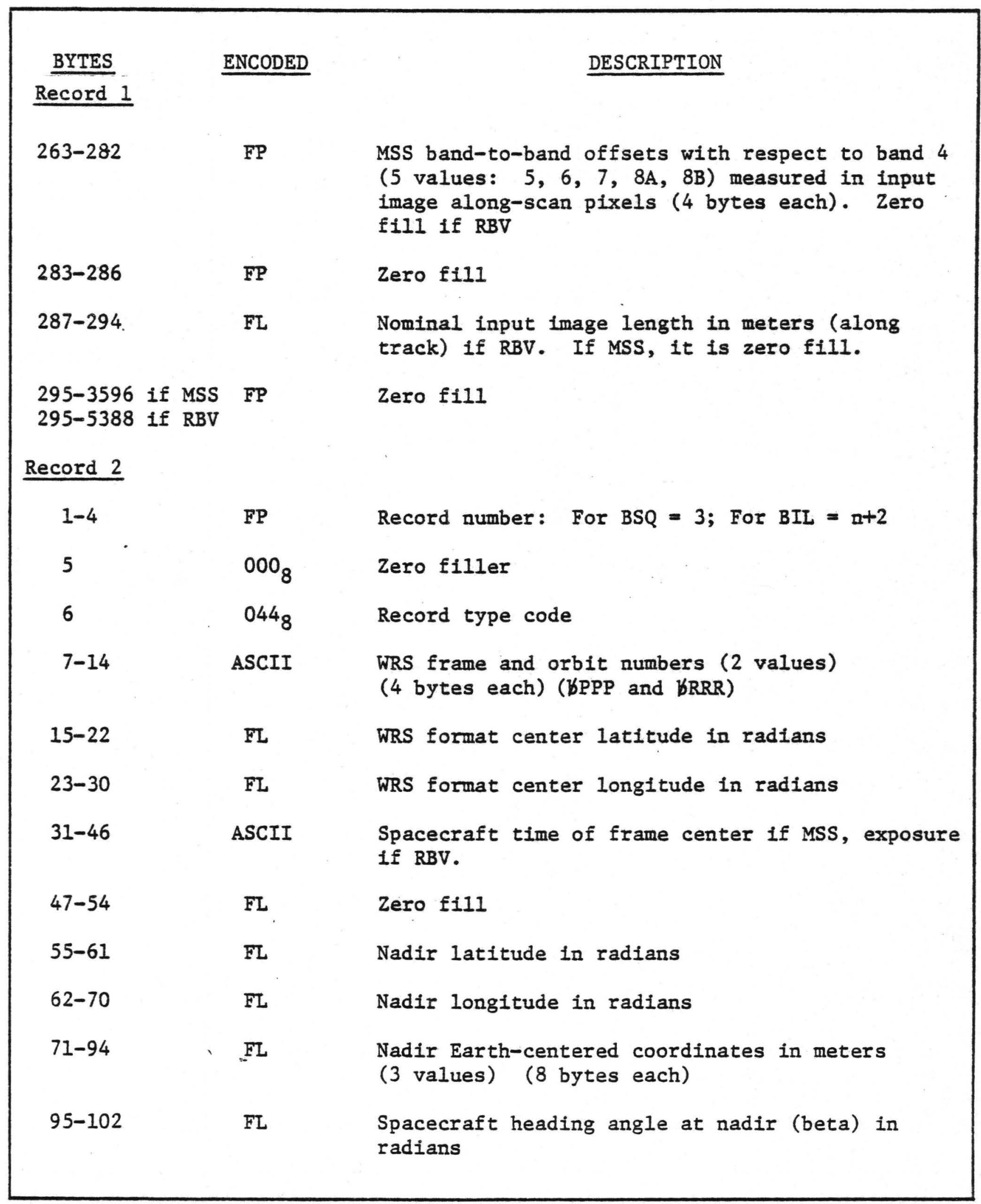




\begin{tabular}{|c|c|c|}
\hline$\frac{\text { Becord } 2}{\text { Ror MSS }}$ & ENCODED & DESCRIPTION \\
\hline $103-110$ & FL & $\begin{array}{l}\text { Input image line coordinate of nadir in partially- } \\
\text { processed output }\end{array}$ \\
\hline $111-118$ & FL & $\begin{array}{l}\text { Input image pixel coordinate of nadir in partially- } \\
\text { processed output }\end{array}$ \\
\hline $119-126$ & FL & If MSS, normalize spacecraft velocity at nadir. \\
\hline $127-134$ & FL & $\begin{array}{l}\text { If MSS, Earth rotation velocity at nadir in } \\
\text { meters per second. }\end{array}$ \\
\hline $135-138$ & FLS & $\begin{array}{l}\text { If MSS, the Earth rotation parameter (image skew), } \\
\text { a } \mathrm{eR}^{\text {' in radians }}\end{array}$ \\
\hline $139-250$ & FL & $\begin{array}{l}\text { Attitude/altitude coefficients ( } 14 \text { values) } \\
\text { ( } 8 \text { bytes each) }\end{array}$ \\
\hline $251-264$ & FP & Number of GCPS in altitude/attitude fit \\
\hline $\begin{array}{l}265-3596 \\
\text { For RBV }\end{array}$ & FP & Zero fill \\
\hline $103-118$ & FP & Zero fill \\
\hline $119-119$ & ASCII & $\mathrm{RBV}$ image identification ( $A, B, C$, or $D)$ \\
\hline $120-142$ & FP & Zero fill \\
\hline $143-166$ & FL & Attitude coefficients ( 3 values) \\
\hline $167-174$ & FL & $\begin{array}{l}\text { Measured. spacecraft altitude (KM) at time of } \\
\text { image exposure. (If MSS altitude is used, } \\
\text { this parameter is taken from MSS data.) }\end{array}$ \\
\hline $175-250$ & FP & Zero fill \\
\hline $251-254$ & FP & Number of GCP's used in attitude fit \\
\hline
\end{tabular}


Table 3.--(cont'd)

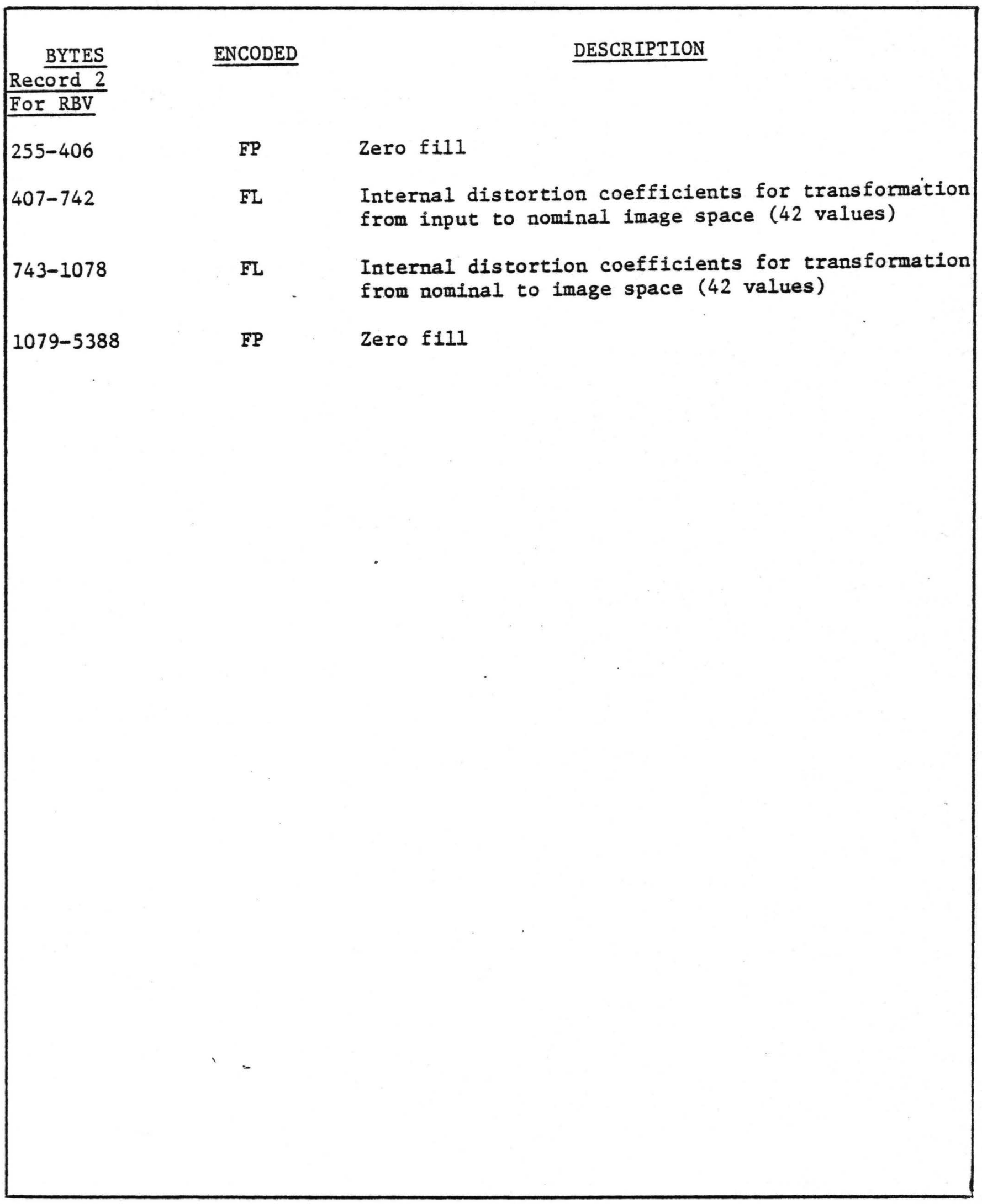


Table 4.--MSS projection-dependent-data records: Record byte assignments

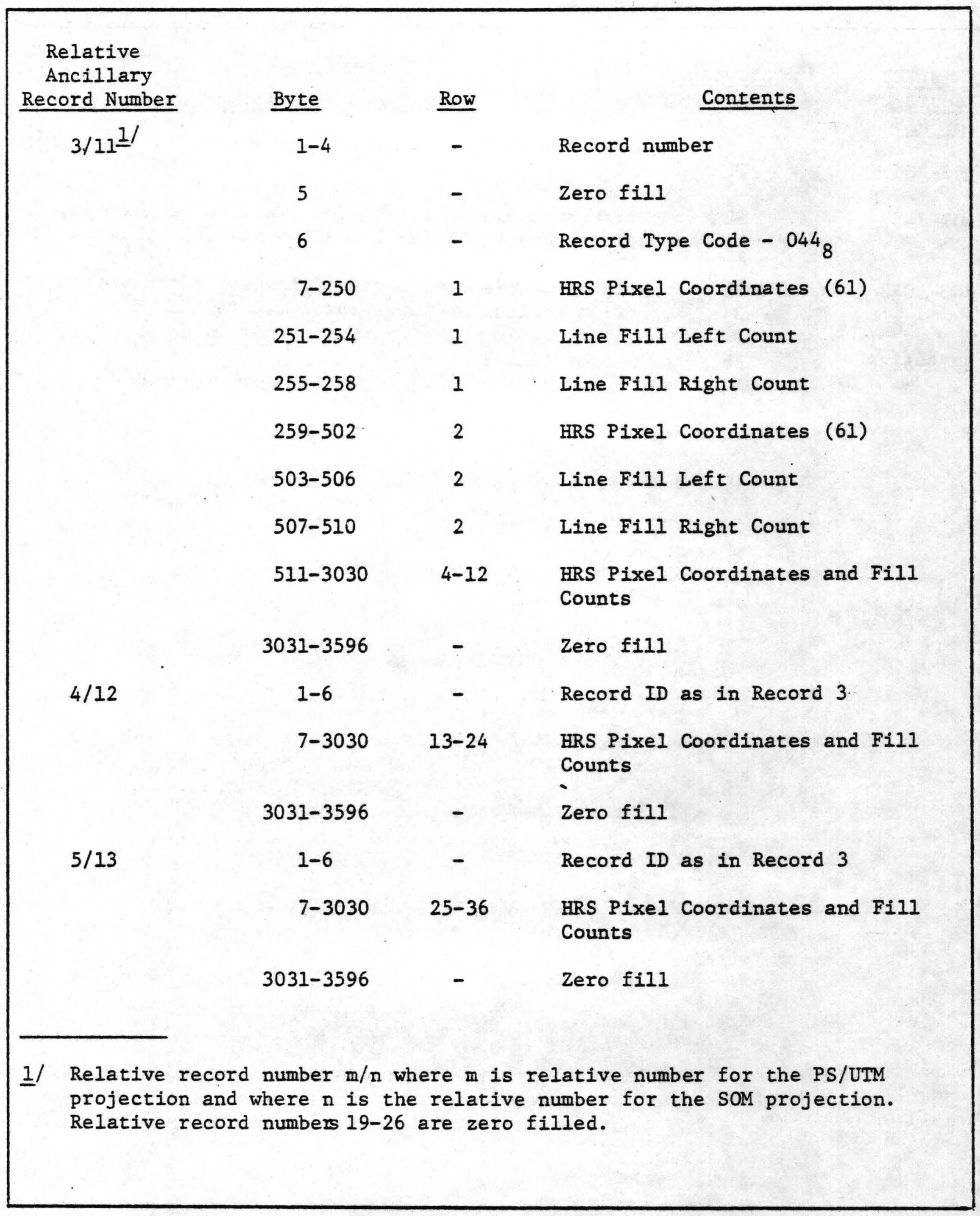


Table 4.--(cont'd)

Relative

Ancillary

Record Number

$6 / 14$

$7 / 15$

$10 / 18$
Bytes

1-6

$7-3030$

3031-3596

1-6

$7-762 \quad 49-51$

763-1014

$1015-1258$

1259-2966

2967-3596

$1-6$

7-2934

2935-3596

1-6

$7-2934$

2935-3596

1-6

7-2934

$33-44$

2935-3078
$37-48$

Row
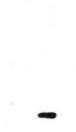

1

2-8

-

-

$9-20$

-

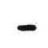

21-32

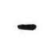

-

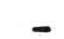

\section{Contents}

Record ID as in Record 3

HRS Pixel Coordinates and Fill Counts

Zero fill

Record ID as in Record 3

HRS Pixel Coordinates and Fill Counts

Zero fill

VRS Line Coordinates (61)

VRS Line Coordinates

Zero fill

Record ID as in Record 3

VRS Line Coordinates

Zero fill

Record ID as in Record 3

VRS Line Coordinates

Zero fill

Record ID as in Record 3

VRS Line Coordinates

Zero fill 
Table 4.--(cont'd)

Relative

Ancillary

Record Number

$10 / 18\left(\right.$ cont'd $^{\prime} \quad 3079-3080$

$3081-3082$

3083-3102

$3103-3134$

$3135-3150$

$3151-3154$

$3155-3162$

3163-3170 $\underline{\text { Row }}$

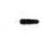

$-$

$-$

$-$

\section{Contents}

Pixel number of WRS in Fully Processed Image

WRS offset from Fully Processed Image Center Pixel

Temporal Registration Scene ID (20 ASCII)

Scan line and Pixel numbers for Temporal Registration Marks P1, P2, P3, and P4 clockwise from upper left corner. Eight bytes for each point. Four bytes for line and four bytes for pixel.

Scan line and Pixel numbers for 4 overlap marks. See Header bytes 215-230 for corrected MSS imagery.

Actual number of tick marks

Input Sample value of 4 corner points in output image (Location of image in output array)

Orientation of image output coordinate system for either UTM or PS if record 10 or SOM if record 18 in radians (Beta UTM or Beta PS) in FL format. 
Table 4.--(cont'd)

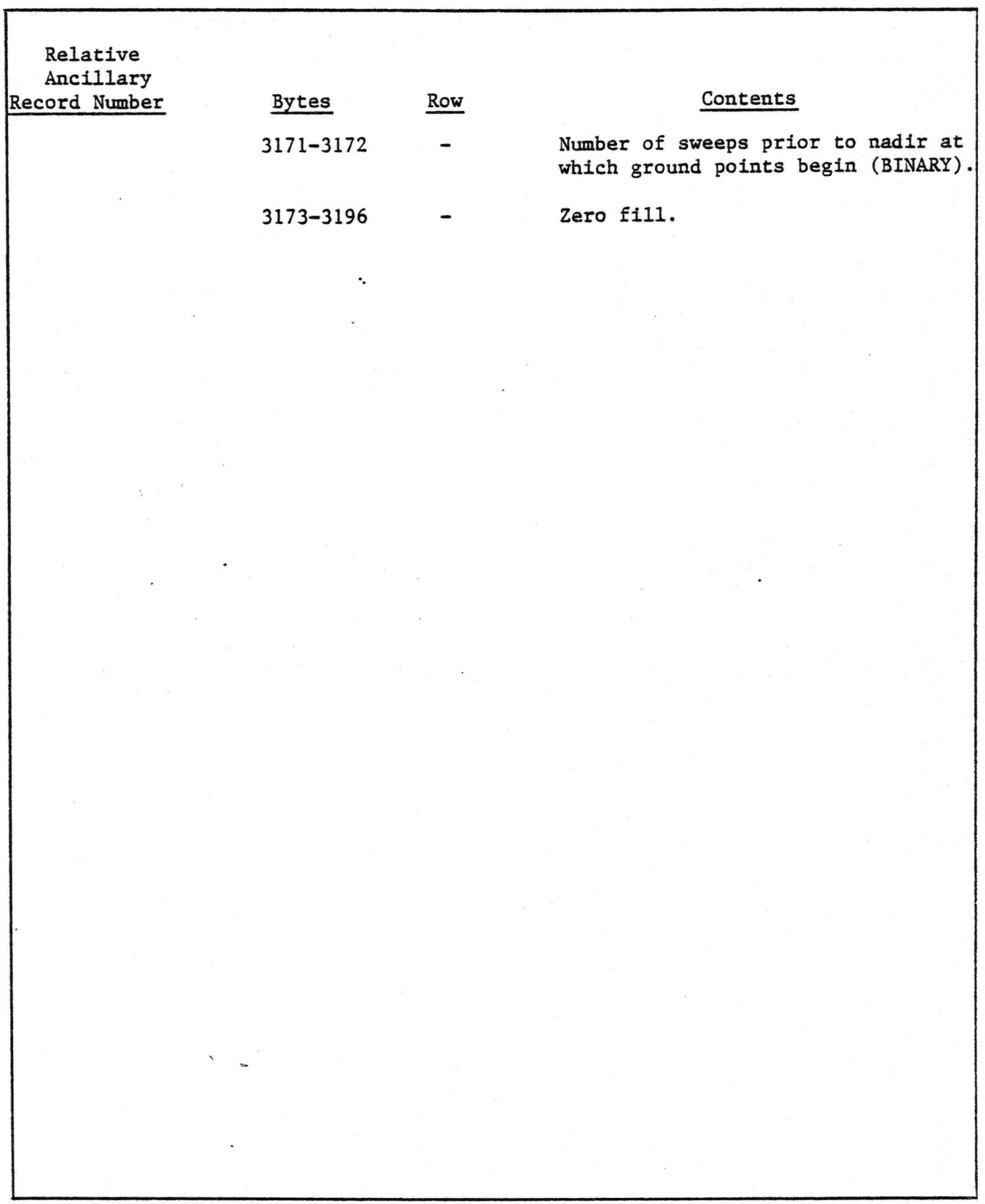


Relative

Ancillary

Record Number

$3 / 171 /$

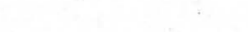

6

$7-82$

$83-86$

$87-806$

$807-882$

$883-886$

$887-1606$

$1607-1682$

1683-1686

$1687-2406$

$2407-5388$

$4 / 18$

$1-6$

$7-5388$

$1-6$

$7-5388$

$5 / 19$
Segment $\underline{\text { Row }}$

Contënts

- Record number

- Zero fill

- Record Type Code - 0448

1 HRS pixel coordinate (19)

1 Left fill count

2-10 HRS pixel coordinates and left fill count

1 HRS pixel coordinates (19)

- Zero fill (no fill for center segment)

2-10 HRS pixel coordinates and zero fill

1 HRS pixèl coordinates

$1 \quad$ Right fill count

2-10 HRS pixel coordinates and right fill counts

- Zero fill

- Record ID as in Record 3

11-20 HRS pixel coordinates, fill counts, and zero fill

- $\quad$ - Record ID as in Record 3

$1-3$
HRS pixel coordinates, fill counts, and zero fill

I/ Relative record number $\mathrm{m} / \mathrm{n}$ where $\mathrm{m}$ is relative number for the PS/UTM projection and where $\mathrm{n}$ is the relative number for the SOM projection. 
Relative

Ancillary

Record Number

$6 / 20$

$7 / 21$

$10 / 24$

$11 / 25$

$$
\begin{gathered}
1-6 \\
7-82 \\
83-158 \\
159-2058 \\
2059-2062 \\
2063-4114 \\
4115-5388
\end{gathered}
$$

Segment Row

Contents -

- Record ID as in Record 3

31-40 HRS pixel coordinates, line fill counts, and zero fill

- Record ID as in Record 3

41-50 HRS pixel coordinates, Iine fill counts, and zero fill

- $\operatorname{Record} I D$ as in Record 3

51-60 HRS pixel coordinates, line fill counts, and zero fill

- $\operatorname{Record} I D$ as in Record 3

61-70 HRS pixel coordinates, line fill counts, and zero fill

- Record ID as in Record 3

71-72 HRS pixel coordinates, line fill counts, and zero fill

- Zero fill

- Record ID as in Record 3

1 VRS line coordinates (19)

2 VRS line coordinates (19)

3-27 VRS line coordinates

- Zero fill

1-27 VRS Iine coordinates

- Zero fill 
MANUAL ON CHARACTERISTICS OF LANDSAT COMPUTER-COMPATIBLE TAPES

Table 5.--(cont'd)

Relative

Ancillary

Record Number

$12 / 26$

$1-6$
$7-2058$
$2059-2062$
$2063-4114$
$4115-5388$

$13 / 27$

$14 / 28$

$1-6$
$7-2058$
$2059-2062$
$2063-4114$
$4115-5388$

$14 / 28$

$15 / 29$

$$
1-6
$$

$$
7-2058
$$

2059-2062

2063-4114

4115-5388

$16 / 30$

$1-6$
$7-2058$
$2059-5388$

1-6

$7-8$
Segment Row

Contents

- Record ID as in Record 3

1-27 VRS line coordinates

- Zero fill

28-54 VRS line coordinates

- Zero fill

- Record ID as in Record 3

28-54 VRS line coordinates.

- Zero fill

28-54 VRS Iine coordinates

- Zero fill

- Record ID as in Record 3

55-81 VRS line coordinates

- Zero fill

55-81 VRS line coordinates

- Zero fill

- Record ID as in Record 3

55-81 VRS line coordinates

- Zero fill

- Record ID as in Record 3

- Pixel number of WRS in fully processed image 


\section{Relative}

Ancillary

Record Number

\section{Bytes}

$9-10$

$11-30$

$31-62$

$63-66$

$67-390$

$391-406$

$407-414$

$415-426$

$427-438$

$439-1238$

$1239-2038$

$2039-2838$
Segment Row

- Scan line number of WRS in fully processed image

- Temporal registration scene ID (20 ASCII)

- Scan line and pixel number for P1, P2, P3, P4

- Number of tick marks for top, left, right, bottom (binary)

- Computed Reseau locations, 81 sets of coordinates

- Line and-sample values of 4 corner points in output image (location of image data in output array)

- Orientation of image output coordinate system for UTM or PS if record 16 and for SOM/HOM if record 30 . Beta in radians.

- Number of fill lines to be used for each segment before image data. Three fixed point binary (FP) values.

- Number of input image lines to be skipped for each segment at top of image. Three FP values.

- Top left fill counts - up to 200 FP values

- Top right fill counts - up to 200 FP values

- Bottom left fill counts - up to 200 FP values 
MANUAL ON CHARACTERISTICS OF LANDSAT COMPUTER-COMPATIBLE TAPES

Table 5.--(cont'd)

Relative

Ancillary

Record Number

$16 / 30$

(cont'd)
Bytes Segment $\underline{\text { Row }}$

- Bottom right fill counts - up to 200 $2839-3638$

$3639-5388$
$-$

$-$ FP values

- Zero fill 


\section{ANNOTATION RECORDS}

The annotation records contain all of the alphanumeric information printed on the bottom of standard film products and the tick information that surrounds the corrected and framed image (table 6). For a CCT-AM or CCT-AR, within the attributes are two annotation records (SOM and UTM or PS) for each band or subscene. The record content is projection dependent and is as it would be on a corrected CCT for each projection.

All tick-mark information is given in bytes 122-2256 of the annotation record. Figure 11 shows the relationship the alphanumeric annotation and tick-mark information to the image array. Each tick mark is 9 bytes and represents a ground distance of 1000 meters. Figure 12 illustrates the tick mark features and their proper interpretation of the tick mark location bytes (first two bytes). Figure 13 illustrates the format of UTM and PS tick mark annotation. The order of the tick mark data on the CCT is summarized as follows:

$\begin{array}{ll}\text { TICK MARK ZONE } & \text { ORDER OF APPEARANCE } \\ \text { Top } & \text { Left to right } \\ \text { Left } & \text { Top to bottom } \\ \text { Right } & \text { Top to bottom } \\ \text { Bottom } & \text { Left to right }\end{array}$

TABLE 6.--Annotation record: Record-byte assignments

\section{Bytes}

$$
1-4
$$

5

6

$7-14$

15-31

$32-40$

41-57

$58-67$

Record number

Zero fill

Record Type Code: $333_{3}$

Day, month, year of exposure (ASCII), e.g., 07 JUN676

Format center - latitude and longitude at the center of the MSS and RBV images format are indicated in degrees and minutes (ASCII): e.g., C6N33-05/W115-18

Nominal path row identifier (ASCII), e.g., D202-101. " $D$ " indicates descending acquisition; "A" indicates ascending acquisition. The path is 202, row is 101 .

Nominal latitude and longitude (ASCII), e.g., N6R33-03/W115-42

$58-67$

Characters in this group are ASCII and sensor and spectral band dependent

FOR RBV,

$58-62$

Sensor spectral band identification code

$63-64$

RBV shutter duration code (shutter speed in msec):

$X A=2.4, X B=4.0, X C=5.6, X D=8.0, X E=12.0$ 
TABLE 6.-- (cont'd)

Bytes

65

66

67

FOR MSS

$58-64$

65

66

67

$68-81$

82

The sensor spectral-band identification code

Blank

Transmission:

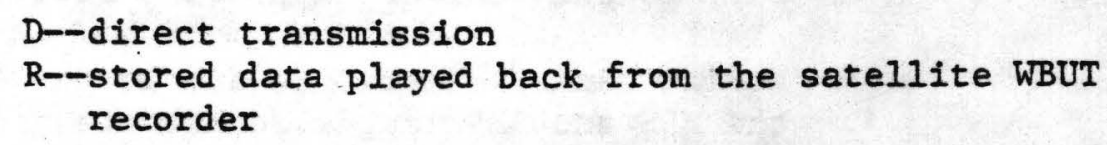
recorder

\section{Description}

Aperture correction indicator:

$$
\begin{aligned}
& \text { I--aperture correction "in" } \\
& \text { 0--aperture correction "out" } \\
& \text { b--blank }
\end{aligned}
$$

Transmission:

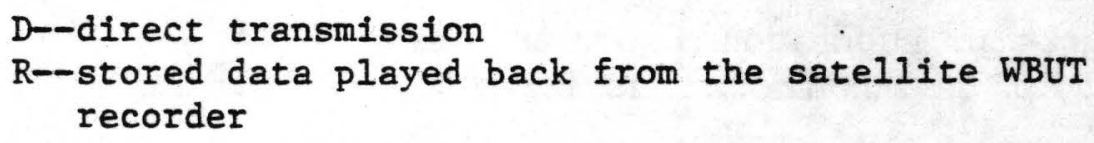
recorder

Blank 
Scale of image: (ASCII)

$$
\begin{aligned}
& 1--185 \mathrm{~km} \times 185 \mathrm{~km} \\
& 2--99 \mathrm{~km} \times 99 \mathrm{~km} \\
& 3--185 \mathrm{~km} \times 170 \mathrm{~km}
\end{aligned}
$$

84

Projection: (ASCII)

$$
\begin{aligned}
& \text { L--Lambert projection } \\
& \text { P--Polar stereographic projection } \\
& \text { S--Space oblique mercator projection } \\
& \text { U--Universal transverse mercator projection } \\
& \text { H--Hotine oblique mercator projection }
\end{aligned}
$$

Resampling algorithm: (ASCII)

$$
\begin{aligned}
& \text { C--cubic convolution } \\
& \mathrm{N} \text {--nearest neighbor }
\end{aligned}
$$

Type of ephemeris data used to compute image center: (ASCII)

\section{P--predictive \\ D--definitive (for system level correction only)}

$$
\begin{aligned}
& \text { A--abnormal } \\
& \text { N--normal }
\end{aligned}
$$

Defines whether an earth image or RBV calibration image has been processed: (ASCII)

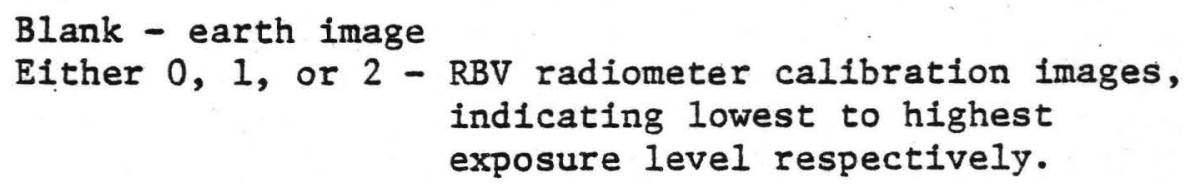
indicating lowest to highest exposure level respectively.

Sensor gain options: (ASCII)

$$
\begin{aligned}
& \text { H--high gain } \\
& \text { L--low gain }
\end{aligned}
$$


TABLE 6.--(cont'd)

Bytes

92

93

94-106

$107-121$

$122-404$

405-548

$549-802$

803-964

$965-1200$

$1201-1263$
Description

Type of MSS transmission: (ASCII)

1-linear mode

2--compressed mode

Blank (ASCII)

Agency and project: (ASCII)

NASA Landsat

Frame identification number. (ASCII) Each image has a unique identifier which will contain encoded information consisting primarily of time of exposure relative to launch. Its format is:

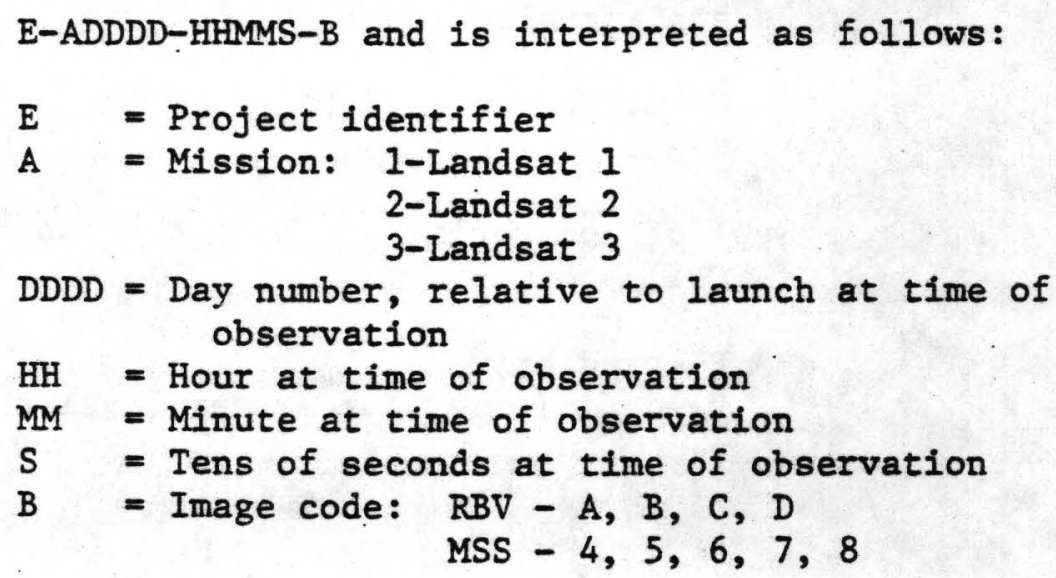

\section{Zero fill}

Top edge tick mark data, 16 coordinates ( 9 bytes each)

Zero fill

Left side tick mark data, 18 coordinates ( 9 bytes each)

Zero fill

Left side tick mark data (concluding) 7 coordinates ( 9 bytes each) 
Table 6.--(cont'd)

Bytes

$1264-1598$

$1599-1760$

1761-1996

1997-2059

$2060-2394$

2395-2538

2539-3596 if MSS

$2539-5388$ if $\mathrm{RBV}$

\section{Description}

Zero fill

Right side tick mark data, 18 coordinates ( 9 bytes each)

Zero fill

Right side tick mark data (concluding) 7 coordinates

( 9 bytes each)

Zero fill

Bottom edge tick mark data, 16 coordinates ( 9 bytes each)

Zero fill

Zero fill

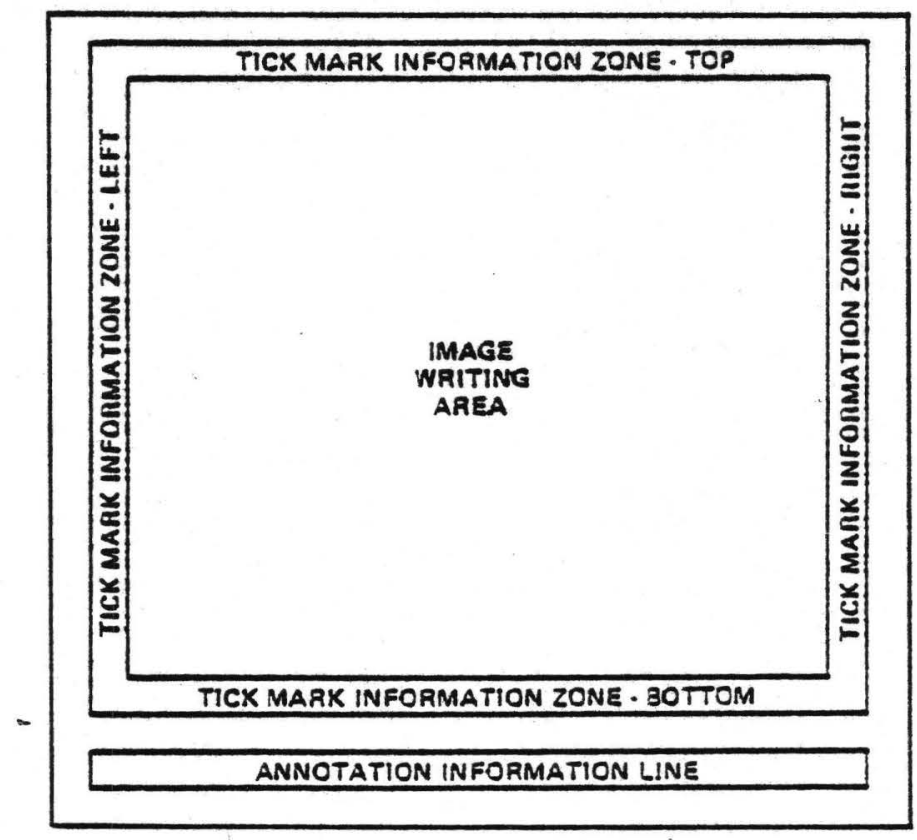

Figure 11.-Standard placement of CCT annotation information on film products. 


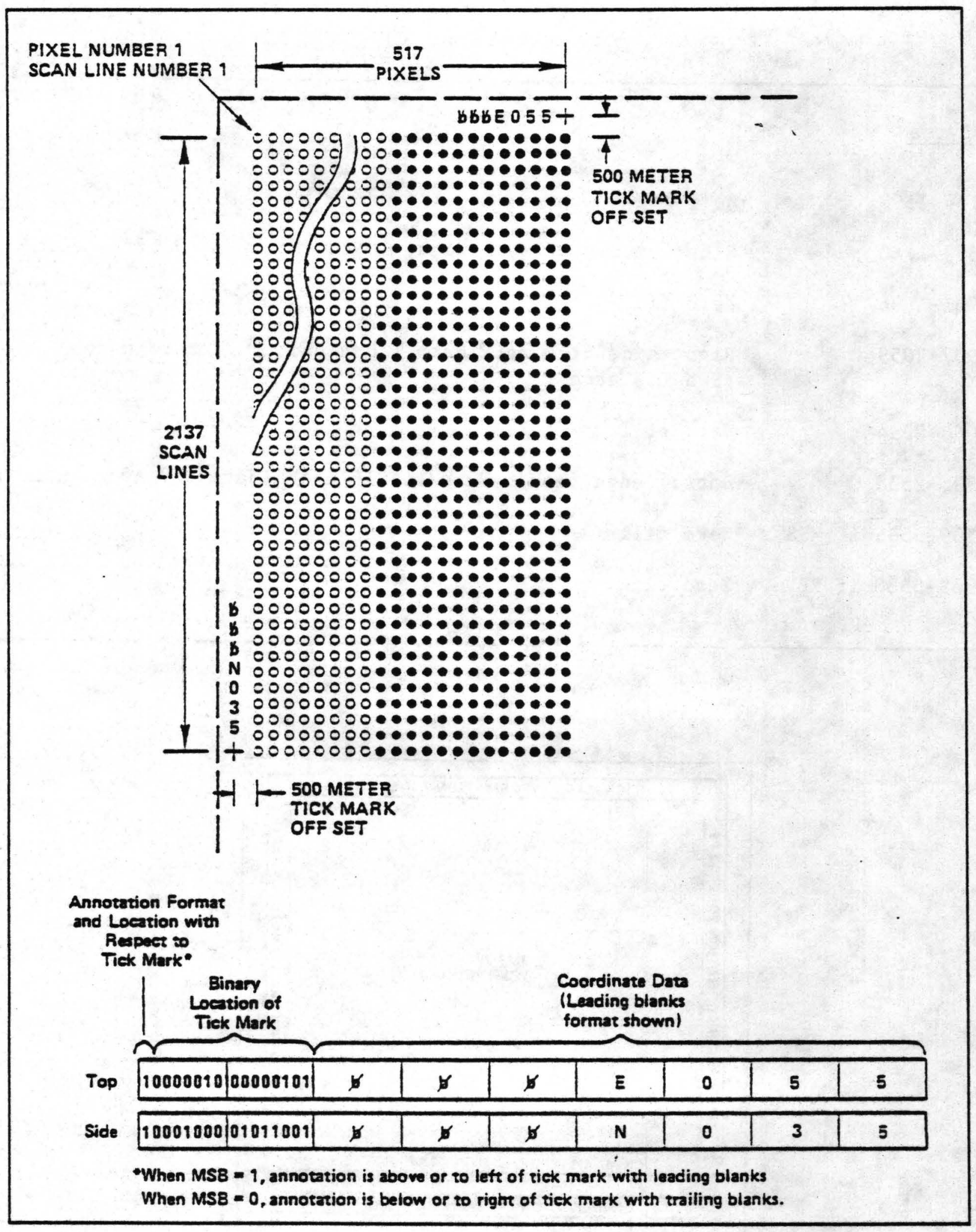

Figure 12.-An example of the placement of two tickmark coordinates and their corresponding annotation with respect to fully processed image data. 
UTM Coordinate Tick Mark (ASCII Notation)

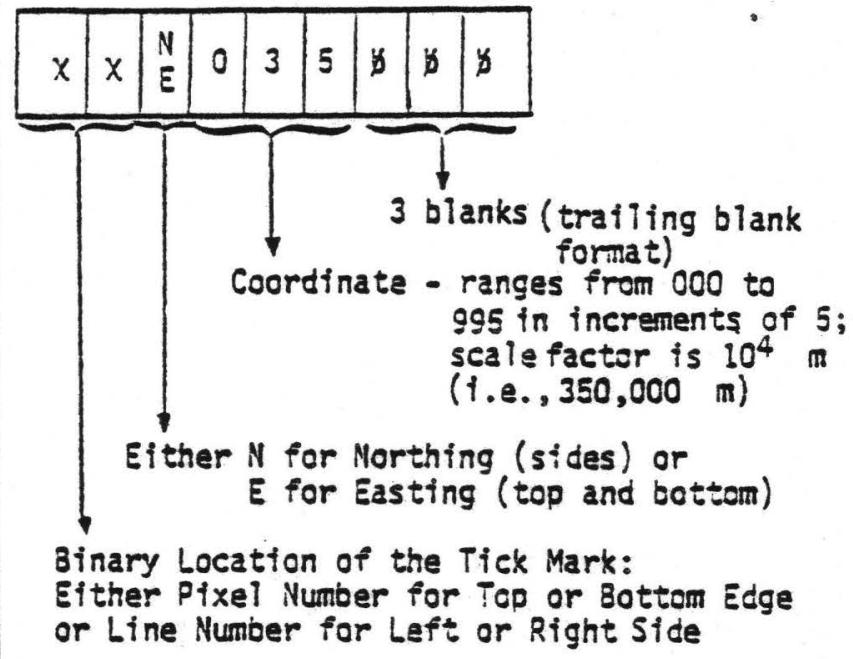

SOM, HOM, and PS Tick Mark (ASCII Notation)

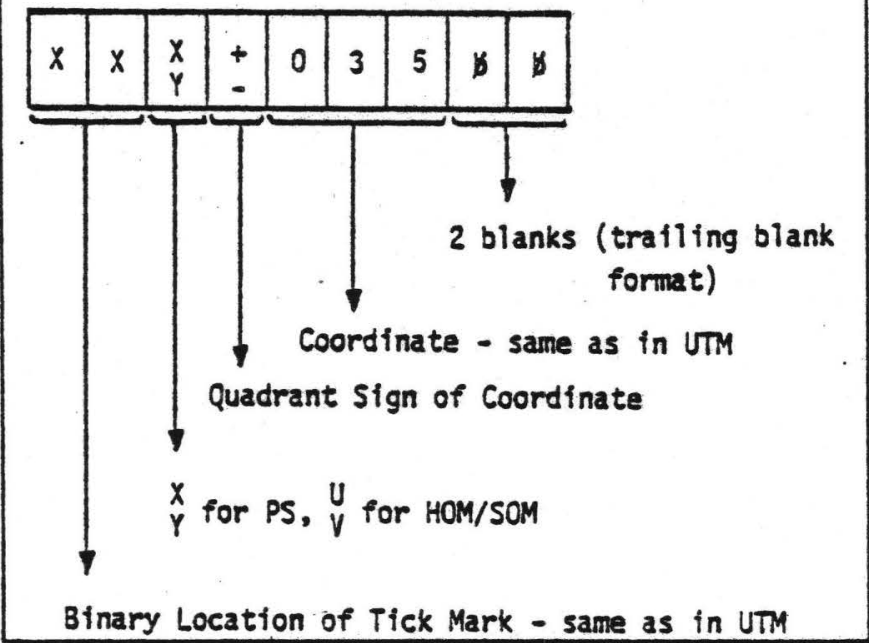

Figure 13.-Examples of tick-mark annotation for UTM and PS.

\section{IMAGE DATA FILE}

The image-data file contains the image-data records as shown in tables $7-10$ and figures 14 and 15 . Each record contains sensor data representing one scan line plus the calibration and quality data associated with that scan line. The header record described above gives the image data characteristics including the number of pixels per scan line, interleaving, and so forth. The content of the image file depends on the interleaving and correction status of the data.

\section{BAND SEQUENTIAL}

In a band sequential (BSQ) format, the image data for each band is given in a separate image file as sequential records for the total number of scan lines in the image array. For RBV data, the CCT set is as if it were BSQ for only one band.

\section{BAND INTERLEAVED BY LINE}

In a band interleaved by line (BIL) format, the image data for all bands are given in one image file as shown in figure 9 . If the the data for a band are missing, the band image data will be zero filled. As each record still contains one line of one band, the record lengths are not changed. Although each band of BSQ requires header, annotation, ancillary, and trailer data, one set of these is sufficient for all bands of BIL.

The scan lines of BIL are sequenced by interleaving four bands of Landsat-1 or -2 MSS data or five bands of Landsat-3 MSS data. Where bands are missing, zero-filled scan lines are interleaved. For example, Landsat-3 while ascending only acquires band 8 data. If a scene of band 8 data were requested in BIL format, the CCT would contain five bands interleaved as four records of zeros followed by one record of valid data. Figure 16 shows the layout difference between BIL and BSQ.

The values of the pixels on the CCT-AM have been radiometrically corrected using gain and offset values, and decompressed using a decompresssion look-up table. The gain and offset values are provided in bytes $3577-3584$ of each record. It should be noted, however, that the radiometric correction process is not uniquely reversible because of computational roundoffs and dual entries in the decompression tables.

The quality of each scan line is recorded in each scan-line record as Q0, Q1, Q2, and Q3. A quality code of $\mathrm{Q} O$ is assessed when no faults are known. A quality of Q1 is assessed when the output line is determined from input lines, any of which were synthetically generated during the preprocessing state at GSFC. A quality of Q2 is assessed when the output line 
Table 7.--MSS uncorrected image-data record

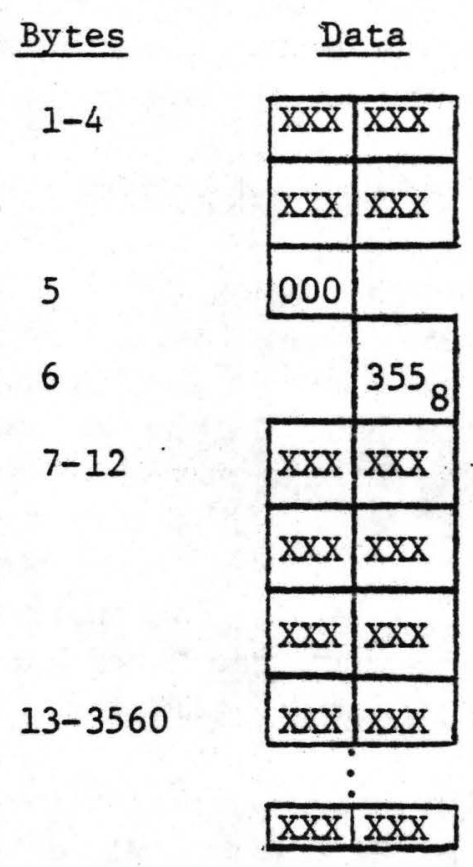

$3561-3562 \quad \mathrm{xxx} \mid \mathrm{xxx}$
3564 $\mathrm{xxx}$

$$
\mathrm{xxx}
$$

\section{Description}

Record number

Zero fill

Record type code

Scan line count

See Figure 14

Image pixels. Image data start in byte 13 + offset for band-to-band registration. Offset $=75,73,71$, $69,3,0$ for bands $4,5,6,7,8 \mathrm{~A}, 8 \mathrm{~B}$, respectively. (First image pixel for band 6 is in byte $13+71=84$ )

Binary number of pixels in scan line. Encrypted as binary bits $x_{11}$ through $x_{0}$ and encoded in the two bytes as: $0_{11} \mathrm{x}_{10} \mathrm{x}_{9} \mathrm{x}_{8} \mathrm{x}_{7} \mathrm{x}_{6} 00 \mathrm{x}_{5} \mathrm{x}_{4} \mathrm{x}_{3} \mathrm{x}_{2} \mathrm{x}_{1} \mathrm{x}_{0}$

Quality code for scan line: $Q 0=000_{8}, Q 1=077_{8}$, $\mathrm{Q} 2=007_{8}, \mathrm{Q} 3=070_{8}$

Nominal calibration indicator:

1 bit for each wedge sample; eg $010_{8}=00001000=00 \mathrm{X}_{1} \mathrm{X}_{2} \mathrm{X}_{3} \mathrm{x}_{4} \mathrm{x}_{5} \mathrm{x}_{6}$ indicates that sample 3 is a substituted nominal.

3565-3570 \begin{tabular}{|l|l|l|l|}
\hline $\mathrm{XXX}$ & $\mathrm{XXX}$ \\
\hline
\end{tabular}

\begin{tabular}{|l|l|}
\hline $\mathrm{XXX}$ & $\mathrm{XXX}$ \\
\hline
\end{tabular}

\begin{tabular}{|l|l|}
\hline$X X X X X$ \\
\hline
\end{tabular}

$3571-3576$

\begin{tabular}{|l|l|}
\hline 000 & 000 \\
\hline 000 & 000 \\
\hline 000 & 000 \\
\hline$x x x$ & $x x x$ \\
\hline
\end{tabular}


TABLE 7.--(cont'd)

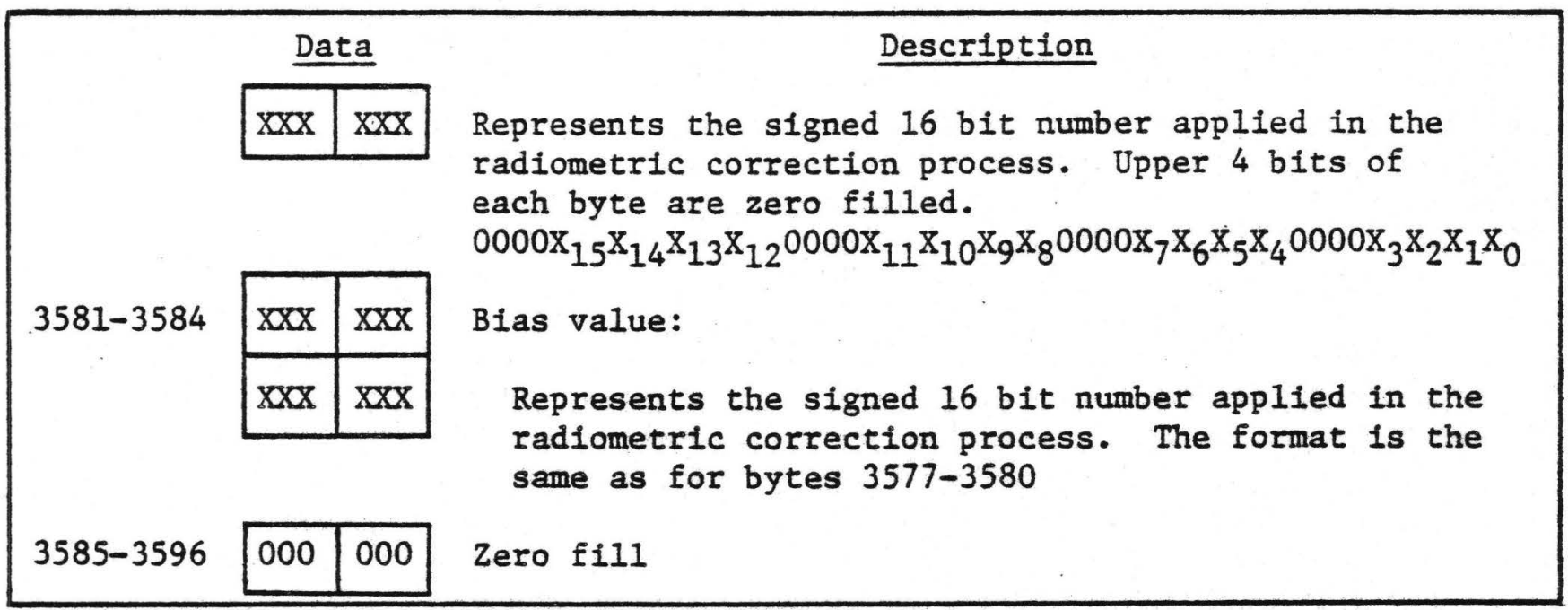

TABLE 8.--MSS fully corrected image-data record

\begin{tabular}{|c|c|c|c|}
\hline Bytes & \multicolumn{2}{|c|}{ Data } & Description \\
\hline \multirow[t]{2}{*}{$1-4$} & $x x x$ & $x x x$ & Record Number \\
\hline & $x \times x$ & $x x x$ & 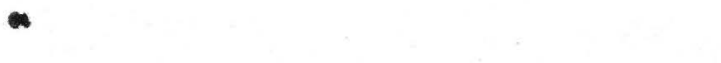 \\
\hline 5 & 000 & & Zero Fill \\
\hline 6 & & $355_{8}$ & Record Type Code \\
\hline \multirow[t]{2}{*}{$7-9$} & $\operatorname{xxx}$ & $x x x$ & Scan Line Count - binary \\
\hline & $\operatorname{xxd}$ & & $\begin{array}{l}\text { Quality Code: } \\
\qquad 0-300_{8} \\
\text { Q1 - } 011_{8} \\
\text { Q2 - } 0228 \\
\text { Q3 - } 333_{8}\end{array}$ \\
\hline 10 & & $\operatorname{xxx}$ & \multirow{2}{*}{$\begin{array}{l}\text { Left fill and right fill counts } \\
\text { Binary Value: } \\
\text { LFC is left-most } 12 \text { bits } \\
\text { RFC is right-most } 12 \text { bits }\end{array}$} \\
\hline $11-12$ & $x \times x$ & $x x x$ & \\
\hline \multirow[t]{2}{*}{$13-3560$} & $\mathrm{xxx}$ & $x x x$ & \multirow[t]{2}{*}{ Image Pixels: binary $0-127$} \\
\hline & $\mathrm{xxX}$ & $\mathrm{xxx}$ & \\
\hline \multirow[t]{2}{*}{$561-3596$} & 177 & 177 & \multirow[t]{2}{*}{ One's Fill } \\
\hline & 177 & 177 & \\
\hline
\end{tabular}


Table 9.--RBV uncorrected image-data record

\begin{tabular}{|c|c|c|c|}
\hline Bytes & \multicolumn{2}{|c|}{ Data } & Description \\
\hline $1-4$ & $x x x$ & $\mathrm{xxx}$ & Record Number \\
\hline & $x x x$ & $x x x$ & \\
\hline 5 & 000 & & Zero Fill \\
\hline 6 & & $355_{8}$ & Record Type Code \\
\hline $7-12$ & $\mathrm{XXX}$ & $\mathrm{XXX}$ & Scan Iine Count \\
\hline & $x \times x$ & $x x x$ & See Figure 15 \\
\hline & $\mathrm{xxx}$ & $x x x$ & \\
\hline $13-5387$ & $x x x$ & $\mathrm{xxx}$ & Image Pixels: \\
\hline & $x \times x$ & & \\
\hline 5388 & & $\mathrm{xxx}$ & $\begin{array}{c}\text { Scan Line Quality } \\
\text { Q0 - } 000_{8} \\
\text { Q1 - } 0778 \\
\text { Q2 - } 0078 \\
\text { Q3 - } 070_{8}\end{array}$ \\
\hline
\end{tabular}

\begin{tabular}{|c|c|c|c|c|c|c|c|c|c|c|c|c|}
\hline $\begin{array}{l}\text { BVTE } \\
\text { ASSIGNMENT }\end{array}$ & $\begin{array}{l}\text { MSB } \\
0123\end{array}$ & 4567 & 891011 & $\begin{array}{r}158 \\
12131415\end{array}$ & 0123 & 4567 & 891011 & 12131415 & 0123 & 4567 & 891011 & 12131415 \\
\hline BIT WEIGHT & 8421 & 8421 & 8421 & 8421 & 8421 & 8421 & 8421 & 8421 & 8421 & 8421 & 8421 & 8421 \\
\hline & \multicolumn{3}{|c|}{ Day of Yeer } & \multicolumn{2}{|c|}{ Hours } & \multicolumn{2}{|c|}{ Minutes } & \multicolumn{2}{|c|}{ Seconds } & Millis. & $\begin{array}{l}\text { Band } \\
\text { Indiewtor }\end{array}$ & $\begin{array}{l}\text { Binary } \\
\text { Count* }\end{array}$ \\
\hline EXAMPLE & 0001 & 1001 & 0101 & $\begin{array}{llllllllll}0 & 0 & 1 & 0\end{array}$ & 0001 & 0101 & 0111 & $\begin{array}{llll}0 & 0 & 0 & 1\end{array}$ & 0010 & 0011 & 0100 & $\begin{array}{llll}0 & 1 & 1 & 1\end{array}$ \\
\hline
\end{tabular}

EXAMPLE $=$ Day of Year 195, Hour 21, Minute 57, Second 12, Millisecond 300, Band 4, Binary Count 7 *Binary count will be reset to zero every other mirror sweep by the time increment. Hence it will run from 1-12) 10 for each band number.

Figure 14.-Scan-line count for MSS. 
TABLE 10.--RBV corrected image-data record

\begin{tabular}{|c|c|c|c|}
\hline Bytes & \multicolumn{2}{|c|}{ Data } & Description \\
\hline \multirow[t]{2}{*}{$1-4$} & $x x x$ & $x x x$ & \multirow[t]{2}{*}{ Record Number } \\
\hline & $x x x$ & $x \times x$ & \\
\hline 5 & 000 & & Zero Fill \\
\hline 6 & & $355_{8}$ & \multirow{3}{*}{$\begin{array}{l}\text { Record Type Code } \\
\text { Binary count of scan line } \\
\text { Left fill count - binary }\end{array}$} \\
\hline $7-8$ & $x x x$ & $x x x$ & \\
\hline $9-10$ & $x x x$ & $x x x$ & \\
\hline $11-12$ & $x x x$ & $x \times x$ & Right full count - binary \\
\hline \multirow[t]{2}{*}{$13-5334$} & $x x x$ & $x x x$ & \multirow[t]{2}{*}{ Image Pixels: binary 0-127 } \\
\hline & $x x x$ & $\mathrm{xxx}$ & \\
\hline $5335-5336 m$ & 1778 & $177_{8}$ & Ones fill \\
\hline 5337 & $x x x$ & & $\begin{array}{l}\text { Scan line quality code: } \\
\text { Q0 }-000_{8}^{8} \\
\text { Q1 }-077_{8} \\
\text { Q2 }-007_{8} \\
\text { Q3 }-070_{8}\end{array}$ \\
\hline 5338 & & $177_{8}$ & Ones fill \\
\hline $5339-5388$ & $177_{8}$ & $177_{8}$ & Ones fill \\
\hline
\end{tabular}

\begin{tabular}{|c|c|c|c|c|c|c|c|c|c|c|c|c|}
\hline \multirow[b]{2}{*}{ BIT WEIGHT: } & \multicolumn{2}{|c|}{ 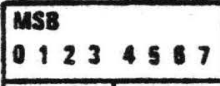 } & \multicolumn{2}{|c|}{ 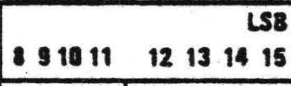 } & \multicolumn{2}{|c|}{01234567} & \multirow{2}{*}{\begin{tabular}{|l|}
891011 \\
8421 \\
\end{tabular}} & $121314 \quad 15$ & \multicolumn{3}{|c|}{012334567} & 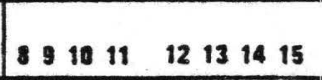 \\
\hline & 8421 & 8421 & 8421 & 8421 & 8421 & 8421 & & $2421^{\circ}$ & 8421 & 21 & $2^{9}$ & $2^{\circ}$ \\
\hline \multirow{2}{*}{ CONTENTS: } & Hua & Tea & Unik & Ten & Unit & Ton & Unit & Ten & Unit & Cam. & \multirow{2}{*}{\multicolumn{2}{|c|}{ Sean Line No. }} \\
\hline & & Day of Yea & & $\begin{array}{ll}A C E \\
\quad \text { Hour } \\
\end{array}$ & C R A & $L^{F} T_{\text {Min }}$ & 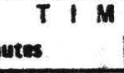 & Secone & & & & \\
\hline XAMPLE: & 100001 & 10001 & 0101 & $\begin{array}{llll}0 & 0 & 1 & 0\end{array}$ & $10 \begin{array}{llll}0 & 0 & 1\end{array}$ & 10101 & 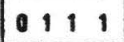 & $\begin{array}{llll}0 & 0 & 0 & 1\end{array}$ & 100000 & 10 & & 00000,11111 \\
\hline
\end{tabular}




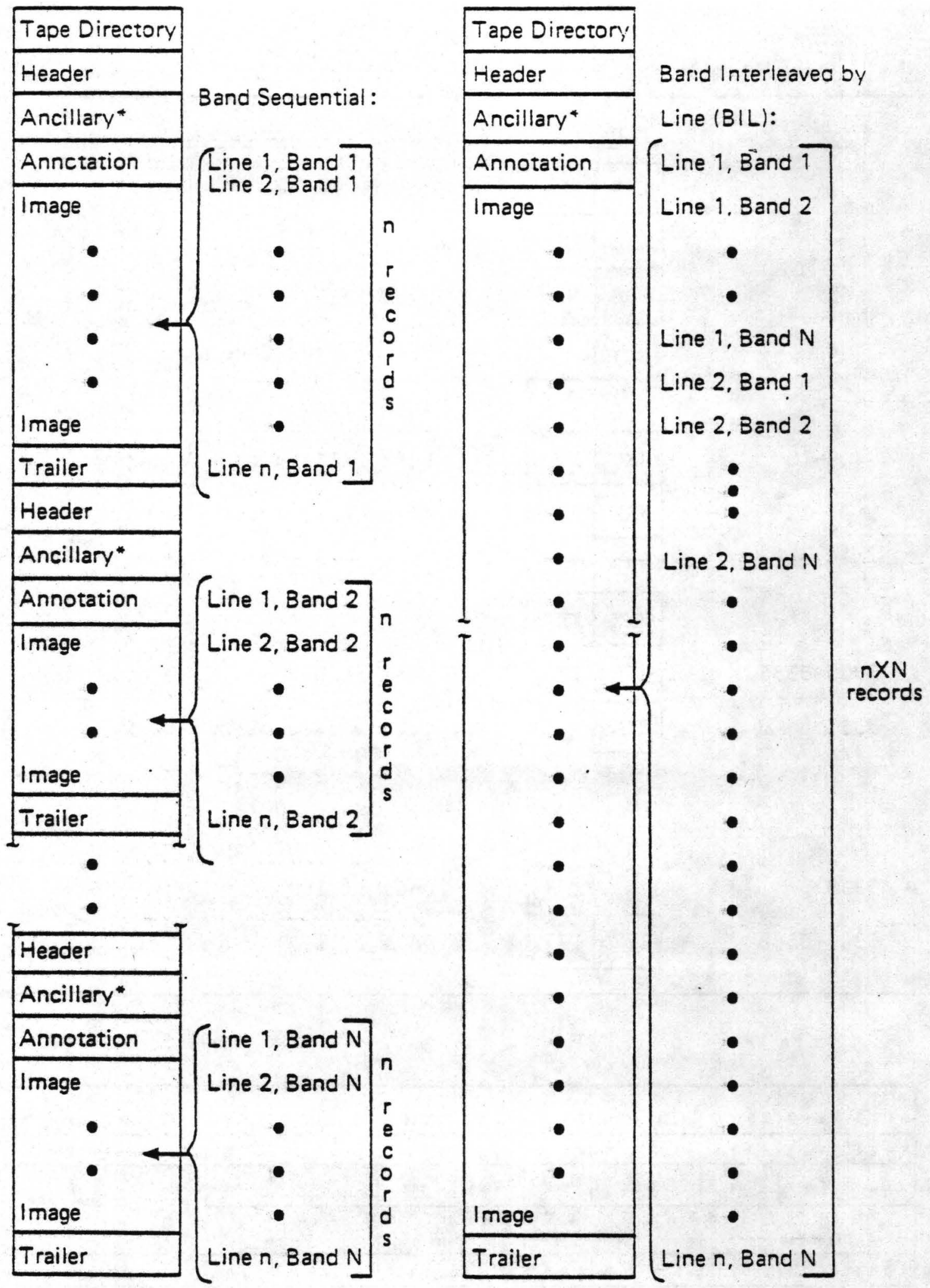

*Present only on CCT's with geometrically uncorrected data.

Figure 16.-Examples of interleaving of MSS image data of $\mathrm{N}$ bands of $\mathrm{n}$ lines each. 
is determined from input lines, any of which were synthetically filled during the data input process, for example, owing to loss of sync. A quality of Q3 is assessed when the output line is determined from data synthetically generated during the output process, such as, top or bottom lines of all fill. When more than one quality assessment affects the output line, the most severe assessment is assigned to the output line, for instance, Q3 is assigned when Q2 and $\mathrm{Q} 3$ occur. Also, quality conditions identified with specific scan lines are reflected in all resulting scan lines.

\section{TRAILER FILE}

The trailer file provides the values used if digital enhancement techniques were applied to the image data. Trailer records are band dependent and are present for each band. Therefore, in BSQ, each image data file is followed by a trailer file containing that band's trailer record. In BIL, the image data file is followed by one trailer file containing four (Landsat-1 and -2) or five (Landsat-3) records. The trailer content is specified in table 11 .

\section{MULTI-VOLUME CCT SET}

Depending on sensor, interleaving, density, and number of bands, one scene may require more than one volume. For a multi-volume tape set:

1) Each volume will begin with a tape directory.

2) The transition between volumes will be at file boundaries or record boundaries within the image file only.

3) All volumes except the last of the set will end with an EOV.

4) The last volume of the set will end with an EOS.

For the application addressed in this document, the exact amount of data to be recorded on each volume of a set is given for each possible type of data configuration shown in table 12. The data allocations for each volume of a CCT tape set are determined by the following:

1) Tape directory files, scene attributes files, and trailer files are not mentioned but are assumed to be on the tapes in the relative locations as given.
2) Tape break points are on an integral record boundary within the image file or after an EOF of an entire band.

3) Break point of an image file is done:

a) with equal distribution, or if it does not divide eveniy, then the lower number goes on the first tape with the residual on the last;

b) if BIL, the number of records must be divisible by the number of lines interleaved.

Figure 17 gives some illustrations of transitions between volumes of a CCT set.

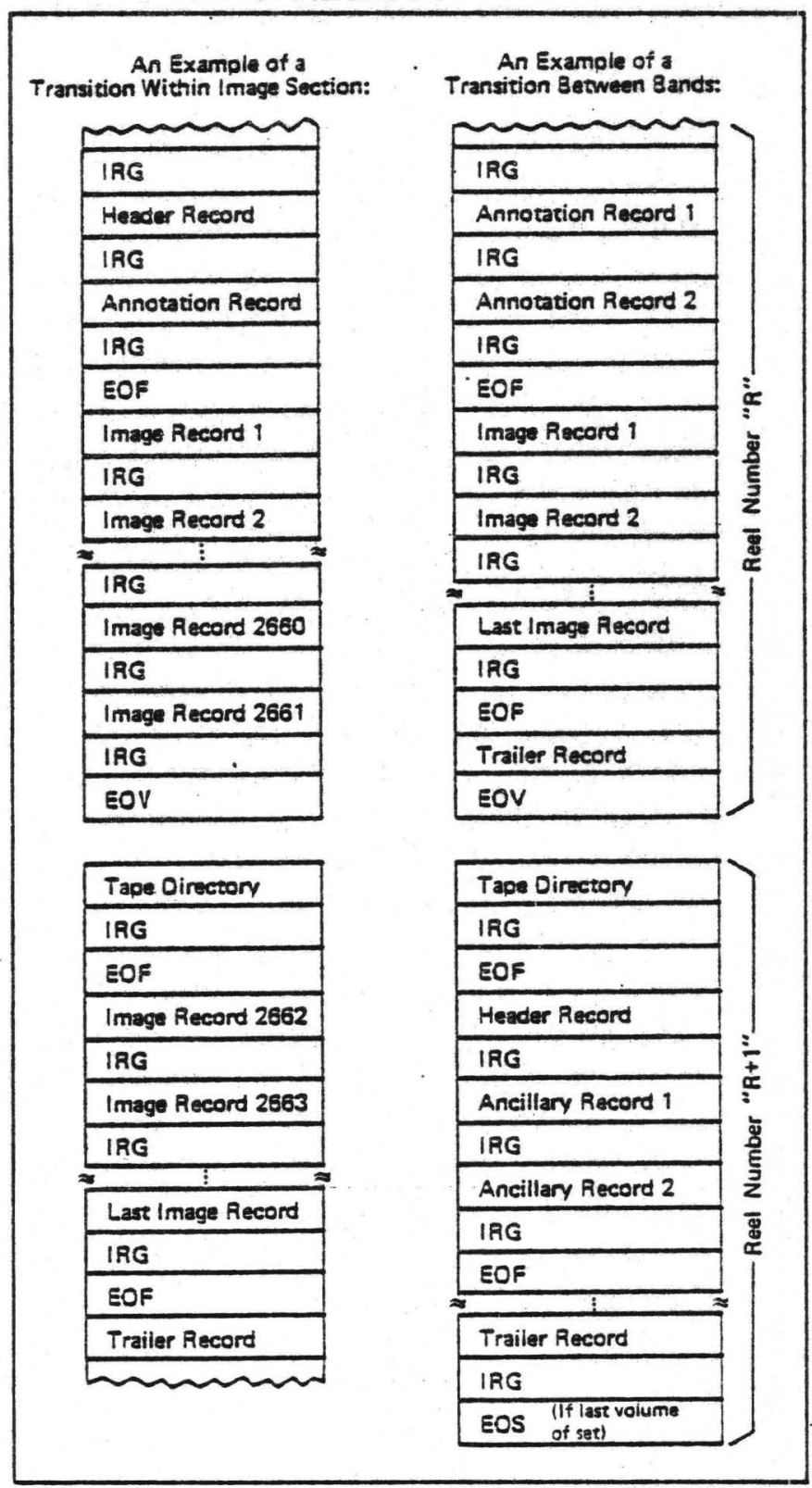

Figure 17.-Illustrations of transition between volumes of a CCT tape set. 
MANUAL ON CHARACTERISTICS OF LANDSAT COMPUTER-COMPATIBLE TAPES

TABLE 11.--Trailer record: Record-byte assignments

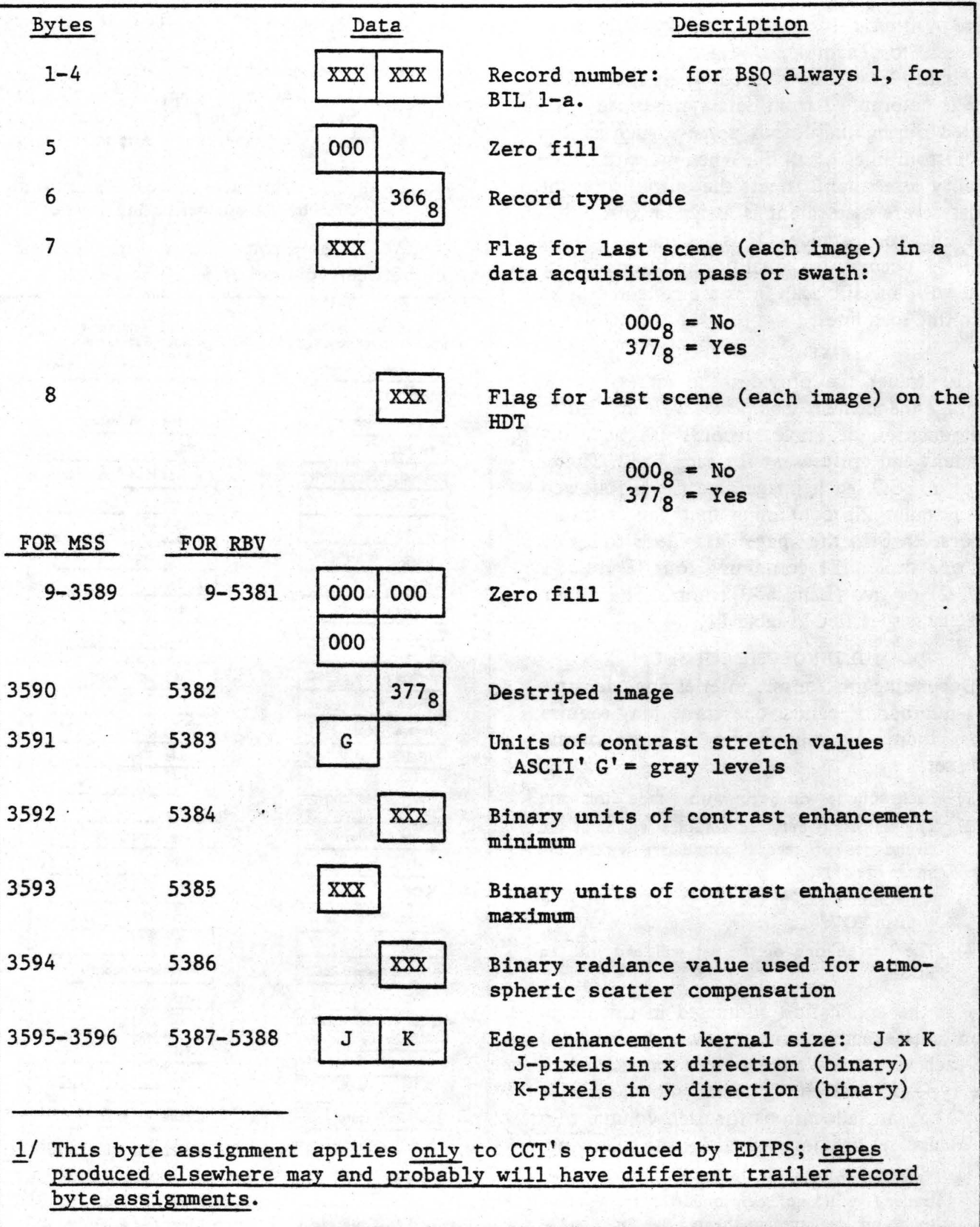


TABLE 12.--Break points of multi-volume CCT sets

Data Type and

Tape Number

RBV

Geometrically uncorrected

Tape 1

Tape 2

Geometrically corrected

Tape 1

Tape 2

MSS BSQ

Geometrically uncorrected
(1 band) Tape 1
( 2 bands) Tape 1
Tape 2
( 3 bands) Tape 1
(4 bands) Tape 1

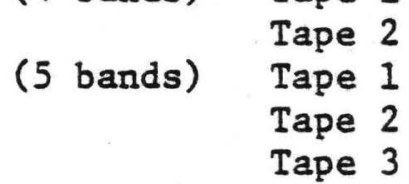

Geometrically corrected

(1 band) Tape 1

( 2 bands) Tape 1

(3 bands) $\begin{aligned} & \text { Tape } 2 \\ & \text { Tape } 1\end{aligned}$

Tape 2

( 4 bands) Tape 1

Tape 2

Tape 3

(5 bands) Tape 1

Tape 2

Tape 3

\section{Image Distribution by Density}

800 BPI

1600 BPI

entire image

remaining image lines

entire image entire image

all images

band 1

band 2

bands 1 and 2

band 3

bands 1 and 2

bands 3 and 4

bands 1 and 2

bands 3 and 4

band 5

entire image

band 1 and 1491 lines

of band 2

1492 lines of band 2

band 1 and 1491 lines

of band 2

1492 lines of band 2

and band 3

band 1 and 1491 Iines

of band 2

1492 lines of band 2

and band 3

band 4

band $I$ and 1987 lines

of band 2

996 of 2 , band 3 , and

996 of 4

1987 lines of band 4

and band 5 all images

all images

bands 1,2 , and 3 bands 4 and 5

entire image

all images

all images

bands 1 and 2

bands 3 and 4

bands 1,2 , and 3

bands 4 and 5 
TABLE 12.--(cont'd)

\section{Data Type and}

Tape Number
Image Distribution by Density

800 BPI $1600 \mathrm{BPI}$

MSS BIL

Geometrically uncorrected

(4 bands) Tape 1

Tape 2

(5 bands) Tape 1

Tape 2

Tape 3

Geometrically corrected

( 4 bands) Tape 1

Tape 2

Tape 3

(5 bands) Tape 1

Tape 2

Tape 3
4800 lines

4800 lines

4000 lines

4000 lines

4000 lines

3976 lines

3976 lines

3980 lines

4970 lines

4970 lines

4975 lines all lines

6000 lines

6000 lines

5964 lines

5968 lines

7455 lines

7460 lines 
APPENDIX A

GEOMETRIC CORRECTION OF CCT-AM OR CCT-AR

(TO BE PROVIDED) 


\section{LANDSAT COMPUTER COMPATIBLE TAPES}

\section{APPENDIX B}

\section{SYSTEMATIC GEOMETRIC CORRECTIONS}

When a Landsat image is corrected, the image data are processed in the steps discussed in Appendix A. During this transformation from geometrically uncorrect to correct, the image data are contorted to match spatial relationships as they are on Earth and as represented by the given projection. During this transformation, the image data must be corrected for the following high frequency geometric errors:

1) Band-to-band offsets

2) Line length

3) Earth rotation

4) Detector-to-detector sampling delay

On a CCT-PM, all of the corrections described in this appendix have been applied to the image data. For a CCT-AM, these corrections have not been applied.

Appendix A, subprocess 3 requires the algorithm necessary to correct for these errors. This correction only applies to a CCT-AM. RBV subscenes do not reflect any of these errors.

This appendix shows the derivation of the complete correction algorithm. Either the full algorithm or any subset may be used in subprocess 3 of Appendix A.

\section{BAND-TO-BAND OFFSETS}

The physical layout of detectors causes each band on Landsat MSS to be offset in along-scan direction relative to the other: integral pixeloffset corrections have been applied to the data contained on a CCT-AM by shifting the pixels within a line. Any fractional pixel offsets (first detector of band 8 is an exception) must be applied during horizontal resampling. The HRS coordinates provided in ancillary data are derived for band four. These pixels coordinates (HR in Appendix A - interpolated to obtain $H R^{\prime}$ ) must be adjusted for each of the other bands. Preliminary values of fractional band sample offsets $\left(\mathrm{SO}_{\mathrm{i}}\right)$ are given in the table below:

Band-Band Offsets

\begin{tabular}{cc} 
Band, $\mathrm{i}$ & $-\mathrm{SO}_{\mathrm{j}}$, pixels \\
\cline { 2 - 2 } 4 & 0 \\
5 & -0.09 \\
6 & -0.18 \\
7 & -0.27 \\
$8 \mathrm{~A}$ & -3.90 \\
$8 \mathrm{~B}$ & -0.45
\end{tabular}

For this correction, the calculation of $\mathrm{HR}^{\prime}$ (subprocess 3 in Appendix A) is given by:

$$
\mathrm{HR}^{\prime}=\mathrm{HR}-\mathrm{SO}_{\mathrm{i}}
$$

These physical offsets are dependent on the mirror velocity since the number of pixels required to cover the angle or translation offset is a function of velocity. A more extensive correction being considered would result in an algorithm of the form: $H^{\prime}=(H R)-k_{1} S O_{i}$. $\mathrm{k}_{2} \mathrm{SO}_{\mathrm{i}}(\mathrm{HR})-\mathrm{k}_{3} \mathrm{SO}_{\mathrm{i}}(\mathrm{HR})^{2}$, where $\mathrm{k}_{1}, \mathrm{k}_{2}, \mathrm{k}_{3}$ are mirror-velocity coefficients given in bytes 71-102 of ancillary record one on CCT-AM. The band-to-band offsets $\left(\mathrm{SO}_{\mathrm{i}}\right)$ will be given in bytes 263-282 of ancillary record one on CCT-AM.

\section{LINE LENGTH VARIATIONS}

The variation in the number of image pixels per line requires a scale correction of the form $\left(\frac{I_{R}}{I_{N}}\right)_{H R}$ where $I_{R}$ is the actual line length of . image data and $I_{N}$ is the nominal line length expected. Preliminary analysis indicated that $\mathrm{I}_{\mathrm{N}}$ $=3,173$ pixels/line. Combining this correction with previous result $H^{\prime}$ would be defined by:

$\mathrm{HR}^{\prime}=\left(\frac{\mathrm{I}_{\mathrm{R}}}{\mathrm{I}_{\mathrm{N}}}-\mathrm{k}_{2} \mathrm{SO}_{\mathrm{i}}\right)(\mathrm{HR})-\mathrm{k}_{1} \mathrm{SO}_{\mathrm{i}}-\mathrm{k}_{3} \mathrm{SO}_{\mathrm{i}}(\mathrm{HR})^{2}$

The actual line length $I_{R}$ is given in the first two words of supporting data following each image line on the CCT-AM. 


\section{APPENDIX B}

\section{EARTH ROTATION}

Earth rotation is included in the geometric modeling which generates the HRS-VRS geometric grid. However, this modeling only accounts for the location of the center (line = 3.5) of a six - line mirror sweep. The linear interpolation between HRS (from HRS table) to obtain HR applies Earth rotation as though each line were scanned separately. The correction for this effect will be given by:

$$
\left(\frac{\mathrm{I}_{\mathrm{R}}}{\mathrm{I}_{\mathrm{N}}} \cdot \frac{\mathrm{K}_{\mathrm{L}}}{\mathrm{K}_{\mathrm{S}}}\right)(3.5-\mathrm{d}) \propto \mathrm{eR}
$$

where:

$$
\begin{aligned}
& \quad \frac{\mathrm{I}_{R}}{\mathrm{I}_{\mathrm{N}}}=\text { previously defined line length factor } \\
& \frac{\mathrm{K}_{\mathrm{L}}}{\mathrm{K}_{\mathrm{S}}}=\text { correction for nominal line-pixel spacing }
\end{aligned}
$$$$
\mathrm{K}_{\mathrm{L}} \sim 79 \text { meters } \mathrm{K}_{\mathrm{S}} \sim 58.4 \text { meters }
$$

$\propto e R=$ earth rotation parameter

(bytes 135-138, ancillary record 2, CCT-AM)

$\mathrm{d}=$ detector number associated with a line

\section{DETECTOR-TO-DETECTOR SAMPLING DELAY}

Due to mirror motion during finite sampling interval, the six lines of a sweep are offset as given by the table below:

\section{Sampling Delay}

\begin{tabular}{cc} 
Detector, d & Delay, pixels $\left(\mathrm{SD}_{\mathrm{d}}\right)$ \\
\cline { 2 - 2 } 2 & .20 \\
2 & .12 \\
3 & .04 \\
4 & -.04 \\
5 & -.12 \\
6 & -.20
\end{tabular}

The sampling-delay constants $\left(\mathrm{SD}_{\mathrm{d}}\right)$ are given in bytes 159-262, ancillary record 1, CCT-AM. Combining the Earth rotation and samplingdelay corrections with the previous result, the complete algorithm which defines $\mathrm{HR}^{\prime}$ is:

$$
\begin{aligned}
& \mathrm{HR}^{\prime}=\left(\frac{\mathrm{I}_{\mathrm{R}}}{\mathrm{I}_{\mathrm{N}}} \cdot \frac{\mathrm{K}_{\mathrm{L}}}{\mathrm{K}_{\mathrm{S}}}\right)(3.5-\mathrm{d}) \propto \mathrm{eR}-\mathrm{k}_{1} \mathrm{SO}_{\mathrm{i}}+\mathrm{SD}_{\mathrm{d}} \\
& +\left(\frac{\mathrm{I}_{\mathrm{R}}}{\mathrm{I}_{\mathrm{N}}}-\mathrm{k}_{2} \mathrm{SO}_{\mathrm{i}}\right)(\mathrm{HR})-\mathrm{k}_{3} \mathrm{SO}_{\mathrm{i}}(\mathrm{HR})^{2}
\end{aligned}
$$

The above review is the preliminary formulation of high frequency corrections required in applying the geometric grid data on a CCT-AM. The final formulation will be derived when final calibration data is available on the Landsat-3 MSS sensor.

\section{APPENDIX C}

\section{MSS RADIOMETRIC CORRECTION}

The radiometric-calibration algorithm, shown in figure C-1, applies in general to all IPF-corrected Landsat MSS data. The differences in the radiometric corrections as they are applied to the various bands of Landsats 1,2 , and 3 are the determination of the values assigned to the variables used in the algorithm. All radiometric calibration and data decompression are done by the master data processor (MDP), wherein the algorithm and look-up tables reside. The flow of processing steps within the MDP is also shown in figure $C-1$. If the data are acquired in the compressed mode, the inverse of the spacecraft compression is applied to both video and calibration-wedge values before the radiometric corrections are calculated and applied. The decompressed values, ranging from 0 to 127 , which are associated with the compressed input values, ranging from 0 to 63 , are given in Appendix E. Description of the elements of the $\mathrm{V}_{\mathrm{c}}=\left(\frac{\mathrm{K}}{\mathrm{M} \cdot \mathrm{b}}(\mathrm{V}-\mathrm{a})\right)-\mathrm{A}$ algorithm follows. 


\section{RADIOMETRIC CALIBRATION ALGORITHM \\ (For Compressed Mode)}
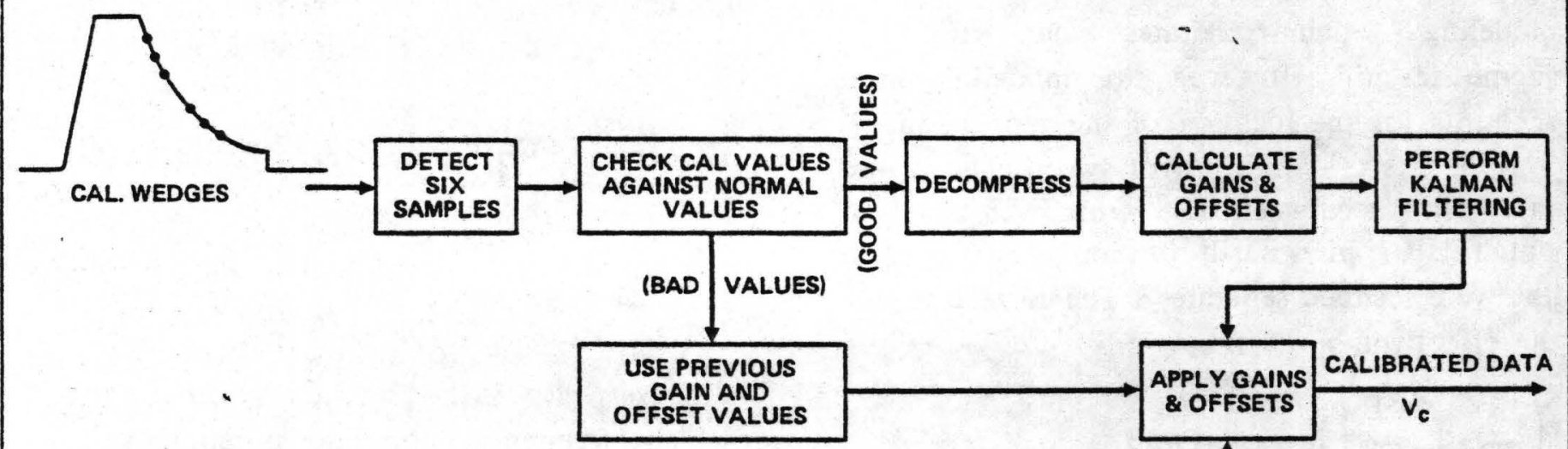

VIDEO DATA DECOMPRESS

$$
V_{c}=\left[\frac{K}{M \cdot b}(V-a)\right]-A
$$

- WHERE: $\quad V_{c}=$ CALIBRATED IMAGE DATA (0-127)

$A=$ OFFSET MODIFIER

$K=$ MAXIMUM IMAGE COUNT (e.g., 127)

$M=$ GAIN MODIFIER

$V=$ DECOMPRESSED INPUT IMAGE DATA (0-127)

a = FILTERED OFFSET VALUE

b = FILTERED GAIN VALUE

Figure C-1 . - MSS radiometric-calibration algorithm.

$\mathrm{V}_{\mathrm{c}}=$ calibrated pixel value, which will range from 0 to 127 for 7-bit pixels

$\mathrm{K}=$ maximum possible value for $\mathrm{V}_{\mathrm{c}}$. (127 for 7-bit pixels)

$a=$ the filtered offset value

$b=$ the filtered gain value $a$ and $b$ are determined as follows:

For band 8 (thermal IR band) a, b are defined as:

$$
a=\frac{N_{R} v_{O}-N_{C} v_{R}}{N_{R}-N_{C}}, b=\left(\frac{v_{R}-v_{O}}{N_{R}-N_{C}}\right) \Delta N
$$

where $N_{R}=$ black body reference radiance;

$\mathrm{N}_{C}=$ "cold" reference radiance;

$\mathrm{V}_{\mathrm{R}}=$ corresponding pixel value (relative radiance), for $N_{R}$, determined by averaging 6 samples, extracted from alternate mirror sweeps on the input raw data HDT (HDT-F);

$\mathrm{V}_{0}=$ corresponding pixel value(relative radiance) for $\mathrm{N}_{\mathrm{C}}$; and

$N=N \max -N \min$, the range betweeen maximum and minimum radiances of the IR detectors. 


\section{APPENDIX C}

$\mathrm{V}=$ input pixel value (from 0 to 127 for 7-bit pixels)

$\mathrm{M}=$ multiplicative gain modifier

$A=$ additive offset modifier

$M$ and $A$ are detector-dependent parameters used to control long term drifts in relative detector responses. They are derived by analyzing Landsat data over a period of time to determine the frequency with which these parameters need updating in order to equalize detector gain and offset changes. At launch, $M=1$ and $A=0$.

For all other bands, $a$ and $b$ are determined once per scan line as follows:

First, estimates of $a$ and $b(\hat{a}$ and $\vec{b})$ are made from the calibration data using the equations:

$$
\begin{aligned}
& \vec{a}=\sum_{i=1}^{6} C_{i} V_{i} \\
& \dot{b}=\sum_{i=1}^{6} D_{i} V_{i}
\end{aligned}
$$

Linear regression

Where $V_{i}$ is the input value of the calibration wedge word $i$, and $C_{i}$ and $D_{i}$ are regression coefficients which are determined on the basis of prelaunch radiance tests. See tables C-1

\begin{tabular}{|c|c|c|c|c|c|c|c|c|c|c|c|c|}
\hline Sensor & $\mathbf{D}_{1}$ & $c_{1}$ & $\mathrm{D}_{2}$ & $c_{2}$ & $D_{3}$ & $c_{3}$ & $D_{4}$ & $c_{4}$ & $\mathbf{D}_{\mathbf{s}}$ & $c_{s}$ & $\mathrm{D}_{8}$ & $c_{8}$ \\
\hline \multicolumn{13}{|l|}{ Band 4} \\
\hline 1 & 1. 036123 & - . 108398 & .854736 & - .065918 & -.247559 & .191850 & - .35878s & .210309 & - .601802 & .274453 & - .688477 & .294928 \\
\hline 2 & 1.047s6s & - . 188477 & .862783 & -.124258 & - .25170s & .332764 & - .357422 & . 375244 & - . 600954 & .475242 & - . & .510254 \\
\hline 3 & 1.116943 & - .140137 & .923574 & - .084961 & - .273928 & .207061 & - .389301 & . 266602 & - .840846 & .934428 & - . 732178 & .361323 \\
\hline 4 & 1.0uss21 & - . . 231592 & .826172 & $\therefore 077393$ & - .25024t & .240479 & - .348877 & .269775 & - . 588613 & .337646 & - .857471 & .360840 \\
\hline $\mathbf{s}$ & 1. 096191 & - .140068 & .884043 & -.003740 & - .273193 & .246582 & -.378906 & .278611 & - .625732 & .346436 & - .712158 & .370850 \\
\hline 6 & $1.11+258$ & - .172387 & .914551 & - .102539 & - .272217 & .305664 & -.382568 & .349750 & - . . & .4351es & - . T51984 & .464111 \\
\hline \multicolumn{13}{|l|}{ Band 5} \\
\hline 7 & 1.062500 & -.100154 & .754699 & - .044922 & - .298701 & .170654 & - .36694s & .185791 & - .587109 & .220708 & -.619385 & .237793 \\
\hline 8 & 1.057373 & .211914 & .765137 & .093750 & - . 2839366 & - . .330322 & - .361572 & - .361572 & - .543701 & - . $435 n 03$ & - .633057 & -.471436 \\
\hline 9 & 1.049805 & - . 195068 & .750480 & - .082784 & -.287354 & .307129 & - .361328 & .334717 & - . 5283691 & .399658 & -.817432 & .431152 \\
\hline 10 & 1.077393 & . .163818 & . T77100 & - .071533 & - .291016 & .285859 & - .369141 & .279297 & . . 552246 & .335937 & -.041846 & .323525 \\
\hline 11 & 1.041992 & -.125000 & .744875 & - .053711 & - .284668 & .192883 & - .35a154 & .209961 & - . 530020 & .250977 & - . 613770 & .272240 \\
\hline 12 & 1.092285 & -.212846 & .784100 & - .09asos & - .296143 & .324219 & -.374268 & .354492 & - .5575011 & .425293 & -.64770s & .460205 \\
\hline Band 8 & & & - & & & . & & & & & & \\
\hline 13 & 1. 118652 & .629883 & .769043 & .247070 & .240479 & - .331787 & - .647949 & -1.305176 & - . 703125 & -1.36572 & - . 777300 & $-1.44677 t$ \\
\hline 14 & 1.104980 & -.000057 & . 773437 & - .003174 & .259521 & .008906 & - . S47705 & .017090 & - . 206053 & .018068 & - .784424 & .019043 \\
\hline 15 & 1. 146484 & -.170654 & .805664 & -.070313 & . 273928 & .085938 & - . 673828 & .364746 & - .75530t & .382812 & -.817383 & .406982 \\
\hline 16 & 1.285645 & .382812 & .902300 & .153320 & .30443 & -.204690 & - .755615 & - .839855 & - .823242 & -.879883 & - .913574 & - .934082 \\
\hline 17 & 1.256104 & -.166016 & .873585 & -.064697 & .284668 & .091064 & - . T3364s & .360840 & - .797607 & .377930 & - .882812 & .400391 \\
\hline 18 & 1.157227 & - .175049 & .808594 & -.070068 & .270752 & .092529 & - .677490 & .3796899 & - . 737798 & .397949 & -.818848 & .422607 \\
\hline Band 7 & & & $=$ & & & & & & & & & \\
\hline 19 & 1. 533203 & -.180664 & 1.105713 & - .083984 & .583496 & .034180 & - .984863 & .389893 & -1.079834 & .411377 & -1.157471 & .428955 \\
\hline 20 & 1.715088 & -.184326 & 1.236816 & -.086426 & .652832 & .032959 & -1.101562 & .392090 & -1.207764 & .413818 & -1.294922 & .431641 \\
\hline 21 & 1.628174 & -.181885 & 3.169189 & -.083496 & .610840 & .035645 & -1.043701 & .389893 & -1.142090 & .4111133 & -1.222656 & .428223 \\
\hline 22 & 1.874512 & - . 177490 & 1.369141 & -.084717 & .743652 & .030029 & -1.212846 & .389160 & -1.338428 & .411865 & -1.438477 & .430664 \\
\hline 23 & 1.934570 & -.171631 & 1.399902 & - .078125 & .744385 & .036377 & -1.245605 & .384521 & -1.386943 & .405518 & -1.466309 & .423096 \\
\hline 24 & 1. 704102 & -.170898 & 1.218018 & -.074707 & . 629395 & .041748 & -1.090088 & .382568 & -1.189941 & .402344 & -1.271484 & .418701 \\
\hline
\end{tabular}
through $C-6$ for the $C_{i}$ 's and $D_{i}$ 's. Then, $a$ and $b$ are filtered for every scan line, $\mathrm{n}$, as follows:

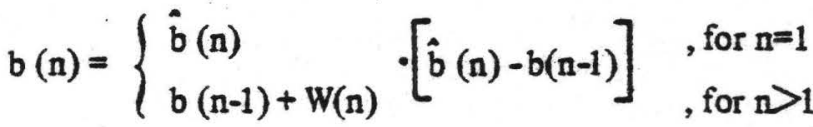

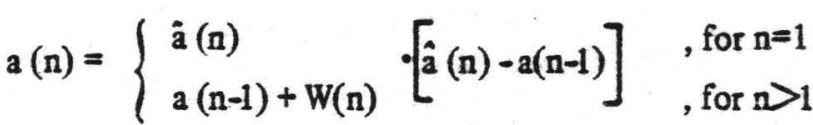

Table C-1 .--Landsat $1 C_{i}^{\prime}$ s and $D_{i}^{\prime}$ s: Low gain decompressed 
where $\mathrm{n}=$ sequential number of scan lines per swath;

$$
\begin{aligned}
& \hat{b}(n), \hat{a}(n)=\text { estimated values of } b \text { and } a \text {; } \\
& b(n-1), a(n-1)=\text { previous filtered value of }
\end{aligned}
$$

$\mathrm{b}$ and $\mathrm{a}$;

$b(n)$ a (n) = new filtered value of $b$ and $a$; $W(n)=1 / n+1$ for $n=1$ to 15 , $W(n)=1 / 16$ for $n \equiv 16$.

\begin{tabular}{|c|c|c|c|c|c|c|c|c|c|c|c|c|}
\hline Seneor & $D_{1}$ & $c_{1}$ & $D_{2}$ & $c_{2}$ & $\mathbf{D}_{3}$ & $c_{3}$ & $\mathrm{D}_{4}$ & $c_{4}$ & $\mathrm{D}_{5}$ & $c_{5}$ & $D_{6}$ & $c_{6}$ \\
\hline Band 4 & & - & & & & & & & & & & \\
\hline 1 & .000000 & .000000 & .000000 & .000000 & 1.712646 & -.410889 & .921133 & - .016914 & - .981689 & $.67 \times 467$ & -1.642578 & .845557 \\
\hline 2 & .000000 & .000000 & .000000 & .000000 & 1. 689697 & - .525391 & . 898193 & - .113037 & - .987773 & .859131 & -1.620117 & 2.198730 \\
\hline 3 & .000000 & .000000 & .000000 & .000000 & 1. 855469 & - .408986 & .987061 & -.108027 & -2.058850 & .617187 & -1.783926 & .872803 \\
\hline 4 & .000000 & .000000 & .000000 & .000000 & 1.625488 & - .282715 & .855957 & -.058350 & - .932861 & .462891 & -1.548584 & .642578 \\
\hline 5 & .000000 & .000000 & .000000 & .000000 & 1.899844 & - .38696s & .972656 & $=.092529$ & -1.052002 & .594971 & -1.760495 & .885693 \\
\hline 6 & .000000 & .000000 & .000000 & .000000 & 1. 757324 & - .354482 & .930664 & -.076660 & -1.007080 & .574607 & -1.681152 & .801270 \\
\hline Band 5 & & & & & & & & & & & & \\
\hline 7 & .000000 & .000000 & .000000 & .000000 & 1.911377 & -.573730 & 1. 038062 &. .200195 & - .985352 & .666504 & -1.965088 & 1.085937 \\
\hline 8 & .000000 & .000000 & .000000 & .000000 & 1. 863281 & -1.102328 & 1. 022461 & - .377441 & -.958008 & 1.327637 & -1.927490 & 2.162354 \\
\hline 9 & .000000 & .000000 & .000000 & .000000 & 1.852783 & - . 517578 & 2.010742 & -.179443 &. .254102 & .610352 & -1.508936 & .993652 \\
\hline 10 & .000000 & .000000 & .000000 & .000000 & 1.929688 & - .852881 & 1.057229 & -.328125 & - .992432 & 1.239R93 & -2.994385 & 1.1457178 \\
\hline 11 & .000000 & .000000 & .000000 & .000000 & 1.883301 & - .509277 & 1.029297 & -.180420 & - .968506 & .588379 & -1.944092 & .964121 \\
\hline 12 & .000000 & .000000 & .000000 & .000000 & 1.875244 & -.440918 & 1.027432 & -.150982 & - .963235 & .510010 & -1.940180 & .837646 \\
\hline
\end{tabular}

Table C-2 .--Landsat $1 C_{i}^{\prime}$ s and $D_{i}^{\prime}$ s: 'High gain decompressed.

\begin{tabular}{|c|c|c|c|c|c|c|c|c|c|c|c|c|}
\hline Seneor & $D_{1}$ & $c_{1}$ & $D_{2}$ & $c_{2}$ & $D_{3}$ & $c_{3}$ & $D_{4}$ & $c_{4}$ & $D_{5}$ & $c_{5}$ & $D_{6}$ & $c_{6}$ \\
\hline \multicolumn{13}{|l|}{ Band 4} \\
\hline 2 & 1. 124023 & -.120850 & .710205 & -.046243 & .031738 & .076416 & - .228770 & .125244 & - .658203 & .201172 & - .968018 & .257324 \\
\hline 2 & 1.268066 & -.158691 & . .8อง77 & -.057861 & .040283 & .098145 & - .269287 & .163086 & - .734131 & .280498 & -1.090332 & .234961 \\
\hline 3 & 2.082379 & - .174561 & .720459 & -.077248 & .045166 & .101562 & -.212646 & .169922 & -.654053 & .286865 & -.986572 & .375000 \\
\hline 4 & 1.1213770. & -.268225 & 780010 & -.078623 & .050587 & .100342 & - .211426 & .166992 & -.684082 & .286621 & -1.027832 & $.373779^{\circ}$ \\
\hline 5 & 1. $14 \operatorname{seg} 6$ &.- .294092 & .736572 & - .078369 & .051025 & .124990 & -.224121 & .192871 & -.680176 & .322021 & -1.028076 & .420410 \\
\hline 6 & 2.114502 & -.251220 & .723877 & -.062256 & .058307 & .093018 & -.229248 & .254058 & -.601865 & .252441 & - .285596 & .5261ข2 \\
\hline \multicolumn{13}{|l|}{ Band 5} \\
\hline 7 & 2. A49561 & -.053711 & .725107 & -.025635 & .073975 & .082715 & - .258592 & .062256 & - .656494 & .097656 & - .944824 & .123291 \\
\hline 8 & 1.221924 & -.089600 & .872559 & - .0458s8 & . 056821 & .058s94 & - . 276967 & .098145 & - .76196s & .158936 & -1.090820 & .200195 \\
\hline 8 & .979004 & - .088379 & . 697754 & - .045898 & .080566 & .047120 & - .230713 & .094482 & - .625478 & .152832 & -.920400 & .197266 \\
\hline 10 & .978027 & -.063740 & . 706299 & - .042480 & .074219 & .052002 & -.237305 & .077881 & -.614502 & .155278 & -.8252520 & .198730 \\
\hline 11 & .238721 & - .094727 & .672607 & - .048828 & .065918 & .055176 & - .231689 & .206445 & - .586914 & .167725 & - .858643 & .214600 \\
\hline 22 & .975586 & - .249902 & .689841 & -.074707 & .058105 & .000382 & -.238057 & .168213 & -.604980 & .264648 & -.8798k3 & .336670 \\
\hline \multicolumn{13}{|l|}{ Band 6} \\
\hline 13 & 2.194580 & -.176758 & . 831787 & - .090332 & .028555 & .203027 & -.278809 & . 174516 & - .753662 & .287354 & -1.011475 & .348RT7 \\
\hline 14 & 1. 132324 & - .1068s4 & . 766602 & -.051258 & .022949 & .060059 & - .251953 & .101807 & - .713899 & .171387 & -.955e11 & .207764 \\
\hline 15 & 1. 233845 & - .135010 & .787598 & -.069824 & .025146 & .072998 & -.240723 & .123047 & - .728271 & .214844 & - .976807 & .261719 \\
\hline 16 & 1.043213 & -.108027 & .740067 & -.055176 & .020752 & .058594 & - .219727 & .096680 & -.675293 & .168701 & - .908936 & .205811 \\
\hline 17 & 1.046875 & -.120605 & . 750244 & -.065490 & .012230 & .072021 & -.224600 & .115967 & -.673840 & .199463 & $\therefore .909180$ & .243652 \\
\hline 28 & 2. 156250 & -.064941 & .782959 & -.031006 & .014160 & .038574 & -.255127 & .062988 & -.724854 & .105713 & -.973145 & .128418 \\
\hline \multicolumn{13}{|l|}{ Band 7} \\
\hline 19 & 1. 763672 & -.473877 & 1.212793 & - .219971 & . 352539 & .075928 & -.383057 & .363281 & -2.077881 & .634277 & -2.767334 & .903320 \\
\hline 20 & 1.740234 & -.709473 & 1. 226709 & -.253760 & .383302 & .076416 & - .348989 & .300244 & -1.077148 & .922363 & -1.825730 & 1.354980 \\
\hline 21 & 1.468262 &. .490479 & .244336 & -.245361 & .390078 & .042504 & -.266113 & .321045 & -.898926 & .616843 & -1.576660 & .934570 \\
\hline 22 & 1. 533936 & - .644775 & 2.005615 & - .333008 & .940576 & .059570 & -.282494 & .427490 & -.053857 & .824463 & -1.644287 & 1.232422 \\
\hline 23 & 1.455811 & - . .363525 & .942383 & -.180176 & .322998 & .059795 & -.280762 & .256104 & - : & .477295 & -1.539068 & .704834 \\
\hline 24 & 2.6222305 & - .535400 & 2. 044922 & - .263916 & . 352539 & .066895 & -.290143 & .377686 & -1.002187 & .713867 & -1.714644 & 1.056885 \\
\hline
\end{tabular}

Table $C-3$.- Landsat $2 C_{i}^{\prime}$ s and $D_{i}^{\prime}$ si Low gain decompressed. 
Table C-4 .--Landsat $2 C_{i}^{\prime}$ s and $D_{i}^{\prime}$ s: High gain decompressed.

\begin{tabular}{|c|c|c|c|c|c|c|c|c|c|c|c|c|}
\hline Sensw: & $\mathrm{D}_{1}$ & $c_{1}$ & $1 D_{2}$ & $c_{2}$ & $n_{3}$ & $c_{3}$ & 134 & $c_{4}$ & $\mathrm{D}_{\mathrm{s}}$ & $c_{5}$ & $1)_{6}$ & $c_{6}$ \\
\hline \multicolumn{13}{|l|}{ Biaud t } \\
\hline 1 & . $9530-1=0$ & 482948. - & $.51 \mathrm{d555}$ & - .053955 & $.27 \div 461$ & .050781 & -.231934 & - 2ti5ti2s & -.612793 & .427734 & - . & .539795 \\
\hline 2 & $1.061 \div 79$ & 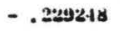 & .585206 & -.051514 & .3115233 & . 050632 & $-.260: 954$ & .263916 & - . เงy799a & $.+272+66$ & - . .990ะ3 & .5 .39795 \\
\hline 3 & 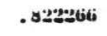 & - .20255st & . 4468066 & - . U70315 & $.24608+4$ & . 04907: & - .2009zs & . tiztigs & -.566406 & . 4372456 & -.797119 & . 547363 \\
\hline$t$ & .867920 & - .2045y & .528280 & - . 065092 & $.26440-1$ & .048584 & - .212402 & $\because 261+75$ & - . Govusa & $.+34+814$ & $-.3+7+112$ & .245166 \\
\hline 5 & נצוצוyו & - . - & .52660111 & - - . . . & . 2ascial 3a & $.0-55110$ & - . .225586 & .262451 & - . 6330asy & . $+3+326$ & $-.07475 t$ & .537598 \\
\hline i) & 43:54: & - 225094 - & $.511+75$ & - . US78til & נינ98676. & .048684 & $-.21926 \%$ & . 262605 & - - G04619 . & ++34570 & - . . 439944 & . 537598 \\
\hline Haukd S & & & . & & & & & & & & & \\
\hline 7 & 1. 200873 & $-.+5+142$ & .702151 & - .20zaal & .2053-12 & . U57\$73 & - .2ustist & . alvests & - .728271 & .5tunizo & -1.233400 & .769775 \\
\hline s & 1. thiotitys & - . +4ย219 & .905518 & - .215uss & $.304+4+3$ & . 0373530 & - . tzasus & . 345947 & - . .44707 & $.51+6+88$ & $-1 .+20+10$ & .7652068 \\
\hline$s$ & 1. 1532043 & - . +42423 & . bassus & - .217:ys & .218750 & . 04ay4s & - .2973633 & .3321466 & - . 6325301 & . Sast & $-1.130 a 56$ & . auvital \\
\hline 10 & 1.156736 & $-.+4+824$ & . 7usus7 & - . 205322 & .216553 & . Us2846 & -.303467 & $.3271+8$ & - . & . 504395 & $-1.13+521$ & $.713+6+4$ \\
\hline 11 & 1. 1 a7!5is & -.450195 & . & -.20776 .1 & .203252 & .053711 & - .846a6s5 & . & -.034521 & $.5107+2$ & $-1.11+990$ & .771 .484 \\
\hline 12 & 1. עצבגבנ & -.502197 & . 70y5:? & 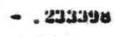 & .200439 & 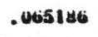 & - .4t78tid & .303311 & -.051865 & . +200826 & $-1.212+402$ & .780762 \\
\hline
\end{tabular}

Table C.5 .--Landsat $3 C_{i}^{\prime}$ s and $D_{i}^{\prime}$ s: Low gain decompressed.

\begin{tabular}{|c|c|c|c|c|c|c|c|c|c|c|c|c|}
\hline Sensor & $D_{1}$ & $c_{1}$ & $\mathrm{D}_{2}$ & $c_{2}$ & $\mathrm{D}_{3}$ & $c_{3}$ & $D_{4}$ & $c_{4}$ & $D_{5}$ & $c_{s}$ & $D_{6}$ & $c_{6}$ \\
\hline \multicolumn{13}{|l|}{ Band 4} \\
\hline 1 & .4723176 & -.0767775 & .3810391 & -.0297305 & .3043025 & .0098215 & .2406069 & .0426518 & -.6967356 & .5257815 & -.7015303 & .5282528 \\
\hline 2 & .5421933 & -.0688948 & .4502282 & -.0289396 & .3697398 & .0060294 & .2839802 & .0432885 & -.8206558 & .5232090 & -.8254856 & .5253074 \\
\hline 3 & .5391159 & -.0680994 & .4479179 & -.0283859 & .3697128 & .0056697 & .2834367 & .0433705 & -.8161466 & .5220696 & -.8237367 & .5253748 \\
\hline 4 & .5232948 & -.0694699 & .4305792 & -.0276320 & .3567997 & .0056610 & .2743931 & .0428468 & -.7901211 & .5232083 & -.7949654 & .5253854 \\
\hline 5 & .5379394 & -.0730701 & .4316658 & -.0257085 & .3612949 & .0056528 & .2837979 & .0401899 & -.8043351 & .5251247 & -.8103626 & .5278108 \\
\hline 6 & .5332242 & -.0701149 & .4458256 & -.0313050 & .3675127 & .0034703 & .2759836 & .0641144 & - .8080823 & .5253005 & -.8144636 & .5283341 \\
\hline Band 5 & & & & & & & & & & & & \\
\hline 7 & .4239522 & -.0664185 & .3611877 & -.0319113 & .3030453 & .0000549 & .2380303 & .0357996 & -.6611714 & .5301728 & -.6650435 & .5323017 \\
\hline 8 & .4469336 & -.0653869 & .3803463 & -.0308140 & .3151260 & .0030491 & .2489183 & .0374251 & -.6931506 & .5265592 & -.6981735 & .5291672 \\
\hline 9 & .4494866 & -.0667386 & .3798666 & -.0305869 & .3163037 & .0024194 & .2513433 & .0361514 & -.6959720 & .5280644 & - .7010281 & .5306900 \\
\hline 10 & .4740652 & -.0666878 & .3995185 & -.0299929 & .3310263 & .0037218 & .2655722 & .0359411 & -.7321719 & .5270723 & -.7380098 & .5299460 \\
\hline 11 & .4348123 & -.0673617 & .3664612 & -.0305733 & .3043171 & .0028745 & .2395270 & .0377464 & -.6697750 & .5271589 & -.6753424 & .5301554 \\
\hline 12 & .4842626 & -.0699236 & .4062586 & -.0318142 & .3346899 & .0031512 & .2697292 & .0348883 & -.7445675 & .5304310 & -.7503722 & .5332669 \\
\hline Band 6 & 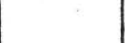 & & & & & $\cdot$ & & & & & & \\
\hline 13 & .4306502 & -.0616200 & .3638981 & -.0262348 & .2940791 & .0107761 & .2357278 & $.0417 n 79$ & -.6597773 & .5164130 & -.6645777 & .5189577 \\
\hline 14 & .4412859 & -.0638097 & .3750842 & -.0292337 & .3046191 & .0075691 & .2459655 & .0382028 & -.6810840 & .5223855 & -.6858705 & .5248854 \\
\hline 15 & .4869690 & -.0616950 & .6105246 & -.0258545 & .3308796 & .0116960 & .2769251 & .0367988 & -.7496077 & .5182062 & -.7556702 & .5210494 \\
\hline 16 & .4808173 & -.0647359 & .4007441 & -.0261992 & .3243656 & .0105595 & .2676444 & .0278477 & -.7338221 & .5198331 & -.7397490 & .5226855 \\
\hline 17 & .4440771 & -.0626419 & .3735553 & -.0262266 & .3045745 & .0093932 & .2441314 & .0406043 & -.6806540 & .5181369 & -.6856842 & .5207343 \\
\hline 18 & .4686363 & -.0630136 & .3939321 & -.0264008 & .3166329 & .0114837 & .2666110 & .0359997 & -.7201201 & .5196000 & -.7256918 & .5223307 \\
\hline 19 & 1.0235090 & -.1806238 & .6710796 & -.0610395 & .3950394 & .0326245 & .1847678 & .1039723 & -1.1279964 & .5494111 & -1.1463995 & .5556555 \\
\hline 20 & .9497854 & -.1754252 & .6131391 & -.0541723 & .3627625 & .0360079 & .1800079 & .1018317 & -1.0464153 & .5435621 & -1.0592794 & .5481956 \\
\hline 21 & .8628369 & -.1793272 & .5684921 & -.0612958 & .3313305 & .0338047 & .1628175 & .1013777 & -.9538993 & .5491753 & - .9715794 & .5562648 \\
\hline 22 & .9447533 & -.1753371 & .6083295 & -.0535507 & .3690969 & .0330526 & .1884683 & .0984407 & -1.0464935 & .5455005 & -1.0641546 & .5518939 \\
\hline 23 & .9123761 & -.1771896 & .5946172 & -.0574325 & .3495100 & .0349436 & .1724302 & .1016812 & -1.0061617 & .5458690 & -1.0227709 & .5521286 \\
\hline 24 & .9417751 & -.1685808 & .6233358 & -.0552244 & .3641466 & .0370401 & .1928612 & .0980132 & -1.0506973 & .5406870 & -1.0714226 & .5480649 \\
\hline
\end{tabular}




\section{LANDSAT COMPUTER COMPATIBLE TAPES}

Table C-6 .--Landsat $3 C_{i}^{\prime}$ s and $D_{i}^{\prime}$ s: High gain decompressed.

\begin{tabular}{|c|c|c|c|c|c|c|c|c|c|c|c|c|}
\hline Sensor & $D_{1}$ & $c_{1}$ & $D_{2}$ & $c_{2}$ & $D_{3}$ & $c_{3}$ & $D_{4}$ & $c_{4}$ & $D_{5}$ & $C_{5}$ & $D_{6}$ & $c_{6}$ \\
\hline Band 4 & & & & & & & & & . & & & \\
\hline 1 & .5247137 & -.1390668 & .4431337 & -.0915327 & .3576929 & -.0417495 & .2731203 & .0075287 & -7900258 & $.6269: 86$ & -.8086318 & .6378295 \\
\hline 2 & .6272712 & -.1385278 & .5143536 & -.0835882 & .4318466 & -.0434456 & .3439335 & -.0006716 & -.9490855 & .6284384 & -.9683148 & .6377941 \\
\hline 3 & .6284514 & -.1389027 & .5095294 & -.0810795 & .4347455 & -.0447175 & .3431122 & -.0001633 & -.9492778 & .6282305 & -.9665548 & .6366310 \\
\hline 4 & .5970588 & -.1364253 & .4858097 & -.0799507 & .4114310 & -.0421927 & .3313130 & -.0015217 & -.9032097 & .6251735 & -.9223989 & .6349147 \\
\hline 5 & .6181401 & -.1444781 & .5175102 & -.0938253 & .4267681 & -.0431162 & .3267191 & .0022107 & -.9264259 & .6329890 & -.9527088 & .6462187 \\
\hline 6 & .6087410 & -.1395825 & .4994858 & -.0846178 & .4265492 & -.0479243 & .3318703 & -.0002923 & -.9243167 & .6316776 & -.9243251 & .6407375 \\
\hline Band 5 & & & & & & & & & & & & \\
\hline 7 & .5518665 & -.1560426 & .4546716 & -.0992072 & .3626205 & -.0453791 & .2734180 & .0067823 & -.8148912 & .6431835 & -.8276793 & .6606611 \\
\hline 8 & .5910916 & -.1513963 & .4867696 & -.1034963 & .3824342 & -.0455884 & .2885204 & .0065343 & -.8674901 & .6481347 & -.8813231 & .6558121 \\
\hline 9 & .5953695 & -.1629270 & .4849899 & -.1018216 & .3833493 & -.0455539 & .2945392 & .0036108 & -.8675578 & .6469432 & -.8906841 & .6597456 \\
\hline 10 & .6206412 & -.1576287 & .5104772 & -.1000667 & .3011881 & -.0430135 & .3041369 & .0077498 & -.9086376 & .6414458 & -.9278972 & .6515092 \\
\hline 11 & .5584256 & -.1580148 & .4660206 & -.1017851 & .3645390 & -.0433260 & .2709705 & .0105744 & -.8216435 & .6399757 & -.8383080 & .6495750 \\
\hline 12 & .6360582 & -.1636969 & .5194108 & -.1031114 & .4058478 & -.0441277 & .3075250 & .0069403 & -.9266692 & .6479717 & -.9421678 & .6560216 \\
\hline
\end{tabular}

\section{APPENDIX D}

\section{RBV RADIOMETRIC CORRECTION}

The radiometric correction of the $R B V$ is functionally computed in two parts. The first part is the radiometric-correction-coefficient computation. This includes preprocessing of Radio Corporation of America (RCA) lamp radiometric data to get an initial correction, and occasional (once a week) processing of radiometric-calibration-lamp images from the spacecraft to update the correction coefficients. The second part is the radiometric-correction-coefficient application; this is the radiometric correction of RBV imagery.

The radiometric correction of RBV imagery is complicated by the fact that the response of the camera is a two-dimensional, spatially varying function. The correction technique divides the RBV image into small zones within which a constant gain and bias correction can be applied with acceptable small error.

Inputs for the correction process are:

- Uniform-radiance RCA lamp data (taken prior to launch) at ten different radiance levels and used to get an initial radiometric correction.
The RCA lamp data is provided in the form of voltages averaged over an $18 \times 18$ grid of small neighborhoods.

- Calibration-lamp data used to update the radiometric-correction coefficients.

- Radiometrically uncorrected RBV images.

Outputs are:

- Two $20 \times 20$ arrays of corrected nominal calibration-lamp-image (CLI) radiometric intensities

- Coordinates of horizontal and vertical radiometric-correction-zone boundaries.

- Gain and bias coefficients for each radiometric-correction zone

- Radiometrically corrected RBV images

PREPROCESSING RCA LAMP DATA

Radiometric-correction-coefficient computation begins with the preprocessing of the RCA lamp data (figure D-1). Using the $18 \times 18$ array of voltage readings provided, the outermost rows and columns of the $18 \times 18$ array are repeated to produce a $20 \times 20$ array of average intensities.

From the ten levels provided, those levels that represent saturation of the camera are eliminated-- only levels from the linear-response 


\section{APPENDIX D}

region are of interest. A linear-least-squares estimate of the gain and bias correction values at each of the $20 \times 20$ data points is computed.

\section{ZONING THE IMAGE}

Zoning of the image is described in figure D-2. Global, eighth-order bivariate polynomials of gain and bias are computed as least - square estimates over the $20 \times 20$ array of gains and biases.

The image is zoned as two one-dimensional problems-- first the horizontal zones are

RCA Lamp Data

at 10 Radiance Levels Averaged Over an 18 × 18 grid

Plot AlI 10

Levels to Select

Unsaturated Levels

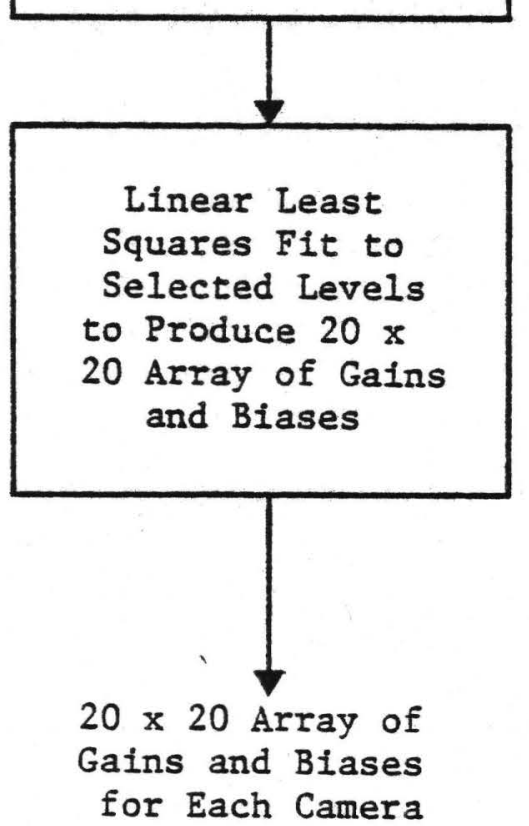

computed and then the vertical zones. Horizontal and vertical zoning are performed in the same manner. For each of the several lines in the

$20 \times 20$ Array of

Gains and Biases

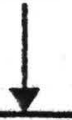

8th order

Bivariate

Polynomial Fit
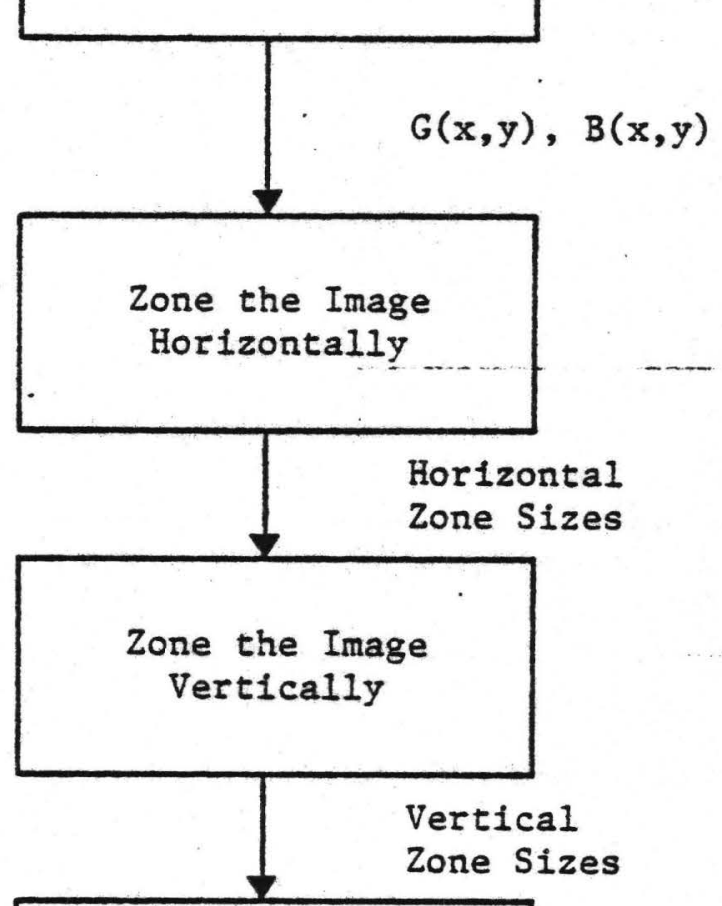

Compute Gain and Bias for Each Zone

Using $G(x, y)$ and $B(x, y)$

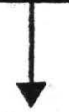

Radiometric

Correction

Coefficients 


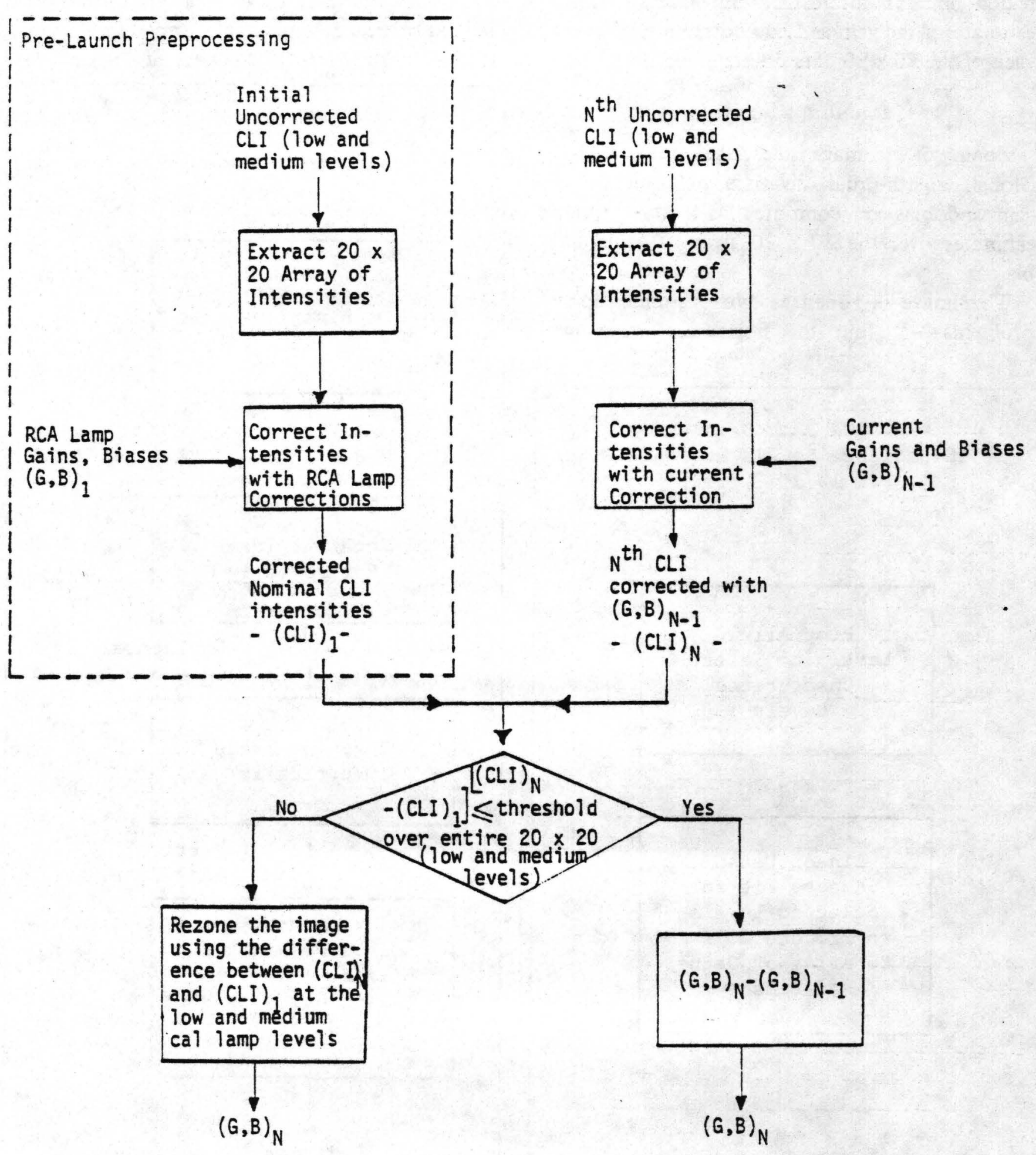

Figure D-3 .--Calibration-lamp image processing. 


\section{APPENDIX D}

image, the zone sizes (as determined by measuring the radiometric distortions along each line) are computed. The final zone size used is the smallest of the zones computed in each line. The zone boundaries are stored on the MDP system disk.

For each zone, gain and bias coefficients are computed, using the eighth order gain and bias polynominal and the coordinates of the center of the zone. These coefficients are also stored the MDP system disk.

\section{CALIBRATION LAMP IMAGE PROCESSING}

For subsequent calibration-lamp-image processing, the gain and bias polynominals are used to compute the gain and bias at the center of each 20 pixel $\times 20$ pixel-intensity sampling array. These values of gain and bias are stored on the MDP system disk.

Calibration-lamp data are used to detect changes in RBV camera response and to update the radiometric-correction coefficients. The first calibration-lamp image is corrected using the RCA lamp coefficients and is used as a baseline from which all future camera-response changes are determined (figure D-3).

From the first calibration-lamp image (CLI), a $20 \times 20$ array of small (20 pixel by 20 pixel) subimages centered at the intensity sampling points, is extracted. An average intensity value is computed for each subimage. For each of the two intensity levels-- calibration zero and calibration one (calibration two tends to be saturated because of its high level) - - the $20 \mathrm{x}$ 20 array of intensities is corrected using the gains and biases computed from RCA lamp data. The output of the preprocessing step is a $20 \mathrm{x}$ 20 array of corrected nominal CLI intensities-(CLI) 1 --for each ' of - two calibration levels. These arrays are stored on the MDP system disk.

After launch, a calibration-lamp image is processed as often as deemed necessary, and a $20 \times 20$ array of small subimages is extracted and averaged to produce a $20 \times 10$ array of intensities. These intensities are corrected using the current radiometric coefficients and tested against the corrected nominal CLI intensities. If the camera response has changed, a new $20 \times 20$ array of gains and biases is computed using the differences between current and corrected nominal CLI intensities, a new eighth order polynomials are computed, and the image is rezoned. The zoning technique is precisely the zoning of figure D-2 (the zoning that was done on the RCA lamp data). If the camera response has not changed, current zoning and coefficients are not changed.

\section{RADIOMETRIC CORRECTION OF DATA}

The radiometric correction of $\mathrm{RBV}$ images is performed by applying the gain and bias for a given zone to all the input-image-intensity values in that zone (figure D-4).

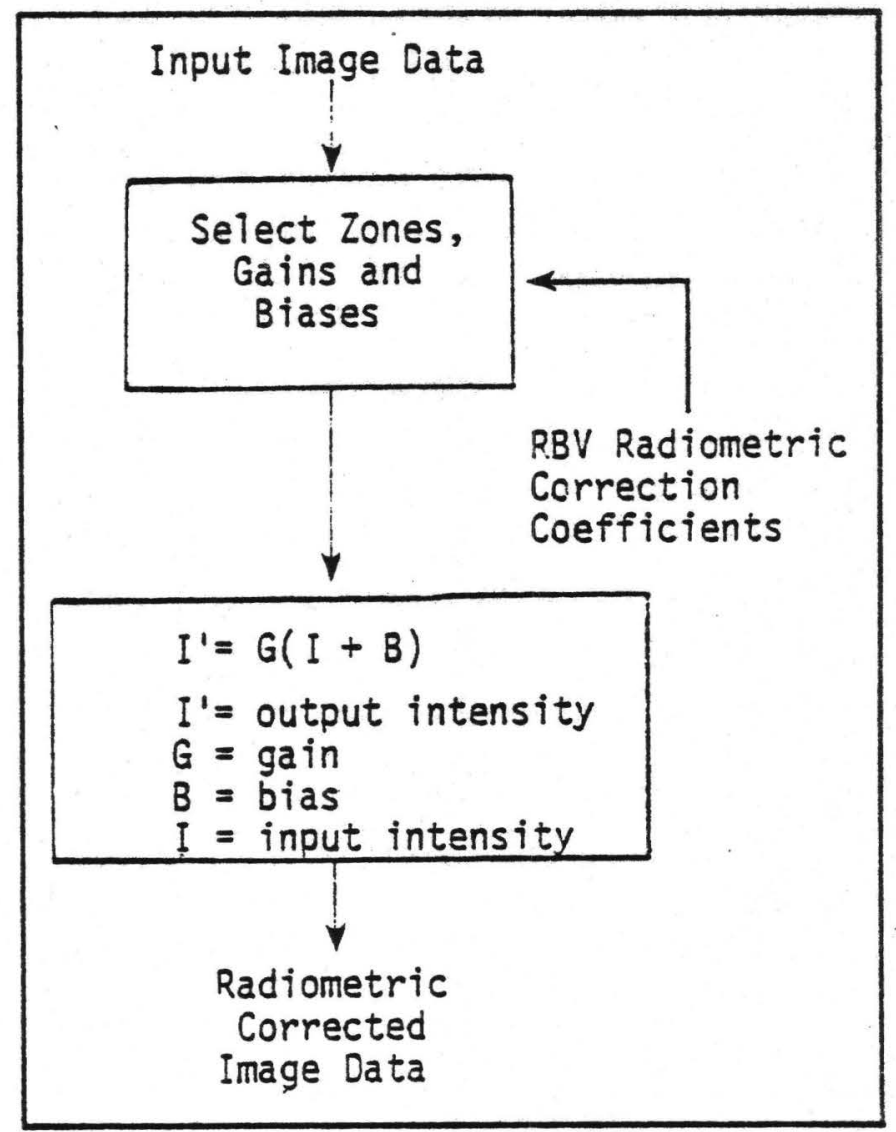

Figure D-4 .--Radiometric-correction-coefficient application. 


\section{LANDSAT COMPUTER COMPATIBLE TAPES}

\section{APPENDIX E}

\section{MSS DECOMPRESSING TABLES}

Tables E-1, E-2, and E-3 are used for decompressing the video data from bands four, five, and six. Bands seven and eight require no decompression.

The values of the compressed video data vary from 0 to 63; after decompression, the videodata values for seven-bit image pixels vary from 0 to 127 . The decompressed values and gains and offsets are used to determine the calibrated values of the video data. To reverse the process and obtain compressed values from the decompressed values on the CCT, the user must have the gain and offset values, in addition to the values in the decompression table. However, due to roundoff and truncation errors, the process is not absolutely reversible.

\begin{tabular}{|c|c|c|c|c|c|}
\hline $\begin{array}{l}\text { COMPRESSED } \\
\text { QUANTUM } \\
\text { LEVEL } \\
\text { (6 BITS) }\end{array}$ & $\begin{array}{l}\text { BAND } 4 \text { AND } 6 \\
\text { EQUIVALENT LINEAR } \\
\text { QUANTUM LEVEL } \\
(7 \text { BITS })\end{array}$ & $\begin{array}{c}\text { BAND } 5 \\
\text { EQUIVALENT LINEAR } \\
\text { QUANTUM LEVEL } \\
(7 \text { BITS })\end{array}$ & $\begin{array}{l}\text { COMPRESSED } \\
\text { QUANTUH } \\
\text { LEVEL } \\
\text { (6 BITS) }\end{array}$ & $\begin{array}{l}\text { BAND } 4 \text { AND } 6 \\
\text { EQUIVALENT LINEAR } \\
\text { QUANTUM LEVEL } \\
\text { (7 BITS })\end{array}$ & $\begin{array}{l}\text { BAND } 5 \\
\text { EQUIVALENT LINEAR } \\
\text { QUANTUM LEVE! } \\
\text { (7 BITS })\end{array}$ \\
\hline $\begin{array}{l}0 \\
1 \\
2,3 \\
4 \\
5 \\
6 \\
7 \\
8 \\
9 \\
10 \\
11 \\
12 \\
13 \\
14 \\
15 \\
16 \\
17 \\
18 \\
19 \\
20 \\
21 \\
22 \\
23 \\
24 \\
25 \\
26 \\
27 \\
28 \\
29 \\
30 \\
31 \\
32\end{array}$ & $\begin{array}{r}0 \\
\vdots \\
2 \\
3 \\
4 \\
5 \\
6 \\
7 \\
8 \\
9 \\
10 \\
11 \\
12 \\
13 \\
14 \\
16 \\
17 \\
18 \\
19 \\
21 \\
22 \\
24 \\
25 \\
27 \\
29 \\
30 \\
32 \\
34 \\
36 \\
38 \\
40 \\
42\end{array}$ & $\begin{array}{r}0 \\
1 \\
2 \\
3 \\
4 \\
5 \\
6 \\
7 \\
8 \\
9 \\
10 \\
11 \\
12 \\
13 \\
14 \\
16 \\
17 \\
18 \\
19 \\
21 \\
22 \\
23 \\
25 \\
27 \\
28 \\
30 \\
32 \\
34 \\
36 \\
38 \\
39 \\
41\end{array}$ & $\begin{array}{l}33 \\
34 \\
35 \\
36 \\
37 \\
38 \\
39 \\
40 \\
41 \\
42 \\
43 \\
44 \\
45 \\
46 \\
47 \\
48 \\
49 \\
50 \\
51 \\
52 \\
53 \\
54 \\
55 \\
56 \\
57 \\
58 \\
59 \\
60 \\
61 \\
62 \\
63\end{array}$ & $\begin{array}{r}43 \\
45 \\
47 \\
49 \\
51 \\
53 \\
56 \\
58 \\
61 \\
63 \\
66 \\
69 \\
72 \\
75 \\
78 \\
81 \\
83 \\
86 \\
89 \\
92 \\
95 \\
98 \\
101 \\
104 \\
106 \\
109 \\
112 \\
115 \\
118 \\
121 \\
124\end{array}$ & $\begin{array}{r}43 \\
45 \\
47 \\
49 \\
51 \\
53 \\
54 \\
58 \\
60 \\
63 \\
66 \\
69 \\
71 \\
74 \\
77 \\
80 \\
83 \\
86 \\
88 \\
91 \\
94 \\
97 \\
100 \\
104 \\
107 \\
109 \\
112 \\
115 \\
117 \\
120 \\
122\end{array}$ \\
\hline
\end{tabular}

Table E-1 .--Landsat 1 decompression values 


\section{APPENDIX E}

Table E-2 .--Landsat 2 decompression values

\begin{tabular}{|c|c|c|c|c|c|}
\hline $\begin{array}{l}\text { COMPRESSED } \\
\text { QUANTUM } \\
\text { LEVEL } \\
\text { (6 BITS) }\end{array}$ & $\begin{array}{l}\text { BAND } 4 \text { AND } 6 \\
\text { EQUIVALENT LINEAR } \\
\text { QUANTUM LEVEL } \\
(7 \text { BITS })\end{array}$ & $\begin{array}{l}\text { BAND } 5 \\
\text { EQUIVALENT LINEAR } \\
\text { QUANTUM LEVEL } \\
\text { (7 BITS })\end{array}$ & $\begin{array}{l}\text { COMPRESSED } \\
\text { QUANTUM } \\
\text { LEVEL } \\
(6 \text { BITS })\end{array}$ & $\begin{array}{l}\text { SANO } 4 \text { ANO } 6 \\
\text { EQUIVALENT LINEAR } \\
\text { QUANTUPA LEVEL } \\
\text { (7 BITS })\end{array}$ & $\begin{array}{l}\text { BAI:C } 5 \\
\text { EQUIVALENT LINEAR } \\
\text { QUANTUP LEVEL } \\
\text { (7 BITS })\end{array}$ \\
\hline $\begin{array}{r}0 \\
1 \\
2 \\
3 \\
4 \\
5 \\
6 \\
7 \\
8 \\
9 \\
9 \\
10 \\
11 \\
12 \\
13 \\
14 \\
15 \\
16 \\
17 \\
18 \\
19 \\
20 \\
21 \\
22 \\
23 \\
24 \\
25 \\
26 \\
27 \\
28 \\
29 \\
30 \\
31\end{array}$ & $\begin{array}{r}0 \\
1 \\
2 \\
3 \\
4 \\
5 \\
6 \\
6 \\
7 \\
8 \\
9 \\
10 \\
12 \\
13 \\
14 \\
15 \\
17 \\
18 \\
19 \\
20 \\
22 \\
23 \\
25 \\
27 \\
28 \\
30 \\
31 \\
33 \\
35 \\
37 \\
39 \\
41\end{array}$ & $\begin{array}{l}0 \\
1 \\
2 \\
3 \\
4 \\
5 \\
6 \\
7 \\
8 \\
9 \\
10 \\
11 \\
12 \\
13 \\
14 \\
16 \\
17 \\
18 \\
19 \\
21 \\
22 \\
23 \\
25 \\
27 \\
28 \\
30 \\
32 \\
34 \\
36 \\
38 \\
40 \\
41\end{array}$ & $\begin{array}{l}32 \\
33 \\
34 \\
35 \\
36 \\
37 \\
38 \\
39 \\
40 \\
41 \\
42 \\
43 \\
44 \\
45 \\
46 \\
47 \\
48 \\
49 \\
50 \\
51 \\
52 \\
53 \\
54 \\
55 \\
56 \\
57 \\
58 \\
59 \\
60 \\
61 \\
62 \\
63\end{array}$ & $\begin{array}{r}43 \\
45 \\
47 \\
49 \\
51 \\
53 \\
55 \\
57 \\
60 \\
62 \\
65 \\
68 \\
71 \\
74 \\
77 \\
79 \\
82 \\
85 \\
88 \\
91 \\
94 \\
97 \\
100 \\
103 \\
106 \\
109 \\
112 \\
115 \\
118 \\
121 \\
124 \\
127\end{array}$ & $\begin{array}{r}43 \\
45 \\
47 \\
49 \\
51 \\
53 \\
55 \\
58 \\
60 \\
63 \\
66 \\
69 \\
71 \\
74 \\
77 \\
80 \\
83 \\
86 \\
89 \\
92 \\
95 \\
98 \\
101 \\
104 \\
107 \\
110 \\
113 \\
116 \\
118 \\
121 \\
124 \\
127\end{array}$ \\
\hline
\end{tabular}




\section{LANDSAT COMPUTER COMPATIBLE TAPES}

Table E-3 .--Landsat 3 decompression values

\begin{tabular}{|c|c|c|c|c|c|}
\hline $\begin{array}{l}\text { COMPRESSED } \\
\text { QUANTUM } \\
\text { LEVEL } \\
\text { (6 BITS) }\end{array}$ & $\begin{array}{l}\text { BAHO } 4 \text { AND } 6 \\
\text { EQLIVALENT LINEAR } \\
\text { QUANTUM LEVEL } \\
(7 \text { BITS })\end{array}$ & $\begin{array}{l}\text { BAND } 5 \\
\text { EQUIVALENT LINEAR } \\
\text { QUANTUH LEVEL } \\
(7 \text { BITS })\end{array}$ & $\begin{array}{l}\text { COMPRESSED } \\
\text { QUANTUN } \\
\text { LEVEL } \\
(6 \text { BITS })\end{array}$ & $\begin{array}{l}\text { BAND } 4 \text { AIIC } 6 \\
\text { EQUIVALENT LINEAF } \\
\text { QUANTUM LEVEL } \\
(7 \text { BITS })\end{array}$ & $\begin{array}{l}\text { BAID } 5 \\
\text { EQUIVALENT LIUEAR } \\
\text { QLAITUM LEVEL } \\
\text { (7 BITS })\end{array}$ \\
\hline $\begin{array}{r}0 \\
1 \\
2 \\
3 \\
4 \\
5 \\
6 \\
7 \\
8 \\
9 \\
10 \\
11 \\
12 \\
13 \\
14 \\
15 \\
16 \\
17 \\
18 \\
19 \\
20 \\
21 \\
22 \\
23 \\
24 \\
25 \\
26 \\
27 \\
28 \\
29 \\
30 \\
31\end{array}$ & $\begin{array}{r}0 \\
1 \\
1 \\
2 \\
3 \\
4 \\
5 \\
6 \\
7 \\
8 \\
9 \\
10 \\
11 \\
12 \\
13 \\
15 \\
16 \\
17 \\
18 \\
20 \\
22 \\
23 \\
25 \\
26 \\
23 \\
30 . \\
32 \\
34 \\
35 \\
37 \\
39 \\
41\end{array}$ & $\begin{array}{r}0 \\
1 \\
2 \\
3 \\
4 \\
5 \\
6 \\
7 \\
8 \\
9 \\
9 \\
10 \\
11 \\
12 \\
13 \\
14 \\
15 \\
17 \\
18 \\
19 \\
20 \\
22 \\
23 \\
25 \\
26 \\
28 \\
30 \\
32 \\
34 \\
35 \\
37 \\
39 \\
41\end{array}$ & $\begin{array}{l}32 \\
33 \\
34 \\
35 \\
36 \\
37 \\
38 \\
39 \\
40 \\
41 \\
42 \\
43 \\
44 \\
45 \\
46 \\
47 \\
48 \\
49 \\
50 \\
51 \\
52 \\
53 \\
54 \\
55 \\
56 \\
57 \\
58 \\
59\end{array}$ & $\begin{array}{r}43 \\
45 \\
47 \\
49 \\
51 \\
53 \\
55 \\
58 \\
60 \\
63 \\
66 \\
68 \\
71 \\
74 \\
77 \\
80 \\
84 \\
87 \\
90 \\
92 \\
95 \\
98 \\
101 \\
104 \\
108 \\
111 \\
114 \\
117 \\
120 \\
123 \\
125 \\
127\end{array}$ & $\begin{array}{r}42 \\
45 \\
47 \\
49 \\
52 \\
54 \\
56 \\
58 \\
60 \\
63 \\
66 \\
69 \\
72 \\
74 \\
77 \\
80 \\
83 \\
86 \\
89 \\
92 \\
95 \\
98 \\
101 \\
104 \\
107 \\
110 \\
113 \\
116 \\
119 \\
122 \\
125 \\
127\end{array}$ \\
\hline
\end{tabular}

\section{APPENDIX F}

\section{CORRESPONDENCE BETWEEN CCT IMAGE DATA}

\section{AND GROUND AREA COVERED}

The MSS sensor operates at a rate that produces pixel overlap within scan lines. The within-line pixel overlap varies due to variation in mirror velocity. The effect of this variation is represented in figures $\mathrm{F}-1$ through F-3. For CCTs with data that have not been geometrically corrected, as was the case for all CCTs produced in the Landsat-1 and -2 "X-Document" format (Thomas, V.L., 1975): individual pixels reflect this overlap, which must be taken into account when determining ground area covered. The geometric-correction process, however, creates a

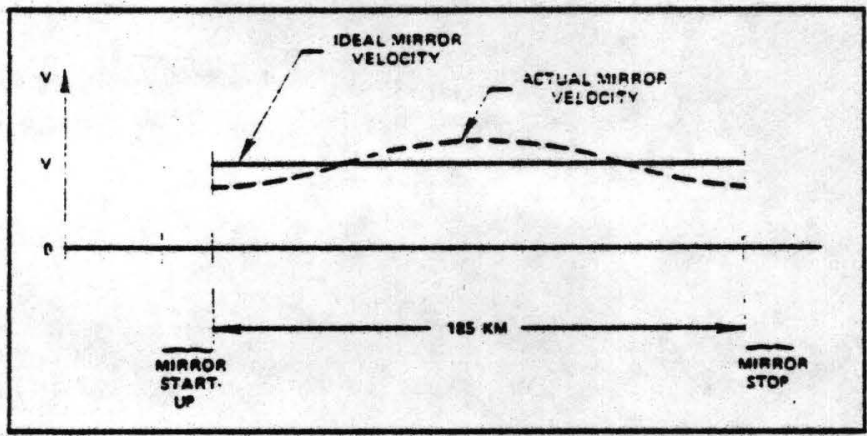

Figure F-1 :-Comparison of the constant mirror velocity and the variable mirror velocity.

new pixel array which represents, in a one to one aspect ratio, an image in a selected map projection, with each corrected pixel covering a unique ground area of 57 square meters.

It should also be noted that with $\mathrm{CCT}$ data 


\section{APPENDIX F}

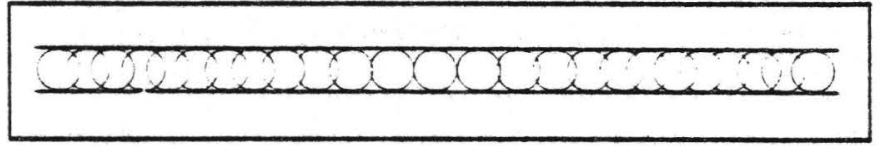

Figure F-2 .--Overlay of pixels, corresponding to a variable mirror velocity.

presented as described in this document, there is a one-to-one correspondence between the scan lines and pixels of the digital data and the scan lines and pixels of the related photographic data. This was not true of the earlier CCTs, because the geometric corrections were applied to the photographic data as part of the image-exposure process, and not to the digital image data. The resulting photographic image had fewer scan lines per scene than did the CCT.

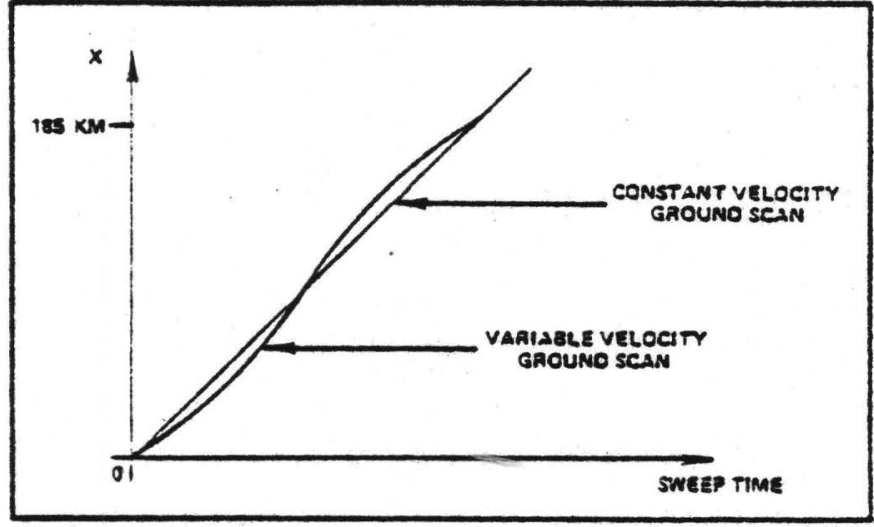

Figure F-3 .--Comparison of distance covered on the ground for a constant mirror velocity and a variable mirsor velocity.

RBV data does not require the type of overlap correction discussed for MSS data; however, geometric corrections are made for effects of aspect distortions, Earth curvature, satellitealtitude variations, and so on, so that the corrected $\mathrm{RBV}$ image data represents the same type of projection as for MSS, with each pixel covering a unique ground area of 19 ground meters.

\section{APPENDIX G}

\section{MAP PROJECTIONS}

The Universal Transverse Mercator (UTM) projection has been found useful as a means of providing numerical geographic data to be combined with Landsat imagery. A worldwide system of zones has been set up for this projection; the transformation equations are fairly easy to put into computer language; and the residual errors are small enough to be nearly negligible over the area of a Landsat-image zone.

Approximately 60 countries publish maps in this projection, especially smaller scale (larger area) maps. The USSR, China, and associated countries use the Gauss-Kruger projection which is the same as the UTM except that the scale factor on the central meridian is 1.0000 instead of 0.9996 .

The Space Oblique Mercator (SOM) projection is being developed as the standard map projection for Landsat imagery. This projection is developed along the lines of M. Hotine's Oblique Mercator projection with account taken of the Earth-rotation effects. A preliminary version is given by A. P. Colvocoresses (1974); the precise mathematical formulation and constants are now being developed and are expected to be available in early 1978.

Richardus and Adler, 1972, provides a good, intermediate-level test on map projections with a mathematical development of the subject using differential and integral calculus.

Thomas, 1952, gives a unified treatment of projections from the standpoint of mapping upon the complex variable plane. The final results are given in considerable detail for those who are unwilling to follow the detailed derivations.

The appendix of Adams, 1949, provides the simplest form for computer calculation of $\mathrm{S}_{\mathrm{p}}$, the geodetic distance along the meridian from the Equator to the point $P$.

"The Universal Grid Systems" is devoted to the development of a worldwide grid system employing the Polar Stereographic projection in the Polar regions and UTM elsewhere. 


\section{LITERATURE CITED}

Adams, O. S., 1940, Latitude developments connected with geodesy and cartography: U. S. Coast and Geodetic Survey S. Pub. $67,132 \mathrm{p}$.

American National Standards Institute, 1973a, Recorded magnetic tape for information interchange (800 CPI, NRZI): ANSI X3. 22-1973.

- $1973 \mathrm{~b}$, Recorded magnetic tape for information interchange (1600 CPI, PE) : ANSI X3.39-1973.

Colvocoresses, A. P., 1974, Space Oblique Mercator: Photogramm. Eng., v. 40, n. 8, p. 921-926.

Richardus, P., and Adler, R. K., 1972, Map projections for geodesists, cartographers, and geographers: New York, Am. Elsevier Publishing Co., 174 p.

Thomas, P. D., 1952, Conformal projections in geodesy and cartography: U. S. Coast and Geodetic Survey S. Pub. 251, 140 p.

Thomas, V. L., 1975, Generation and physical characteristics of the Landsat- 1 and -2 MSS computer-compatible tapes: U. S. Natl. Aeronautics and Space Admin., Goddard Space Flight Center Doc. X-56375-223, $28 \mathrm{p}$.

U.S. Army, 1951, The universal grid systems: U. S. Army Tech. Manual 5-241, 324 p. 